\title{
Implications of cardiac troponin T degradation
}

Citation for published version (APA):

Michielsen, E. C. H. J. (2008). Implications of cardiac troponin T degradation. [Doctoral Thesis, Maastricht University]. Datawyse / Universitaire Pers Maastricht. https://doi.org/10.26481/dis.20080229em

Document status and date:

Published: 01/01/2008

DOI:

10.26481/dis.20080229em

Document Version:

Publisher's PDF, also known as Version of record

\section{Please check the document version of this publication:}

- A submitted manuscript is the version of the article upon submission and before peer-review. There can be important differences between the submitted version and the official published version of record.

People interested in the research are advised to contact the author for the final version of the publication, or visit the DOI to the publisher's website.

- The final author version and the galley proof are versions of the publication after peer review.

- The final published version features the final layout of the paper including the volume, issue and page numbers.

Link to publication

\footnotetext{
General rights rights.

- You may freely distribute the URL identifying the publication in the public portal. please follow below link for the End User Agreement:

www.umlib.nl/taverne-license

Take down policy

If you believe that this document breaches copyright please contact us at:

repository@maastrichtuniversity.nl

providing details and we will investigate your claim.
}

Copyright and moral rights for the publications made accessible in the public portal are retained by the authors and/or other copyright owners and it is a condition of accessing publications that users recognise and abide by the legal requirements associated with these

- Users may download and print one copy of any publication from the public portal for the purpose of private study or research.

- You may not further distribute the material or use it for any profit-making activity or commercial gain

If the publication is distributed under the terms of Article $25 \mathrm{fa}$ of the Dutch Copyright Act, indicated by the "Taverne" license above, 


\section{IMPLICATIONS OF CARDIAC \\ TROPONIN T DEGRADATION}

Etienne Michielsen 
Thesis

IMPLICATIONS OF CARDIAC TROPONIN T DEGRADATION

by Etienne Michielsen

Prepared at:

Department of Clinical Chemistry, University Hospital Maastricht, Maastricht, The Netherlands.

ISBN 978-90-5278-686-5

(C) 2008 Etienne Michielsen

No part of this publication may be reproduced, sorted in a retrieval system or transmitted in any form or by any means without the prior written permission of the author.

Printed by: Universitaire Pers Maastricht

Dit proefschrift is tot stand gekomen mede dankzij een financiële bijdrage van Roche Diagnostics Nederland BV en Abbott Diagnostics. Tevens werd het verschijnen van dit proefschrift mede mogelijk gemaakt door de steun van de Nederlandse Hartstichting en de Stichting ter Bevordering van de Klinische Chemie in Nederland (E.C. Noyons Stichting). 


\section{IMPLICATIONS OF CARDIAC}

\section{TROPONIN T DEGRADATION}

PROEFSCHRIFT

ter verkrijging van de graad van doctor

aan de Universiteit Maastricht,

op gezag van de Rector Magnificus,

prof. mr. G.P.M.F. Mols

volgens het besluit van het College van Decanen,

in het openbaar te verdedigen

op vrijdag 29 februari 2008 om 12.00 uur

door

Etienne Cornelis Hendrikus Johannes Michielsen

Geboren op 12 maart 1976 te Dongen

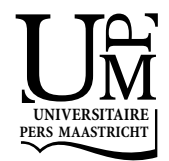


Promotor:

Copromotor:

Beoordelingscommissie:
Prof. dr. M.P. Van Dieijen-Visser

Dr. W.K.W.H. Wodzig

Prof. dr. M.J.A.P. Daemen (voorzitter)

Dr. L. Hofstra

Prof. dr. A van der Laarse (Leids Universitair Medisch Centrum)

Prof. dr. P.W. de Leeuw

Prof. dr. J. Rosing 
Voor mijn ouders, mijn broertje en mijn oma's 



\section{TABLE OF CONTENTS}

Chapter 1 General introduction 9

Chapter 2 Highly sensitive immunoprecipitation assay for extracting and 27 concentrating low abundance proteins from human serum application in dialysis patients

ChAPTER 3 Investigation of release and degradation of cardiac troponin T in 37 patients with acute myocardial infarction

Chapter 4 Size-exclusion chromatography of circulating cardiac troponin T recreational exercise

Chapter 6 Release kinetics of intact and degraded troponin I and T after irreversible cardiomyocyte damage

ChaPter 7 The diagnostic value of serum and urinary NT-proBNP for heart failure 



\section{General introduction}

\section{ACUTE CORONARY SYNDROMES}

The term acute coronary syndromes (ACS) serves as an umbrella to cover clinical symptoms compatible with myocardial ischemia, including unstable angina pectoris and acute myocardial infarction (AMI). These life-threatening disorders are a major cause of emergency medical care and hospitalization. Furthermore, cardiovascular diseases remain the leading cause of death in the Netherlands and Europe. In the Netherlands, 136,553 people died in 2004 and cardiovascular diseases were the leading cause of death with 45,445 deaths (33\%). Second were malignant neoplasms causing 38,824 deaths (28\%). Within cardiovascular diseases, ACS are the most common cause of death $(14,083 ; 31 \%)$, comprised mostly of AMI with 10.012 deaths (71\%) (Table $1-1) .^{1}$

Table 1-1. Causes of death due to cardiovascular diseases in the Netherlands in 2004. From Koek et al. ${ }^{1}$

\begin{tabular}{|c|c|c|c|c|c|c|}
\hline \multirow{2}{*}{$\begin{array}{l}\text { Cause of death } \\
\text { Acute coronary syndromes }\end{array}$} & \multicolumn{2}{|l|}{ Men } & \multicolumn{2}{|l|}{ Women } & \multicolumn{2}{|l|}{ Total } \\
\hline & 7,966 & $37 \%$ & 6,117 & $26 \%$ & 14,083 & $31 \%$ \\
\hline - acute myocardial infarction & 5,543 & & 4,469 & & 10,012 & \\
\hline Cerebrovascular & 4,341 & $20 \%$ & 6,784 & $28 \%$ & 11,089 & $24 \%$ \\
\hline Congenital & 84 & $0.4 \%$ & 84 & $0.4 \%$ & 168 & $0.4 \%$ \\
\hline Rheumatic and valvular & 567 & $2.6 \%$ & 882 & $3.7 \%$ & 1,449 & $3.2 \%$ \\
\hline Infectious & 316 & $1.5 \%$ & 396 & $1.7 \%$ & 712 & $1.6 \%$ \\
\hline Other & 5,690 & $26 \%$ & 7,147 & $30 \%$ & 12,837 & $28 \%$ \\
\hline - heart failure & 2,201 & & 3,423 & & 5,624 & \\
\hline Arterial vascular & 1,334 & $6.1 \%$ & 710 & $3 \%$ & 2,044 & $4.5 \%$ \\
\hline Atherosclerosis / hypertension & 1,049 & $48 \%$ & 1,190 & $5 \%$ & 2,239 & $4.9 \%$ \\
\hline Venous vascular & 58 & $0.3 \%$ & 95 & $0.4 \%$ & 153 & $0.3 \%$ \\
\hline Other (circulation / lymph) & 291 & $1.3 \%$ & 380 & $1.6 \%$ & 671 & $1.5 \%$ \\
\hline Total & 21,696 & $100 \%$ & 23,749 & $100 \%$ & 45,445 & $100 \%$ \\
\hline
\end{tabular}

Rapid diagnosis of ACS is of utmost importance, because most deaths occur in the early hours after onset of symptoms, and therapeutic interventions should preferably start within the first 6 hours. $^{2}$ Clinical evaluation, including anamnesis and electro cardiogram (ECG), combined with laboratory analysis of biomarkers of cardiac function, aid the clinician in correctly diagnosing a patient. Therapeutic interventions are directed primarily at restoring coronary blood flow (reperfusion). These interventions can be either intravenous thrombolytic therapies such as streptokinase, or percutaneous 
coronary intervention (PCI) (Table 1-2). ${ }^{3}$ Preserving myocardial (left ventricular) function and reducing morbidity and mortality are therapeutic goals after the first critical hours have passed.

In the last two decades, one-year mortality resulting from a primary or secondary AMI has reduced from $39 \%$ to $25 \%$ and from $43 \%$ to $29 \%$, respectively. ${ }^{4}$ However, in patients with prior hospital admissions for diabetes, respiratory disease, peripheral vascular disease, cancer or heart failure, the relative risk of dying within 30 days was increased by up to twofold. ${ }^{5}$

Table 1-2. Reperfusion therapy by geographic region. From Eagle et al. ${ }^{3}$

\begin{tabular}{lllll}
\hline \multicolumn{5}{l}{ Patients receiving reperfusion therapy } \\
\hline Therapy & ANC $(\mathbf{n = 2 6 9 )}$ & USA $(\mathbf{n = 3 2 7})$ & AB $(\mathbf{n = 3 3 9})$ & Europe $(\mathbf{n}=\mathbf{7 3 9})$ \\
\hline PCI alone & 1.1 & 17.7 & 13.9 & 16.2 \\
Thrombolysis alone & 66.9 & 30.6 & 53.1 & 49.4 \\
Both & 2.2 & 18.7 & 5.0 & 4.9 \\
Neither & 29.7 & 33.0 & 28.0 & 29.5 \\
\hline
\end{tabular}

$\mathrm{ANC}=$ Australia, New Zealand, Canada; $\mathrm{AB}=$ Argentina, Brazil. $\mathrm{PCI}=$ percutaneous coronary intervention.

\section{MYOCARDIAL INFARCTION}

There have been several attempts to define AMI (Figure 1-1). In the past, definitions of cases for epidemiology studies and clinical trials in ACS were based on World Health Organization (WHO) (1959) and American Heart Association (1964) reports, followed by the WHO European AMI Registry criteria. ${ }^{6,7}$ AMI was defined by a combination of two of three characteristics: typical symptoms (i.e., chest discomfort), cardiac enzyme rise and a typical ECG pattern involving the development of Q waves. ${ }^{8}$ Further specification and working definitions of ACS come from the Framingham Study. ${ }^{9}$ More recently the WHO MONICA Study has modified further the definition of ACS cases. ${ }^{8}$

In 2000, the joint European Society of Cardiology and the American College of Cardiology recommended a new definition for AMI that combined ischemic symptoms with changes in the ECG and in biochemical markers of myocardial necrosis and emphasized the use of cardiac troponins. ${ }^{10,11}$ In the new definition, cardiac troponins (either CTnT or CTnI) are the biomarker of choice because these have been shown to be specific for cardiac tissue and highly sensitive to minor myocardial damage. ${ }^{12-14}$

The criteria for acute, evolving or recent MI have been defined as:

1. A typical rise and gradual fall (troponin) or more rapid rise and fall (CK-MB) of biochemical markers of myocardial necrosis with at least one of the following:
a) ischemic symptoms;
b) development of pathologic Q waves on the ECG;
c) ECG changes indicative of ischemia (ST segment elevation or depression); or
d) coronary artery intervention (e.g. coronary angioplasty).

2. Pathologic findings of an acute MI.

The criteria for established MI have been defined as: 
1. Development of new pathologic Q waves on serial ECGs. The patient may or may not remember previous symptoms. Biochemical markers of myocardial necrosis may have normalized, depending on the length of time that has passed since the infarct developed.

2. Pathologic findings of a healed or healing MI.

In the "old" definition, diagnosis was based on elevations of the creatine kinase MB fraction (CK-MB). The new definition has been criticized for excessive reliance on troponins and insufficient attention to ECG changes. ${ }^{15,16}$ Moreover, there are several important issues regarding the new definition. ${ }^{17,}{ }^{18}$ It was foreseen that the new definition would substantially increase the number of patients diagnosed with AMI. ${ }^{19}$ Recently, prospective application of the new criteria in the community indeed showed a large increase in the number of patients with AMI. ${ }^{20}$ Many people formerly diagnosed with unstable angina, are now diagnosed as having AMI. This has a major impact on epidemiological studies comparing studies performed before and after the new definition. Also, studies based on mortality will face difficulties, as mortalities will fall. ${ }^{18}$

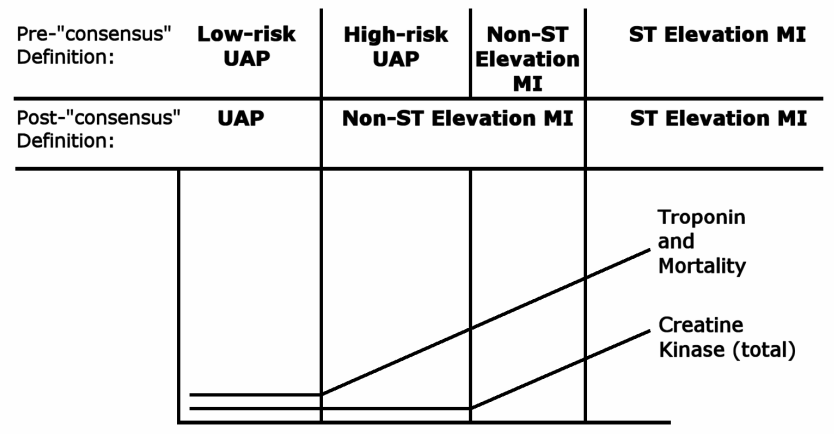

Figure 1-1. Terminology of acute coronary syndromes pre and post-"consensus" definition. ${ }^{10,}{ }^{11}$ Cardiac troponins are elevated earlier than creatine kinase and are more sensitive markers of cardiac injury. UAP, unstable angina pectoris; MI, myocardial infarction. Adapted from. ${ }^{21}$

\section{Ischemia}

Atherosclerosis is a progressive disease, characterized by the accumulation of lipids, cells and fibrous elements in the vessel wall of large and medium-sized arteries. ${ }^{22}$ Such "plaques" can be either stable, or ruptured. Stable plaques have an intact fibrous cap composed of smooth muscle cells and extracellular matrix that encloses a lipid-rich necrotic core. Plaques can become increasingly complex, with calcification, ulceration at the luminal surface, and haemorrhage from small vessels that grow into the lesion from the media of the blood vessel wall (Figure 1-2).

Obstruction of a blood vessel can be caused by two mechanisms. Firstly, advanced plaques can grow sufficiently large to block blood flow. This is a slow process. The occlusion can be up to $70 \%$ without any clinical symptoms due to adaptive mechanisms of the heart. However, eventually, the heart will become transiently ischemic, leading to periods of chest pain.

Secondly, due to unknown events plaques may be subject to erosion or rupture, thereby exposing their contents to the bloodstream. Rupture frequently occurs at the edges of a plaque, which are rich in foam cells, suggesting that factors contributing to inflammation may also influence thrombosis. In this 
regard, it is notable that the incidence of myocardial infarction and stroke increases during acute infections. ${ }^{23}$ The resulting activation of the blood coagulation cascade can lead to thrombus formation..$^{22}$ This can cause obstruction of the vessel lumen, leading to downstream ischemia: an acute myocardial infarction.

\section{Reperfusion techniques}

The main treatment goal for a patient who has suffered an AMI is to open the occluded vessel. From a historical point of view, pharmacological interventions have been the first option. ${ }^{24}$ The first thrombolytic agents included streptokinase and tissue-type plasminogen activator (t-PA). Limitations of the first and second generation agents have resulted in the development of more potent third generation thrombolytic agents, which more specifically degrade fibrin, have increased resistance to plasma protease inhibitors or have longer half-lives. ${ }^{25}$ Adjunctive agents include unfractionated heparin, low-molecular weight heparin and platelet inhibitors (glycoprotein IIb/IIIa inhibitors).

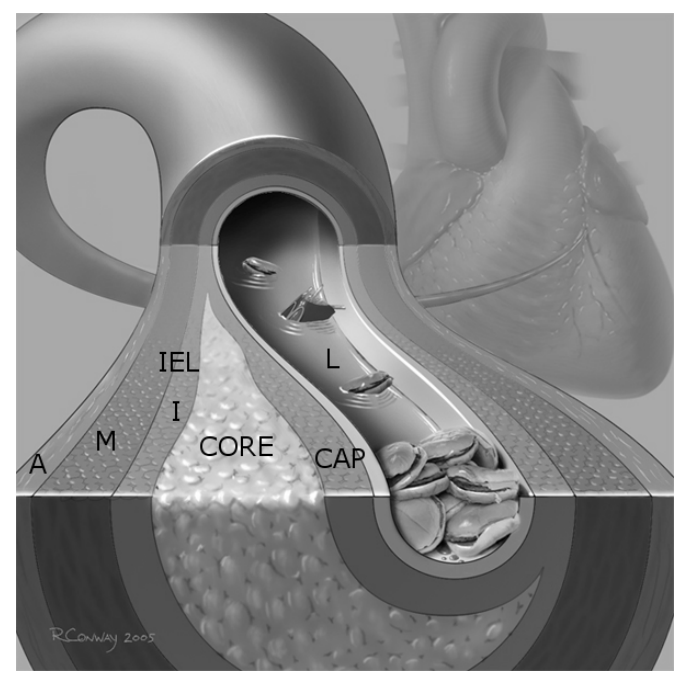

Figure 1-2. Schematic presentation of a stable atherosclerotic lesion. L, lumen; A, adventitia; I, intima; IEL, internal elastic lamina; M, media.

The preferred therapy of today is PCI. This technique involves a fine hollow catheter to be inserted into the femoral artery. This catheter, with a small inflatable balloon at its tip, is fed through to the narrowed coronary artery. When the balloon is gently inflated, this compresses the atherosclerotic plaque -responsible for the narrowing of the vessel-, and widens the lumen of the artery. This is often accompanied by inserting a bare metal stent, an expandable wire mesh tube, used to support the new stretched open position of the artery from the inside, thereby reducing the risk of re-occlusion or restenosis. ${ }^{26}$ The stents used today, drug-eluting stents, are often coated with drugs that help prevent restenosis. ${ }^{27}$ Importantly, however, recent studies have shown that the risk of restenosis, the occurrence of death, reinfarction, or heart failure was not reduced when using drug-eluting stents compared with bare metal stents. ${ }^{28,}{ }^{29}$ Furthermore, a recent study showed that in patients with stable coronary artery disease, PCI did not reduce the risk of death, myocardial infarction, or other major 
cardiovascular events when added to optimal medical therapy. ${ }^{30}$ More literature on this topic is slowly being published. In extreme cases, when PCI is not sufficient, or when there are several occlusions, coronary artery bypass grafting (CABG) is another surgical option.

\section{CARDIAC MARKERS}

The history of protein markers in diagnosis and treatment of ACS dates back to 1954 with reports on aspartate aminotransferase (AST). ${ }^{31,32}$ Ever since, this important field has evolved and new and better markers have been described aiding clinicians in diagnosis and treatment of ACS. These included the enzymes lactate dehydrogenase $(\mathrm{LDH}){ }^{33}$ a-hydroxybutyrate dehydrogenase $(\mathrm{HBDH}){ }^{34}$ creatine kinase $(\mathrm{CK}){ }^{35,}{ }^{36}$ and the protein myoglobin. ${ }^{37}$ More recently, the more cardiac tissue specific markers CK$M B,{ }^{38-41}$ heart-type fatty acid binding protein (H-FABP), ${ }^{42}$ brain natriuretic peptide (BNP), ${ }^{43,44}$ and the cardiac troponins I and $\mathrm{T}$ have been introduced as markers of cardiac dysfunction. ${ }^{12,14}$ The time course of appearance of some of these cardiac markers in the circulation is shown in Figure 1-3.

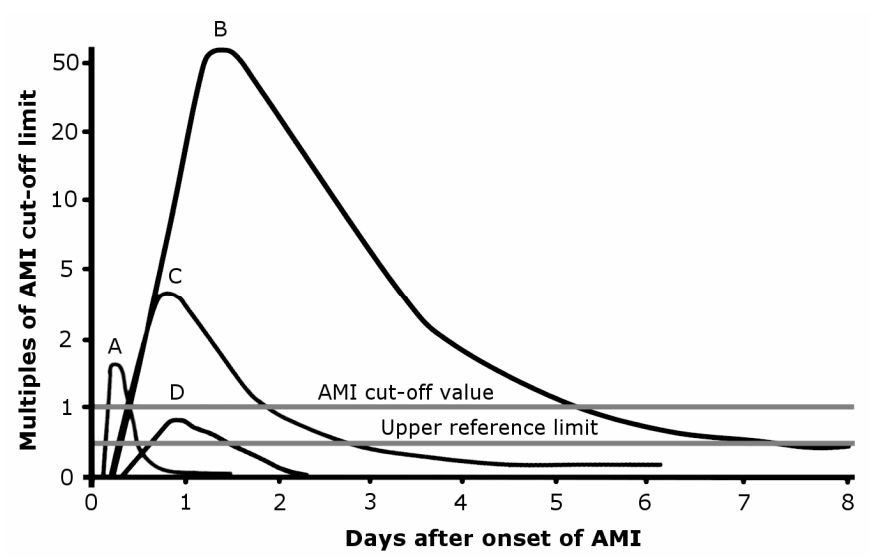

Figure 1-3.Time course of appearance of cardiac markers in blood after onset of AMI.

Peak A, early release of myoglobin or CK-MB isoforms after AMI; peak B, cardiac troponin after AMI; peak C, CK-MB after AMI; peak D, cardiac troponin after unstable angina. Data are plotted on a relative scale, where 1.0 is set at the AMI cutoff concentration. Adapted from Wu et al. ${ }^{45}$

\section{Creatine kinase and iso-enzymes}

Creatine kinase is a cytosolic enzyme ( $81 \mathrm{kDa}$ ) expressed in various tissue types. The two subunits of this dimeric enzyme can either be B-type (brain) or M-type (muscle), yielding three possible isoenzymes (MM, BB and MB), which are all present in tissue, but the composition varies. Skeletal muscle expresses CK-MM at high levels (99\%) and CK-MB at low levels (1.1\%), whereas cardiac muscle, in contrast, expresses CK-MM at $79 \%$ and CK-MB at $20 \% .{ }^{46}$ It is important to realize that the total CK activity in skeletal muscle is about 5-10 fold higher than in cardiac muscle, so that in absolute values (activity per gram wet weight tissue), skeletal muscle contains approximately equal amounts of CK- 
MB. ${ }^{46}$ However, because cardiac muscle contains the largest proportion of CK-MB, this was the first biochemical marker for AMI that was relatively specific for necrotic myocardium. Depending on the analytical method (substrate conversion or immunologically), CK-MB is expressed either as activity in $\mathrm{U} / \mathrm{L}\left(\mathrm{CK}-\mathrm{MB}_{\mathrm{act}}\right)$, or as concentration in $\mu \mathrm{g} / \mathrm{L}\left(\mathrm{CK}-\mathrm{MB}_{\text {mass }}\right)$.

The function of $\mathrm{CK}$ is the conversion of creatine to creatinephosphate, consuming adenosine triphosphate (ATP) and generating adenosine diphosphate (ADP), and the reverse reaction (equation 11).

Creatinine + ATP $\stackrel{C K}{\longleftrightarrow}$ Creatinine phosphate + ADP

Creatinephosphate is the major source of energy in biochemical reactions and serves as an energy reservoir for the regeneration of ATP in tissues that consume ATP rapidly (especially striated muscle, but also the brain and smooth muscle cells). First, ATP is generated inside the mitochondria of the cell. The mitochondrial CK then catalyses the phosphorylation of creatine to creatinephosphate, which is then transported to sites of energy need. There CK facilitates the reverse transformation of ADP into ATP.

Throughout the studies presented in this thesis, CK activity is measured on a Synchron LX system (Beckman Coulter) by an enzymatic rate method. CK catalyses the transfer of a phosphate group from the creatinephosphate substrate to ADP. This formation of ATP is measured through the use of two coupled reactions catalyzed by hexokinase $(\mathrm{HK})$ and glucose-6-phosphate dehydrogenase (G6PDH) which results in the production of reduced $\beta$-nicotinamide adenine dinucleotide $\left(\mathrm{NADH}^{+}\right)$from $\beta$ nicotinamide adenine dinucleotide $\left(\mathrm{NAD}^{+}\right)$(Equation 1-2). The system measures the change in absorbance at $340 \mathrm{~nm}$, which is directly proportional to the activity of CK.

Creatine phosphate + ADP $\stackrel{C K}{\longrightarrow}$ Cretinine + ATP

ATP + Glucose $\stackrel{H K}{\longrightarrow}$ Glucose-6-phosphate + ADP

Glucose-6-phosphate $+\mathrm{NAD}^{+} \stackrel{\mathrm{G} 6 \mathrm{PDH}}{\longrightarrow}$ 6-phosphogluconate $+\mathrm{NADH}^{+}$

To specifically measure the activity of the CK-MB isoform, a monoclonal antibody against the $M$ subunit is incubated with the serum sample. This completely blocks CK-MM activity, and 50\% of the CK-MB activity. Because CK-BB is not normally present in measurable amounts in serum, the measured activity is exactly half of the total CK-MB activity. Doubling of the result yields the total activity of CKMB.

Throughout the studies presented in this thesis, the CK-MB concentration (CK-MB ${ }_{\text {mass }}$ ) is measured on the Elecsys 2010 immunoassay system with a sandwich principle. In the first step, serum is combined with a reagent mixture containing biotinylated monoclonal anti-CK-MB antibody and a rutheniumlabelled monoclonal anti-CK-MB antibody. In the second step, streptavidin-coated paramagnetic micro particles are added and incubated. The now formed immune complexes are magnetically captured on an electrode in a measuring cell and application of a $0.2 \mathrm{mV}$ voltage results in an electrochemiluminescent signal. This is calibrated against an internal standard curve, constructed with

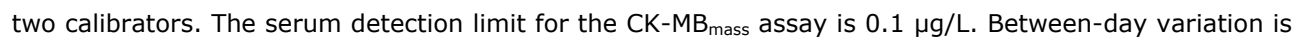
$3.6 \%$ and $5.3 \%$ at concentrations of $5.58 \mu \mathrm{g} / \mathrm{L}$ and $53.3 \mu \mathrm{g} / \mathrm{L}$, respectively $(n=75)$. The reference values are $<4.9 \mu \mathrm{g} / \mathrm{L}$ for men and $<2.9 \mu \mathrm{g} / \mathrm{L}$ for women. 


\section{TROPONINS}

\section{Immunoassays}

The principal components of the contractile apparatus of striated muscle (sarcomere) are the actin based thin filament, the myosin based thick filament, tropomyosin, and the troponin complex (Figure 14). During muscle contraction, the actin and myosin filaments slide over each other. This action is energy consuming and requires adenosine triphosphate (ATP) and calcium, which is released from the sarcoplasmic reticulum upon calcium influx resulting from depolarization of nerve fibres.

The troponin complex is comprised of three proteins: troponin $\mathrm{T}$, troponin I and troponin $\mathrm{C}$, and resides on the thin filament. Troponin T structurally binds the troponin complex via troponin $\mathrm{C}$ to tropomyosin. Binding of $\mathrm{Ca}^{2+}$ to troponin $\mathrm{C}$ results in conformational changes and increased affinity of troponin $\mathrm{C}$ for troponin I. Troponin I then releases its inhibitory function on actomyosin ATPase, which leads to ATP hydrolysis and muscle contraction. ${ }^{47}$

Troponin C is identical in both skeletal and cardiac muscle. Troponin I and T, however, are encoded by different genes, yielding two immunologically different proteins. ${ }^{12}, 14,48,49$ Both proteins have specific isoforms for skeletal muscle (sTnT, sTnI) and cardiac muscle (cTnT, cTnI). The latter are highly specific and highly sensitive biomarkers for detecting minor cardiac damage. ${ }^{12,14,50}$ Hence, CTnI and CTnT are now the preferred biomarkers for diagnosis and prognosis of acute coronary syndromes and have replaced $\mathrm{CK}-\mathrm{MB}_{\text {mass. }}{ }^{10,11,51}$

Ever since it became apparent that antibodies against CTnT were able to discriminate between skeletal and cardiac isoforms, immunoassays have been developed and improved. ${ }^{53}$ In 1989 the first generation CTnT immunoassay was released. This was a one step ELISA method, which employed polyclonal goatanti-human anti-troponin $\mathrm{T}$ antibodies, immobilised on polyvinylchloride test tubes and peroxidase labelled monoclonal anti-troponin $\mathrm{T}$ antibody $1 \mathrm{~B} 10$ for detection. ${ }^{12}$ The latter had $12 \%$ cross reactivity to skeletal muscle troponin $\mathrm{T}^{54,55}$ Overall, the assay displayed $1 \%$ cross reactivity to skeletal $\mathrm{TnT},{ }^{12}$ likely attributable to unspecific binding of skeletal muscle troponin $\mathrm{T}$ to the test tube and detection by the cross-reactive monoclonal antibody 1 B 10 used as label. ${ }^{56}$ The detection limit of this assay was 0.04 $\mu \mathrm{g} / \mathrm{L}$ and the turnaround time was 90 minutes. Some years later, the assay (Enzymun ${ }^{\circledR}$ ) was improved by replacing the capture antibodies with biotin labelled monoclonal capture antibody M7, without significant cross reactivity to skeletal TnT, and antibody $1 \mathrm{~B} 10$ for detection, combined with streptavidincoated tubes as the solid phase to reduce unspecific binding. ${ }^{54}$

The second generation, a new and more-specific version of the troponin T ELISA, was developed and used a new antibody combination. ${ }^{56}$ The second generation CTnT immunoassay used two cardiospecific monoclonal anti-cTnT antibodies, biotin labelled monoclonal capture antibody M11.7 (recognising amino acid residues 136-147) and horseradish peroxidase labelled monoclonal detection antibody M7 (recognising amino acid residues 125-131). The latter was first used as capture antibody. The detection limit of this assay was lower $(0.0123 \mu \mathrm{g} / \mathrm{L})$, the imprecision was lower and the turnaround time was reduced to 45 minutes. ${ }^{56,57}$ Calibration of the assay was performed with purified bovine CTnT spiked in human serum. It was proposed to use a cut-off of $0.1 \mu \mathrm{g} / \mathrm{L}$ for diagnosis of patients with myocardial damage. ${ }^{56}$

The third generation assay uses recombinant human $\mathrm{cTnT}$ as calibration material. The new assay has a more linear calibration curve. Thus, linearity problems observed with the second generation assay have been eliminated. The assay has high precision, especially at the low end of measuring range. ${ }^{58}$ The 
detection limit in serum and heparin plasma is $<0.010 \mu \mathrm{g} / \mathrm{L}$, which is equal to the $99^{\text {th }}$ percentile reference limit in healthy volunteers. ${ }^{59,} 60$ Heparin plasma has, however, been shown to generate markedly decreased concentrations compared with serum. ${ }^{61,} 62$ Speth et al. concluded that the apparent decrease in CTnT values in heparin plasma was a result of direct molecular interaction between the negatively charged glycosaminoglycan and clusters of basic residues within the cTnT molecule. ${ }^{63}$

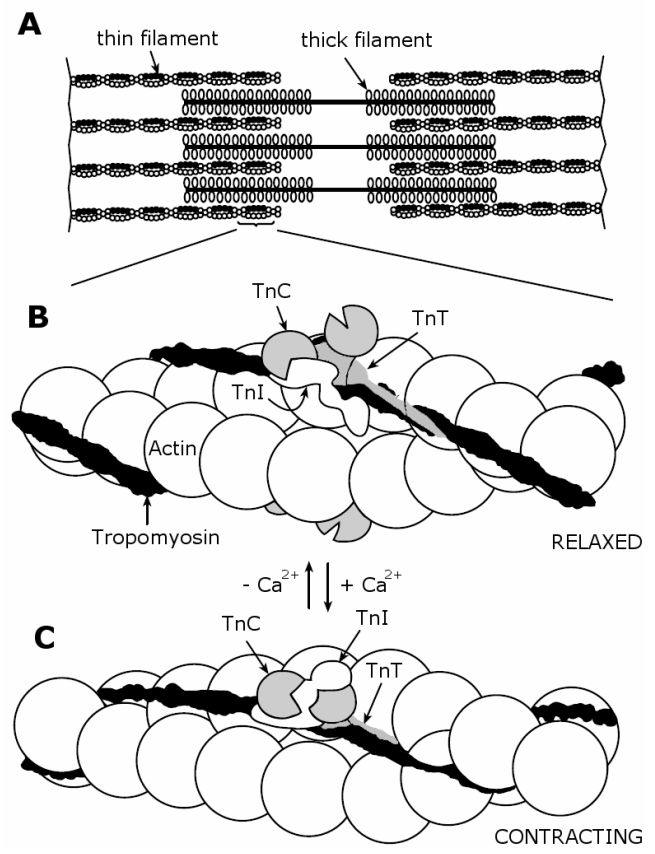

Figure 1-4. Structure of the striated muscle contractile apparatus. A) Structure of a sarcomere with the actin based thin filament and the myosin based thick filament. B) Position of tropomyosin and actin when the muscle is relaxed and no $\mathrm{Ca}^{2+}$ is bound. C) Position of tropomyosin and actin when muscle is contracting after $\mathrm{Ca}^{2+}$ binding to troponin $\mathrm{I}$. TnC, troponin C; TnI, troponin I; TnT, troponin T. Adapted from Collinson et al. ${ }^{52}$

For diagnosis of myocardial damage, it has been recommended to use a cut-off value at which the coefficient of variation (CV) is less than or equal to $10 \% \cdot{ }^{10,11}$ For the third generation assay this is 0.03 $\mu \mathrm{g} / \mathrm{L}$. Recently, a study comparing the second and third generation assays showed excellent agreement $(r=0.99$ Spearman, $p<0.0001, n=135)$ across the analytical range. This correlation was linear in the range from 0.01-0.2 $\mu \mathrm{g} / \mathrm{L}$ and curvilinear above $0.2 \mu \mathrm{g} / \mathrm{L} .{ }^{64}$ The third generation assay classified $35 \%$ more patients as having AMI, identified a $10 \%$ larger low-risk group, and was better able to identify patients with signs of very minor myocardial necrosis (cTnT $>0.01-0.02 \mu \mathrm{g} / \mathrm{L}$ ). ${ }^{65}$ The antibodies do not show cross reactivity with skeletal isoforms $(<0.001 \%)$ and may therefore be used to detect cardiac damage in the context of exercise-induced skeletal muscle damage. ${ }^{13}$

The fourth generation troponin $T$ assay has recently been tested for analytical and clinical performance. This method differs from the previous generation in the composition of reagent 1 , which has an inhibitor of heparin cationic activity added to make heparin plasma samples suitable for CTnT determination. Although preliminary data suggested a reduction of the lower detection limit with 
adequate precision, ${ }^{66}$ the manufacturer recently determined the $10 \% \mathrm{CV}$ concentration to be 0.028 $\mu \mathrm{g} / \mathrm{L} .{ }^{67}$ These results were evaluated in a laboratory setting by measuring $\mathrm{CTnT}$ in a frozen human serum pool prepared by selecting fresh leftover samples from patients with cTnT concentrations around the selected MI cut-off. This group showed an average total CV (SD) of 9.8\% (0.7) at an overall cTnT mean (SD) concentration of $0.041 \mu \mathrm{g} / \mathrm{L}(0.004) .{ }^{68}$ The fourth generation is now the laboratory standard for analysis of CTnT and a high sensitive assay with a lower detection limit is now being tested.

Throughout the studies described in this thesis, the third generation cTnT short turnaround time (STAT) immunoassay was used on the Elecsys 2010 immunoassay system. In the first step, serum is combined with a reagent mixture containing biotinylated monoclonal anti-cTnT antibody and a ruthenium-labelled monoclonal anti-cTnT antibody. In the second step, streptavidin-coated paramagnetic micro particles are added and incubated. The now formed immune complexes are magnetically captured on an electrode in a measuring cell and application of a $0.2 \mathrm{mV}$ voltage results in an electrochemiluminescent signal. This is calibrated against an internal standard curve, constructed with two calibrators. The serum detection limit of the third generation CTnT immunoassay, equal to the $99^{\text {th }}$ percentile reference limit, is $<0.010 \mu \mathrm{g} / \mathrm{L} .{ }^{60}$ Between-day variation is $7.9 \%$ and $6.7 \%$ at concentrations of $0.134 \mu \mathrm{g} / \mathrm{L}$ and $2.85 \mu \mathrm{g} / \mathrm{L}$, respectively $(n=89)$. It has been recommended to use a cut-off value at a concentration where the $\mathrm{CV}$ is less than or equal to $10 \%(0.03 \mu \mathrm{g} / \mathrm{L}) .{ }^{59}$ In the general population, however, CTnT elevations are rare in subjects without chronic heart failure, left ventricular hypertrophy, chronic kidney disease, or diabetes. It has been suggested to use the upper limit of normal should be $<0.010 \mu \mathrm{g} / \mathrm{L}$, because even minimally increased cTnT may represent subclinical cardiac injury and have important clinical implications. ${ }^{69}$

\section{Degradation of cardiac troponins}

The troponins together form a complex of three proteins. Upon cell death, these, and all other proteins constituting the cell, are released into the circulation. After AMI it has been shown in serum of patients with AMI that the predominant forms in blood are free cTnT and the cTnI-TnC binary complex. ${ }^{70,71}$ Free cTnI, the cTnI-cTnT binary complex, and the CTnT- cTnI-TnC ternary complex were seldom present, and when present, only in small quantities compared with the binary complex. ${ }^{70,72,73}$ To complicate matters even more, CTnI was shown to be present in many different degraded and modified (phosphorylated or oxidized) forms. ${ }^{73-77}$ This has many analytical implications ${ }^{78}$ Because there are many manufacturers marketing different CTnI immunoassays, using different antibody combinations and different calibrators, results are not comparable between assays. Standardization of CTnI assays is essential for comparability of studies measuring $\mathrm{CTnI}$ and optimal patient care. ${ }^{79}$

The difficulties seen with CTnI standardization are not relevant for $\mathrm{CTnT}$, because there is only one manufacturer with a cTnT assay due to international patents (Roche). However, Wu et al. showed the presence of immunoreactive cTnT fragments in the circulation of AMI patients. ${ }^{73}$ Somewhat later, in a study by Labugger et al. on troponin I and T degradation in patients with AMI, Western blot data clearly showed the intact protein at $\sim 42 \mathrm{kDa}$, one major $(\sim 26 \mathrm{kDa})$ fragment and two additional minor fragments $(\sim 32 \mathrm{kDa}) .{ }^{75}$ In addition to their presence in serum, cTnT fragments have also been detected in healthy human heart tissue homogenates using the antibodies of the third generation CTnT immunoassay. ${ }^{80,81}$ These data all support the hypothesis that, just as CTnI, CTnT is present in the circulation in degraded form. This might not have the standardization issues, but might aid in understanding the unexplained CTnT elevations sometimes encountered in clinical situations. 
A mechanism that has been suggested for the degradation of cardiac troponins is proteolytic degradation. It has been shown that the calcium activated cysteine proteases such as $\mu$-calpain (calpain 1) and caspase- 3 are capable of degrading CTnT (and cTnI) in vitro. ${ }^{82}$ Studies in the rat and mouse have shown that $\mu$-calpain activation results in a $27 \mathrm{kDa}$ fragment after ex-vivo ischemia and reperfusion of the isolated heart. ${ }^{83}$ Furthermore, addition of inhibitors of $\mu$-calpain showed a decrease in this degradation reaction. ${ }^{83}$ Communal et al. showed that caspase- 3 cleaves CTnT when it is in complex with CTnI and TnC, but not as free $\mathrm{cTnT}^{84}$ This cleavage resulted in a $25 \mathrm{kDa} \mathrm{cTnT}$ fragment on Western blot when using an anti-cTnT antibody recognizing the C-terminal part of the molecule.

In the field of expertise of clinical chemistry it is important to realize what exactly an assay measures. First, to fully understand the pathophysiology of a disease and, more importantly, because this allows for a better interpretation of the test result and advise to clinicians. As there are many diseases with unexplained CTnT elevations, it is necessary to clarify what is being measured. Our hypothesis is that degradation of $\mathrm{CTnT}$ results in the appearance of immunoreactive fragments. Renal impairment might result in the accumulation of these fragments.

\section{Natriuretic peptides (BNP and NT-proBNP)}

Brain natriuretic peptide was first discovered in pigs. ${ }^{85}$ Further research in humans lead to the unravelling of the release and effects of brain natriuretic peptides. ${ }^{86,87}$ In humans, this natriuretic peptide is released mainly from the ventricular endothelium and is referred to as B-type natriuretic peptide (BNP). ${ }^{88}$ Figure 1-5 shows the release of BNP as the 108 amino acid prohormone proBNP, which is then split into the amino-terminal proBNP (NT-proBNP, 76 amino acids) and the biologically active BNP (32 amino acids).

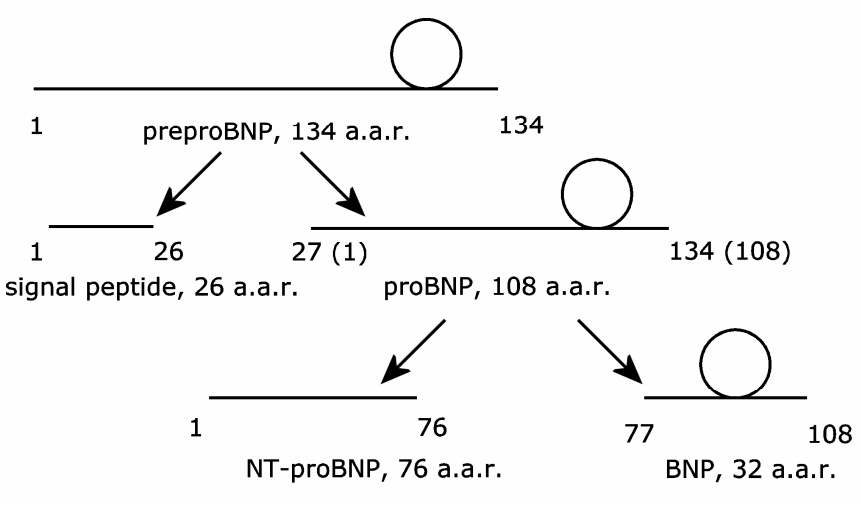

Figure 1-5. Release of BNP and NT-proBNP. A.a.r., amino acid residue.

Upon increased stretch of the ventricular wall (e.g. increased filling pressures due to hypertension), BNP and NT-proBNP are released into the circulation mainly as the prohormone proBNP. ${ }^{89}$ After cleavage, both are present in equimolar amounts. In addition to the diuretic and natriuretic effects that prevent water retention and excess salt concentration, the biologically active BNP is also a peripheral vascular and coronary vascular vasodilator, which reduces afterload and preload of the heart. These properties lead to a reduction in blood pressure and thus a decrease in ventricular stress. ${ }^{90}$ BNP has 
been shown to be a strong prognostic indicator for both asymptomatic patients and for patients with heart failure at all stages of disease. ${ }^{43,44}$

In the studies presented in this thesis, BNP was collected in EDTA plasma tubes to which the protease inhibitor aprotinin was added to improve stability. ${ }^{91}$ The concentration was measured with the Shionoria BNP assay. This is a one-step immunoradiometric assay that uses two different monoclonal antibodies that recognize the C-terminal structure and the disulfide bond-mediated ring structure of BNP $32 .{ }^{92,93}$ Between-day variation is $14,1 \%$ and $4.3 \%$ at concentrations of $1.2 \mathrm{pmol} / \mathrm{L}$ and $584 \mathrm{pmol} / \mathrm{L}$, respectively $(n=30)$.

NT-proBNP is more stable than BNP and can be collected in serum, EDTA plasma or lithium-heparin plasma with good stability. ${ }^{94}$ NT-proBNP does not have a direct biological function in vivo. However, because BNP and NT-proBNP originate from a single precursor molecule (proBNP), ${ }^{95}$ NT-proBNP does have diagnostic and prognostic value in chronic and acute heart failure. ${ }^{89,96,97}$ In addition, elevated levels of NT-proBNP predict cardiovascular morbidity and mortality, independent of other prognostic markers, and identify at-risk individuals even in the absence of systolic or diastolic dysfunction by echocardiography. ${ }^{98}$ After adjusting for confounding variables, both BNP and NT-proBNP levels were shown to be strongly associated with death and heart failure events in multiple studies across heterogeneous patient populations. ${ }^{99-103}$ Furthermore, preoperative NT-proBNP levels are a strong predictor of long-term mortality and major adverse cardiac events after major non-cardiac vascular surgery. ${ }^{104}$

In the studies presented in this thesis, the NT-proBNP immunoassay was used on the Elecsys 2010

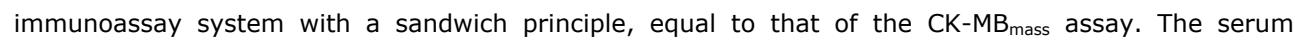
detection limit of the NT-proBNP immunoassay is $0.6 \mathrm{pmol} / \mathrm{L}$. Between-day variation is $2.4 \%$ and $2.2 \%$ at concentrations of $51.2 \mathrm{pmol} / \mathrm{L}$ and $800 \mathrm{pmol} / \mathrm{L}$, respectively $(n=60)$. The reference values for the identification and exclusion of acute coronary heart failure were shown to be age dependent: $53 \mathrm{pmol} / \mathrm{L}$ (<50 years) and $106 \mathrm{pmol} / \mathrm{L} \mathrm{pg/mL} \mathrm{(>=50} \mathrm{years).}{ }^{105}$ These cut-off values can also be used effectively for diagnosis of chronic heart failure. ${ }^{106}$

\section{OUTLINE AND AIM OF THIS THESIS}

The work presented in this thesis focuses on biochemical markers of acute coronary syndromes, in particular cardiac troponin T. Although this biomarker is an established and valuable laboratory parameter, it remains unclear in what form(s) this protein is present in the circulation. The question whether CTnT is present in the intact form or circulates (partly) in degraded form is relevant for assay accuracy. Depending on the antibody combinations used, immunoassays cannot always distinguish between the intact protein and its degradation products.

Chapter 1 outlines a general introduction regarding the epidemiology and terminology of acute coronary syndromes (including acute myocardial infarction), the different cardiac biomarkers used for diagnosis and prognosis, and the laboratory assays used to measure them. This chapter also outlines the aims of the thesis.

Because analysis of low abundant proteins like cTnT in an in vivo setting can be rather difficult, concentrating these proteins can be highly valuable. In Chapter 2 the development and optimization of a new and highly sensitive immunoprecipitation technique used for extracting and purifying human 


\section{Chapter 1}

cTnT from human serum samples is described. We analyzed serum from patients on hemodialysis to investigate the sometimes unexplained cTnT elevations seen in these patients.

With this technique we then investigated the molecular forms of cTnT present in serum of patients who suffered an AMI (Chapter 3). We describe the changes in the composition of the molecular forms of cTnT.

Using a different analytical approach, we sought to investigate the forms of circulating cTnT in an in vitro experimental setup. Using high performance liquid chromatography (HPLC) in combination with a size-exclusion chromatography column we investigated the molecular forms of cTnT (Chapter 4). Patient material of AMI patients was also examined.

In Chapter 5 we analysed the available literature on CTnT elevations after endurance events such as marathon and triathlon. Also, the levels of cTnT seen in untrained individuals from the general population after a short exercise are presented and discussed.

Chapter 6 describes in vitro experiments investigating the release of CTnT and cTnI in a model of cardiac ischemia using neonatal rat cardiomyocytes.

In Chapter 7 the use of a marker for cardiac function and volume overload, NT-proBNP, is evaluated for its diagnostic value in diagnosing heart failure.

Finally, Chapter 8 discusses the results and conclusions of the above mentioned studies. Furthermore, directions for future research will be discussed. 


\section{REFERENCES}

[1] Koek HL, Engelfriet-Rijk CJM, Bots ML. Hart- en vaatziekten in Nederland. In: Jager-Geurts $\mathrm{MH}$, Peters RJG, Van Dis SJ, Bots ML, eds. Hart- en vaatziekten in Nederland 2006, cijfers over risicofactoren, ziekte, behandeling en sterfte. Den Haag: Nederlandse Hartstichting; 2006.

[2] Indications for fibrinolytic therapy in suspected acute myocardial infarction: collaborative overview of early mortality and major morbidity results from all randomised trials of more than 1000 patients. Fibrinolytic Therapy Trialists' (FTT) Collaborative Group. Lancet 1994; 343: 311-22.

[3] Eagle KA, Goodman SG, Avezum A, Budaj A, Sullivan CM, Lopez-Sendon J. Practice variation and missed opportunities for reperfusion in STsegment-elevation myocardial infarction: findings from the Global Registry of Acute Coronary Events (GRACE). Lancet 2002; 359: 373-7.

[4] Buch P, Rasmussen S, Gislason GH, Rasmussen JN, Kober L, Gadsboll N, Stender S, Madsen M Torp-Pedersen C, Abildstrom SZ. Temporal Decline in the Prognostic Impact of a Recurrent Acute Myocardial Infarction 1985 to 2002. Heart 2006.

[5] Capewell S, Livingston BM, MacIntyre $K$, Chalmers JW, Boyd J, Finlayson A, Redpath A, Pell JP, Evans CJ, McMurray JJ. Trends in casefatality in 117718 patients admitted with acute myocardial infarction in Scotland. Eur Heart ] 2000; 21: 1833-40.

[6] Weinstein BJ, Epstein FH. Comparability Of Criteria And Methods In The Epidemiology Of Cardiovascular Disease. Report of A Survey. Circulation 1964; 30: 643-53.

[7] WHO. Report of the Fifth Working Group, Copenhagen, 26-29 April 1971. Copenhagen Denmark: Regional Office for Europe, World Health Organization 1971; Report No. Eur 8201(5).

[8] Tunstall-Pedoe $\mathrm{H}$, Kuulasmaa $\mathrm{K}$, Amouyel $\mathrm{P}$ Arveiler D, Rajakangas AM, Pajak A. Myocardial infarction and coronary deaths in the World Health Organization MONICA Project. Registration procedures, event rates, and casefatality rates in 38 populations from 21 countries in four continents. Circulation 1994; 90: 583-612.

[9] Section 8: Two-year incidence by exam interval by age and sex at exam 1. Bethesda: US National Heart Institute; 1968.

[10] Alpert JS, Thygesen K, Antman E, Bassand JP. Myocardial infarction redefined--a consensus document of The Joint European Society of Cardiology/American College of Cardiology Committee for the redefinition of myocardial infarction. J Am Coll Cardiol 2000; 36: 959-69.

[11] Myocardial infarction redefined--a consensus document of The Joint European Society of Cardiology/American College of Cardiology Committee for the redefinition of myocardial infarction. Eur Heart J 2000; 21: 1502-13.
[12] Katus HA, Remppis A, Looser S, Hallermeier K, Scheffold T, Kubler W. Enzyme linked immuno assay of cardiac troponin $T$ for the detection of acute myocardial infarction in patients. J Mol Cell Cardiol 1989; 21: 1349-53.

[13] Shave R, Dawson E, Whyte G, George K, Ball D, Collinson P, Gaze D. The cardiospecificity of the third-generation cTnT assay after exerciseinduced muscle damage. Med Sci Sports Exerc 2002; 34: 651-4.

[14] Cummins B, Auckland ML, Cummins P. Cardiacspecific troponin-I radioimmunoassay in the diagnosis of acute myocardial infarction. Am Heart J 1987; 113: 1333-44.

[15] Tunstall-Pedoe H. Redefinition of myocardial infarction by a consensus dissenter. J Am Coll Cardiol 2001; 37: 1472-4.

[16] Richards AM, Lainchbury JG, Nicholls MG Unsatisfactory redefinition of myocardia infarction. Lancet 2001; 357: 1635-6.

[17] Panteghini $M$. The new definition of myocardia infarction and the impact of troponin determination on clinical practice. Int J Cardiol 2006; 106: 298-306.

[18] Birkhead JS, Norris RM. Redefinition of myocardial infarction. Lancet 2001; 358: 764.

[19] Kontos MC, Fritz LM, Anderson FP, Tatum JL, Ornato JP, Jesse RL. Impact of the troponin standard on the prevalence of acute myocardial infarction. Am Heart J 2003; 146: 446-52.

[20] Roger VL, Killian JM, Weston SA, Jaffe AS, Kors J, Santrach PJ, Tunstall-Pedoe H, Jacobsen SJ. Redefinition of Myocardial Infarction. Prospective Evaluation in the Community. Circulation 2006

[21] Management of unstable angina. Guidelines-2000. The National Heart Foundation of Australia, The Cardiac Society of Australia and New Zealand. Med J Aust 2000; 173 Suppl: S65-88.

[22] Lusis AJ. Atherosclerosis. Nature 2000; 407 : 233-41.

[23] Smeeth L, Thomas SL, Hall AJ, Hubbard R, Farrington $P$, Vallance $P$. Risk of myocardial infarction and stroke after acute infection or vaccination. N Engl J Med 2004; 351: 2611-8.

[24] Lowe HC, Neill BD, Van de Werf F, Jang IK. Pharmacologic reperfusion therapy for acute myocardial infarction. J Thromb Thrombolysis 2002; 14: 179-96.

[25] Verstraete M. Third-generation thrombolytic drugs. Am J Med 2000; 109: 52-8.

[26] Yock A, Isbill JM, King SB, 3rd. Bare-metal stent outcomes in an unselected patient population. Clin Cardiol 2006; 29: 352-6

[27] Eisenberg MJ, Konnyu KJ. Review of randomized clinical trials of drug-eluting stents for the prevention of in-stent restenosis. Am J Cardiol 2006; 98: 375-82. 
[28] Tung R, Kaul S, Diamond GA, Shah PK. Narrative review: drug-eluting stents for the management of restenosis: a critical appraisal of the evidence. Ann Intern Med 2006; 144: 913-9.

[29] Hochman JS, Lamas GA, Buller CE, Dzavik V, Reynolds HR, Abramsky SJ, Forman S, Ruzyllo W, Maggioni AP, White H, Sadowski Z, Carvalho AC, Rankin JM, Renkin JP, Steg PG, Mascette AM, Sopko G, Pfisterer ME, Leor J, Fridrich V, Mark DB, Knatterud GL. Coronary Intervention for Persistent Occlusion after Myocardial Infarction. N Engl J Med 2006; 355: 2395-407.

[30] Boden WE, O'Rourke R A, Teo KK, Hartigan PM, Maron DJ, Kostuk WJ, Knudtson $M$, Dada $M_{\text {, }}$ Casperson $\mathrm{P}$, Harris $\mathrm{CL}$, Chaitman BR, Shaw $\mathrm{L}$, Gosselin G, Nawaz S, Title LM, Gau G, Blaustein AS, Booth DC, Bates ER, Spertus JA, Berman DS, Mancini GB, Weintraub WS. Optimal Medical Therapy with or without PCI for Stable Coronary Disease. N Engl J Med 2007.

[31] Karmen A, Wroblewski F, LaDue JS. Transaminase activity in human blood. J Clin Invest 1954; 34: 126-33.

[32] LaDue JS, Wroblewski F, Karmen A. Serum glutamic oxaloacetic transaminase activity in human acute transmural myocardial infarction. Science 1954; 120: 497-9.

[33] Wroblewski F, LaDue JS. Lactic dehydrogenase activity in blood. Proc Soc Exp Biol Med 1955; 90: 210-3.

[34] Rosalki SB. Serum Alpha-Hydroxybutyrate Dehydrogenase: A New Test For Myocardial Infarction. Br Heart J 1963; 25: 795-802.

[35] Dreyfus JC, Schapira G, Resnais J, Scebat L. [Serum creatine kinase in the diagnosis of myocardial infarct]. Rev Fr Etud Clin Biol 1960; 5: 386-7.

[36] Duma RJ, Siegel AL. Serum Creatinine Phosphokinase In Acute Myocardial Infarction: Diagnostic Value. Arch Intern Med 1965; 115: 443-51.

[37] Stone MJ, Willerson JT, Gomez-Sanchez CE, Waterman MR. Radioimmunoassay of myoglobin in human serum. Results in patients with acute myocardial infarction. J Clin Invest 1975; 56: 1334-9.

[38] Neumeier D, Prellwitz W, Wurzburg $U$, Brundobler $M$, Olbermann $M$, Just $H J$, Knedel $M$, Lang $H$. Determination of creatine kinase isoenzyme MB activity in serum using immunological inhibition of creatine kinase $M$ subunit activity. Activity kinetics and diagnostic significance in myocardial infarction. Clin Chim Acta 1976; 73: 445-51.

[39] Gerhardt W, Ljungdahl L, Borjesson J, Hofvendahl S, Hedenas B. Creatine kinase Bsubunit activity in human serum. I. Development of an immunoinhibition method for routine determination of S-creatine kinase B-sununit activity. Clin Chim Acta 1977; 78: 2941.

[40] Ljungdahl L, Hofvendahl S, Gerhardt W, Borjesson J. Creatine kinase B-subunit activity in human serum. II. Evaluation of s-ck bsubunit activity in the diagnosis of acute myocardial infarction. Clin Chim Acta 1977; 78: 43-53.
[41] Panteghini M, Pagani F. Comparison of catalytic activity and mass concentration of serum creatine kinase MB isoenzyme in the detection of coronary reperfusion in acute myocardial infarction after therapeutic thrombolysis. J Clin Chem Clin Biochem 1988; 26: 277-80.

[42] Kleine $\mathrm{AH}$, Glatz JFC, Van Nieuwenhoven FA, Van der Vusse GJ. Release of fatty-acid binding protein into plasma after acute myocardial infarction in man. Mol Cell Biochem 1992; 116: 155-62.

[43] Clerico A, Emdin M. Diagnostic accuracy and prognostic relevance of the measurement of cardiac natriuretic peptides: a review. Clin Chem 2004; 50: 33-50.

[44] Doust JA, Pietrzak E, Dobson A, Glasziou P. How well does B-type natriuretic peptide predict death and cardiac events in patients with heart failure: systematic review. Bmj 2005; 330: 625.

[45] Wu AH, Apple FS, Gibler WB, Jesse RL, Warshaw MM, Valdes R, Jr. National Academy of Clinical Biochemistry Standards of Laboratory Practice: recommendations for the use of cardiac markers in coronary artery diseases. Clin Chem 1999; 45: 1104-21.

[46] Urdal P, Urdal K, Stromme JH. Cytoplasmic creatine kinase isoenzymes quantitated in tissue specimens obtained at surgery. Clin Chem 1983; 29: 310-3.

[47] Farah CS, Reinach FC. The troponin complex and regulation of muscle contraction. Faseb $]$ 1995; 9: 755-67.

[48] Townsend PJ, Farza $\mathrm{H}$, MacGeoch C, Spurr NK, Wade R, Gahlmann R, Yacoub MH, Barton PJ. Human cardiac troponin $\mathrm{T}$ : identification of fetal isoforms and assignment of the TNNT2 locus to chromosome 1q. Genomics 1994; 21: 311-6.

[49] Vallins WJ, Brand NJ, Dabhade N, ButlerBrowne G, Yacoub MH, Barton PJ. Molecular cloning of human cardiac troponin I using polymerase chain reaction. FEBS Lett 1990; 270: $57-61$

[50] Adams JE, 3rd, Bodor GS, Davila-Roman VG, Delmez JA, Apple FS, Ladenson JH, Jaffe AS. Cardiac troponin I. A marker with high specificity for cardiac injury. Circulation 1993; 88: $101-6$.

[51] Newby LK, Goldmann BU, Ohman EM. Troponin an important prognostic marker and riskstratification tool in non-ST-segment elevation acute coronary syndromes. J Am Coll Cardiol 2003; 41: 31S-6S.

[52] Collinson PO, Boa FG, Gaze DC. Measurement of cardiac troponins. Ann Clin Biochem 2001; 38: 423-49.

[53] Rosalki SB, Roberts R, Katus HA, Giannitsis E, Ladenson $\mathrm{JH}$, Apple FS. Cardiac biomarkers for detection of myocardial infarction: perspectives from past to present. Clin Chem 2004; 50: 2205-13.

[54] Katus HA, Looser S, Hallermayer K, Remppis A, Scheffold T, Borgya A, Essig U, Geuss U. Development and in vitro characterization of a new immunoassay of cardiac troponin T. Clin Chem 1992; 38: 386-93. 
[55] Wu AH, Valdes R, Jr., Apple FS, Gornet T, Stone MA, Mayfield-Stokes $S$, Ingersoll-Stroubos AM, Wiler B. Cardiac troponin-T immunoassay for diagnosis of acute myocardial infarction. Clin Chem 1994; 40: 900-7.

[56] Muller-Bardorff M, Hallermayer K, Schroder A, Ebert C, Borgya A, Gerhardt W, Remppis A, Zehelein J, Katus HA. Improved troponin $T$ ELISA specific for cardiac troponin $T$ isoform: assay development and analytical and clinical validation. Clin Chem 1997; 43: 458-66.

[57] Baum H, Braun S, Gerhardt W, Gilson G, Hafner G, Muller-Bardorff M, Stein W, Klein G, Ebert C, Hallermayer K, Katus HA. Multicenter evaluation of a second-generation assay for cardiac troponin T. Clin Chem 1997; 43: 1877-84.

[58] Hallermayer K, Klenner D, Vogel R. Use of recombinant human cardiac Troponin $T$ for standardization of third generation Troponin $T$ methods. Scand J Clin Lab Invest Suppl 1999; 230: 128-31.

[59] Apple FS, Murakami MM. Serum 99th percentile reference cutoffs for seven cardiac troponin assays. Clin Chem 2004; 50: 1477-9.

[60] Apple FS, Quist HE, Doyle PJ, Otto AP, Murakami MM. Plasma 99th Percentile Reference Limits for Cardiac Troponin and Creatine Kinase MB Mass for Use with European Society of Cardiology/American College of Cardiology Consensus Recommendations. Clin Chem 2003; 49: 1331-6.

[61] Gerhardt W, Nordin G, Herbert AK, Linaker Burzell B, Isaksson A, Gustavsson E, Haglund S, Muller-Bardorff M, Katus HA. Troponin T and I Assays Show Decreased Concentrations in Heparin Plasma Compared with Serum: Lower Recoveries in Early than in Late Phases of Myocardial Injury. Clin Chem 2000; 46: 817-21.

[62] Stiegler $\mathrm{H}$, Fischer $\mathrm{Y}$, Vazquez-Jimenez JF, Graf J, Filzmaier K, Fausten B, Janssens U, Gressner AM, Kunz D. Lower cardiac troponin $T$ and I results in heparin-plasma than in serum. Clin Chem 2000; 46: 1338-44.

[63] Speth M, Seibold K, Katz N. Interaction between heparin and cardiac troponin $\mathrm{T}$ and troponin I from patients after coronary bypass surgery. Clin Biochem 2002; 35: 355-62.

[64] Gaze DC, Collinson PO. Clinical effect of recalibration of the roche cardiac troponin $T$ assay. Med Princ Pract 2006; 15: 29-32.

[65] Jernberg $T$, Venge $P$, Lindahl B. Comparison between second and third generation troponin $T$ assay in patients with symptoms suggestive of an acute coronary syndrome but without ST segment elevation. Cardiology 2003; 100: 2935.

[66] Giannitsis E, Katus HA. 99th Percentile and Analytical Imprecision of Troponin and Creatine Kinase-MB Mass Assays: An Objective Platform for Comparison of Assay Performance. Clin Chem 2003; 49: 1248-9.

[67] Hermsen D, Apple F, Garcia-Beltran L, Jaffe A, Karon $B$, Lewandrowski E, Muhlbacher A, Muller R, Ordonez J, Pagani F, Panteghini M, Plecko T, Jarausch J. Results from a multicenter evaluation of the 4th generation Elecsys Troponin T assay. Clin Lab 2007; 53: 1-9.
[68] Dolci A, Dominici R, Luraschi P, Panteghini M. $10 \% \mathrm{CV}$ concentration for the fourth generation Roche cardiac troponin $\mathrm{T}$ assay derived from Internal Quality Control data. Clin Chem Lab Med 2006; 44: 1495-6.

[69] Wallace TW, Abdullah SM, Drazner MH, Das SR, Khera A, McGuire DK, Wians F, Sabatine MS Morrow DA, de Lemos JA. Prevalence and Determinants of Troponin T Elevation in the General Population. Circulation 2006.

[70] Giuliani I, Bertinchant JP, Granier C, Laprade M, Chocron S, Toubin G, Etievent JP, Larue C, Trinquier S. Determination of cardiac troponin I forms in the blood of patients with acute myocardial infarction and patients receiving crystalloid or cold blood cardioplegia. Clin Chem 1999; 45: 213-22.

[71] Fahie-Wilson MN, Carmichael DJ, Delaney MP, Stevens PE, Hall EM, Lamb EJ. Cardiac Troponin $\mathrm{T}$ Circulates in the Free, Intact Form in Patients with Kidney Failure. Clin Chem 2006; 52: 41420.

[72] Katrukha AG, Bereznikova AV, Esakova TV, Pettersson K, Lovgren T, Severina ME, Pulkki K, Vuopio-Pulkki LM, Gusev NB. Troponin I is released in bloodstream of patients with acute myocardial infarction not in free form but as complex. Clin Chem 1997; 43: 1379-85.

[73] Wu AH, Feng YJ, Moore R, Apple FS, McPherson $\mathrm{PH}$, Buechler KF, Bodor G. Characterization of cardiac troponin subunit release into serum after acute myocardial infarction and comparison of assays for troponin $\mathrm{T}$ and $\mathrm{I}$. American Association for Clinical Chemistry Subcommittee on cTnI Standardization. Clin Chem 1998; 44: 1198-208.

[74] McDonough JL, Labugger R, Pickett W, Tse MY, Mackenzie S, Pang SC, Atar D, Ropchan G, Van Eyk JE. Cardiac troponin I is modified in the myocardium of bypass patients. Circulation 2001; 103: 58-64.

[75] Labugger R, Organ L, Collier C, Atar D, Van Eyk JE. Extensive troponin I and $T$ modification detected in serum from patients with acute myocardial infarction. Circulation 2000; 102: 1221-6.

[76] Morjana NA. Degradation of human cardiac troponin I after myocardial infarction. Biotechnol Appl Biochem 1998; 28: 105-11.

[77] Katrukha AG, Bereznikova AV, Filatov VL, Esakova TV, Kolosova OV, Pettersson K, Lovgren $T$, Bulargina TV, Trifonov IR, Gratsiansky NA, Pulkki K, Voipio-Pulkki LM, Gusev NB. Degradation of cardiac troponin I: implication for reliable immunodetection. Clin Chem 1998; 44: 2433-40.

[78] Christenson RH, Duh SH, Apple FS, Bodor GS, Bunk DM, Dalluge J, Panteghini M, Potter JD, Welch MJ, Wu AH, Kahn SE. Standardization of cardiac troponin I assays: round Robin of ten candidate reference materials. Clin Chem 2001; 47: 431-7.

[79] Panteghini M. Standardization of cardiac troponin I measurements: the way forward? Clin Chem 2005; 51: 1594-7. 
[80] Ricchiuti V, Voss EM, Ney $A$, Odland $M$, Anderson PA, Apple FS. Cardiac troponin T isoforms expressed in renal diseased skeletal muscle will not cause false-positive results by the second generation cardiac troponin $T$ assay by Boehringer Mannheim. Clin Chem 1998; 44: 1919-24.

[81] Davis GK, Labugger R, Van Eyk JE, Apple FS. Cardiac Troponin $\mathrm{T}$ is not detected in western blots of diseased renal tissue. Clin Chem 2001; 47: 782-3.

[82] Di Lisa F, De Tullio R, Salamino F, Barbato R Melloni E, Siliprandi N, Schiaffino S, Pontremoli $\mathrm{S}$. Specific degradation of troponin $\mathrm{T}$ and $\mathrm{I}$ by mu-calpain and its modulation by substrate phosphorylation. Biochem J 1995; 308 (Pt 1): 57-61.

[83] Zhang Z, Biesiadecki BJ, Jin JP. Selective deletion of the $\mathrm{NH} 2$-terminal variable region of cardiac troponin $\mathrm{T}$ in ischemia reperfusion by myofibril-associated mu-calpain cleavage. Biochemistry 2006; 45: 11681-94.

[84] Communal C, Sumandea M, de Tombe P, Narula J, Solaro RJ, Hajjar RJ. Functional consequences of caspase activation in cardiac myocytes. Proc Natl Acad Sci U S A 2002; 99: 6252-6.

[85] Sudoh T, Kangawa K, Minamino N, Matsuo H. A new natriuretic peptide in porcine brain. Nature 1988; 332: 78-81.

[86] Sudoh T, Maekawa K, Kojima M, Minamino N Kangawa $K$, Matsuo $H$. Cloning and sequence analysis of CDNA encoding a precursor for human brain natriuretic peptide. Biochem Biophys Res Commun 1989; 159: 1427-34.

[87] Kambayashi $Y$, Nakao K, Mukoyama M, Saito $Y$, Ogawa Y, Shiono S, Inouye K, Yoshida N, Imura $\mathrm{H}$. Isolation and sequence determination of human brain natriuretic peptide in human atrium. FEBS Lett 1990; 259: 341-5.

[88] Chen $\mathrm{HH}$, Burnett JC. Natriuretic peptides in the pathophysiology of congestive heart failure. Curr Cardiol Rep 2000; 2: 198-205.

[89] Seferian KR, Tamm NN, Semenov AG, Mukharyamova KS, Tolstaya AA, Koshkina EV, Kara AN, Krasnoselsky MI, Apple FS, Esakova TV, Filatov VL, Katrukha AG. The brain natriuretic peptide (BNP) precursor is the major immunoreactive form of BNP in patients with heart failure. Clin Chem 2007; 53: 866-73.

[90] Levin ER, Gardner DG, Samson WK. Natriuretic peptides. N Engl J Med 1998; 339: 321-8.

[91] Tsuji $T$, Imagawa $K$, Masuda $H$, Haraikawa $M$, Shibata $\mathrm{K}$, Kono $\mathrm{M}$, Inouye $\mathrm{K}$, Uchida $\mathrm{K}$. Stabilization of human brain natriuretic peptide in blood samples. Clin Chem 1994; 40: 672-3.

[92] Kono M, Yamauchi A, Tsuji T. An immunoradiometric assay for brain natriuretic peptide in human plasma. Jpn Soc Nuc Med Tech 1993; 13: 2-7.

[93] Shimizu H, Aono K, Masuta K, Asada H, Misaki A, Teraoka H. Stability of brain natriuretic peptide (BNP) in human blood samples. Clin Chim Acta 1999; 285: 169-72.

[94] Barnes SC, Collinson PO, Galasko G, Lahiri A Senior R. Evaluation of $\mathrm{N}$-terminal pro-B type natriuretic peptide analysis on the Elecsys 1010 and 2010 analysers. Ann Clin Biochem 2004; 41: 459-63.
[95] Hunt PJ, Yandle TG, Nicholls MG, Richards AM, Espiner EA. The amino-terminal portion of probrain natriuretic peptide (Pro-BNP) circulates in human plasma. Biochem Biophys Res Commun 1995; 214: 1175-83.

[96] Hartmann F, Packer M, Coats AJS, Fowler MB Krum $\mathrm{H}$, Mohacsi $\mathrm{P}$, Rouleau $\mathrm{JL}$, Tendera $\mathrm{M}$ Castaigne $A$, Anker SD, Amann-Zalan I, Hoersch S, Katus HA. Prognostic Impact of Plasma N-Terminal Pro-Brain Natriuretic Peptide in Severe Chronic Congestive Heart Failure: A Substudy of the Carvedilol Prospective Randomized Cumulative Survival (COPERNICUS) Trial. Circulation 2004; 110: 1780-6.

[97] Januzzi J, James L., Camargo CA, Anwaruddin $S$, Baggish AL, Chen AA, Krauser DG, Tung R, Cameron R, Nagurney JT. The $\mathrm{N}$-terminal ProBNP Investigation of Dyspnea in the Emergency department (PRIDE) study. The American Journal of Cardiology 2005; 95: 948-54.

[98] Bibbins-Domingo K, Gupta R, Na B, Wu AH, Schiller NB, Whooley MA. N-terminal fragment of the prohormone brain-type natriuretic peptide (NT-proBNP), cardiovascular events, and mortality in patients with stable coronary heart disease. Jama 2007; 297: 169-76.

[99] de Lemos JA, Morrow DA, Bentley JH, Omland $T$, Sabatine MS, McCabe CH, Hall C, Cannon CP, Braunwald $\mathrm{E}$. The prognostic value of B-type natriuretic peptide in patients with acute coronary syndromes. N Engl J Med 2001; 345 1014-21.

[100] James SK, Lindahl B, Siegbahn A, Stridsberg M, Venge $P$, Armstrong $P$, Barnathan ES, Califf $R$, Topol EJ, Simoons ML, Wallentin L. N-terminal pro-brain natriuretic peptide and other risk markers for the separate prediction of mortality and subsequent myocardial infarction in patients with unstable coronary artery disease: a Global Utilization of Strategies To Open occluded arteries (GUSTO)-IV substudy. Circulation 2003; 108: 275-81.

[101] Kragelund C, Gronning B, Kober L, Hildebrandt $\mathrm{P}$, Steffensen R. N-Terminal Pro-B-Type Natriuretic Peptide and Long-Term Mortality in Stable Coronary Heart Disease. N Engl J Med 2005; 352: 666-75.

[102] Schnabel R, Rupprecht HJ, Lackner KJ, Lubos E, Bickel C, Meyer J, Munzel T, Cambien F, Tiret L, Blankenberg $\mathrm{S}$. Analysis of $\mathrm{N}$-terminal-pro-brain natriuretic peptide and C-reactive protein for risk stratification in stable and unstable coronary artery disease: results from the AtheroGene study. Eur Heart J 2005; 26: 2419.

[103] Khan IA, Fink J, Nass C, Chen H, Christenson R, deFilippi CR. N-terminal pro-B-type natriuretic peptide and B-type natriuretic peptide for identifying coronary artery disease and left ventricular hypertrophy in ambulatory chronic kidney disease patients. Am J Cardiol 2006; 97: 1530-4.

[104] Feringa HH, Schouten O, Dunkelgrun M, Bax JJ, Boersma $E$, Elhendy $A$, de Jonge $R$, Karagiannis $\mathrm{SE}$, Vidakovic R, Poldermans D. Plasma $\mathrm{N}$ terminal pro-B-type natriuretic peptide as longterm prognostic marker after major vascular surgery. Heart 2006. 
[105] Januzzi JL, Jr., Camargo CA, Anwaruddin S, Baggish AL, Chen AA, Krauser DG, Tung $R_{\text {, }}$ Cameron R, Nagurney JT, Chae CU, Lloyd-Jones DM, Brown DF, Foran-Melanson S, Sluss PM, Lee-Lewandrowski $\mathrm{E}$, Lewandrowski KB. The Nterminal Pro-BNP investigation of dyspnea in the emergency department (PRIDE) study. Am J Cardiol 2005; 95: 948-54.
[106] Hulsmann M, Berger R, Mortl D, Gore O, Meyer $B$, Pacher $R$. Incidence of normal values of natriuretic peptides in patients with chronic heart failure and impact on survival: a direct comparison of $\mathrm{N}$-terminal atrial natriuretic peptide, $\mathrm{N}$-terminal brain natriuretic peptide and brain natriuretic peptide. Eur J Heart Fail 2005; 7: 552-6. 



\title{
HIGHLY SENSITIVE IMMUNOPRECIPITATION ASSAY FOR EXTRACTING AND CONCENTRATING LOW ABUNDANCE PROTEINS FROM HUMAN SERUM - APPLICATION IN DIALYSIS PATIENTS
}

\begin{abstract}
Background. Purification and identification of small, low abundance proteins like cardiac troponin T (cTnT) from complex samples such as serum for use in immunoblot experiments has long been a challenge. Commercially available immunoprecipitation methods do not always allow the use of small sample volumes. We have therefore developed a highly sensitive immunoprecipitation assay for extracting and concentrating $\mathrm{CTnT}$ from human serum using small sample volumes and compared it with a commercially available method.
\end{abstract}

Methods. A mixture of anti-cTnT antibodies was coupled to Protein-A Sepharose and cross-linked with a diimidoester. We validated the method by using purified CTnT which was spiked into serum. Serum samples from patients with myocardial infarction were used to compare the effectiveness both immunoprecipitation methods. Serum samples from 63 hemodialysis patients were then used to determine the sensitivity of our method. SDS-PAGE and immunoblotting with monoclonal anti cTnT antibody $4 \mathrm{C} 5$ were used to visualize $\mathrm{CTnT}$.

Results. Both methods were able to concentrate CTnT. However, our method yielded higher concentrations and showed better results. We applied this technique to serum samples from dialysis patients and showed the presence of immunoreactive CTnT fragments, but not the intact protein.

Conclusion. With our newly developed method we were able to visualize CTnT and fragments, even when the CTnT was below the $0.010 \mu \mathrm{g} / \mathrm{L}$ detection limit of the current commercially available immunoassay (Roche). Moreover, this method allows us to further investigate cTnT fragmentation and clearance in vivo.

Parts of this Chapter have been published:

Clinical Chemistry 2005;51:222-4. 


\section{INTRODUCTION}

Purification and identification of small, low abundance proteins from complex samples such as serum for use in immunoblot experiments has long been a challenge. Highly abundant proteins such as albumin and immunoglobulins are complicating factors, sometimes masking the presence of lower abundant proteins. Although many methods of effective and specific removal of albumin and immunoglobulins from serum and plasma samples have been described, ${ }^{1-3}$ there are some important drawbacks. In the circulation, albumin acts as a transporter protein that binds many (often lower abundant) proteins and peptides. Depletion of albumin can lead to loss of these peptides and proteins. ${ }^{4}$ The same principle goes for immunoglobulins that also have affinity for binding to specific molecules. In addition, left over patient samples (as used in this study) are usually small quantities and commercially available methods are not always suitable for small sample volumes. Furthermore, to avoid contamination it is best to provide each sample with its own set of chemicals and materials.<smiles>CN=C(CCC(=NCl)OC)OC</smiles>

Figure 2-1. Structure of dimethyl pimelimidate (DMP), a diimidoester, used for cross-linking of antibodies to protein-A Sepharose.

The formation of amidines from imidoesters and amines from protein side chains was first described in 1962 by Hunter et al., who suggested this method for cross-linking purposes. ${ }^{5}$ Levy et al. described the use of diimidoesters for covalent coupling of antibodies to immobilized antigens. ${ }^{6}$ Later studies reported similar methods for antibody immobilization with cross-linkers like dimethyl pimelimidate (DMP) and dimethyl suberimidate (DMS). ${ }^{7,8}$ Both are symmetric molecules containing two identical and reactive imidoester groups, separated by five or six $\mathrm{CH}_{2}$ groups, respectively (Figure 2-1).

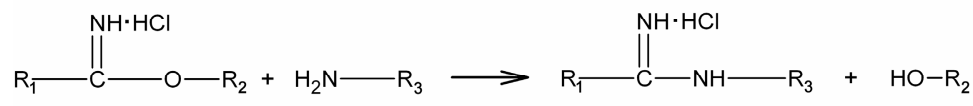

Figure 2-2. Formation of amidine from an imidoester and a deprotonated amine.

These methods are based on the fact that an amine is only able to react with an imidoester if it is deprotonated (Figure 2-2), which occurs at $\mathrm{pH}>\mathrm{pKa}$. At these $\mathrm{pH}$ values, the nucleophilic attack of an $\mathrm{R}-\mathrm{NH}_{2}$ on one of the two outer backbone carbon atoms of DMP results in a tetrahedral intermediate that splits into the amidine link and methanol. Hunter et al. showed that the right choice of $\mathrm{pH}$ even allows a distinction to be made between a-amines and $\varepsilon$-amines ${ }^{5}$. They showed that a $\mathrm{pH}$ between 7 and 8 favors reaction with a-amines, while a $\mathrm{pH}$ between 9 and 10 favors reaction with $\varepsilon$-amines. At a $\mathrm{pH}$ between 8 and 9 both reactions occur at a significant rate. In a protein, only the $\mathrm{N}$-terminal ending of a peptide chain contains an a-amine. The remaining amines are $\varepsilon$-amines from the amino acids lysine or arginine. The different pKa-values for lysine show that with increasing $\mathrm{pH}$, first the a-amine is deprotonated $(\mathrm{pKa}=8.9)$ and subsequently the $\varepsilon$-amine (pKa=10.5) (Figure $2-3)$. The $\varepsilon$-amine of 
arginine $(\mathrm{pKa}=12.5)$ is still protonated at $\mathrm{pH}$ values between 8 and 9 , which leaves, besides the $\mathrm{N}$ terminal a-amine, only the $\varepsilon$-amine from lysine residues available for reaction. Because the variable regions of mouse IgG are generally almost devoid of lysine residues (Kabat Database), ${ }^{9}$ binding will predominantly be at constant regions, minimizing interference of the cross-linker with the antigen binding capacity of the antibody at $\mathrm{pH} 8.6$.

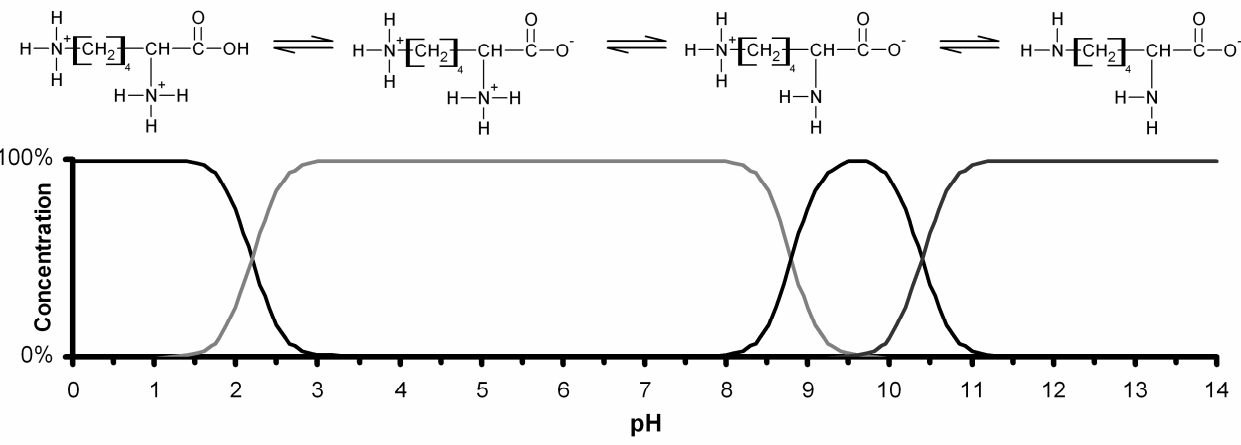

Figure 2-3. Deprotonation of lysine is dependent on pH. First the a-amine is deprotonated $(\mathrm{pKa}=8.9)$ and subsequently the $\varepsilon$-amine (pKa=10.5).

Commercially available methods also use this technique. Unfortunately, these methods are usually marketed for large volume samples. Here we present a highly sensitive immunoprecipitation assay we developed for extracting and concentrating low abundant cTnT from human serum. The performance of our assay was compared with that of the commercially available ImmunoPure ${ }^{\circledR}$ Protein-A IgG orientation kit (Pierce). Both methods are based on the binding of antibodies to protein-A Sepharose beads and subsequent cross-linking with a diimidoester. We validated the method by using purified cTnT which was spiked into serum. Serum samples from patients with myocardial infarction were used to compare the effectiveness both immunoprecipitation methods. Serum samples from 63 hemodialysis patients were then used to determine the sensitivity of our method.

\section{Methods}

All reactions were performed at room temperature and phosphate buffered saline (PBS) was used at $\mathrm{pH}$ 7.0, unless stated otherwise.

\section{Immunoprecipitation assay}

We washed $100 \mathrm{mg}$ protein-A Sepharose (Pharmacia Biotech) once with PBS and blocked with $0.1 \%$ bovine serum albumin (BSA) (Sigma) in PBS for 60 minutes. A mixture of anti-cTnT antibodies (9G6, 7F4 and 1C11, Research Diagnostics Inc.; 4C5, BioSpacific/Fortron) (70 $\mu \mathrm{g}$ per antibody) in PBS with $0.1 \%$ BSA was mixed with the Sepharose beads and rotated for one hour. After binding of the antibodies, the beads were washed twice with excessive PBS. Antibodies were cross-linked to protein-A 
Sepharose by adding $200 \mathrm{mmol} / \mathrm{L}$ triethanolamine in PBS to which $20 \mathrm{mmol} / \mathrm{L} \mathrm{DMP} \mathrm{(Sigma)} \mathrm{was} \mathrm{added}$ directly before use (final $\mathrm{pH}$ 8.6). After rotation for 30 minutes the beads were washed with 200 $\mathrm{mmol} / \mathrm{L}$ triethanolamine in PBS. In contrast with the method by Schneider et al. ${ }^{8}$ and modifications hereon, ${ }^{10}$ cross-linking and washing were repeated twice to improve cross-linking efficiency. Remaining reactive amino groups were quenched by adding $50 \mathrm{mmol} / \mathrm{L}$ ethanolamine in PBS for 60 minutes. Non cross-linked antibodies were removed by incubating for 20 minutes with $1.0 \mathrm{~mol} / \mathrm{L}$ glycine- $\mathrm{HCl}(\mathrm{pH} \mathrm{3.0)}$ twice at $56^{\circ} \mathrm{C}$. Cross-linked beads were stored at $4{ }^{\circ} \mathrm{C}$ in PBS with $0.02 \%$ Tween-20 (PBST) and $0.02 \%$ sodium azide until use. Loading of the Sepharose beads to the column of the ImmunoPure ${ }^{\circledR}$ Protein-A IgG orientation kit was done with the same mixture of anti-cTnT monoclonal antibodies ( $285 \mu \mathrm{g}$ per antibody) and was cross-linked according to the manufacturer's instructions.

The immunoprecipitation of $\mathrm{CTnT}(37 \mathrm{kDa}$ ) required $8 \mathrm{mg}$ (dry weight) antibody-coupled Sepharose beads per sample for our method. To each tube $250 \mu \mathrm{L}$ serum, $100 \mu \mathrm{L}$ urea $(6 \mathrm{~mol} / \mathrm{L})$ and $150 \mu \mathrm{L}$ wash buffer (PBS with $0.01 \%$ Tween-20 (PBST) and $0.7 \mathrm{~g} / 100 \mathrm{~mL}$ non-fat dry milk (Protifar Plus) (Nutricia, Cuijk, The Netherlands) were added. Beads were rotated for 90 minutes and then washed twice with PBST. Elution was performed by heating $\left(56^{\circ} \mathrm{C}\right)$ for 20 minutes in $100 \mu \mathrm{L} 1.0 \mathrm{~mol} / \mathrm{L} \mathrm{glycine} \mathrm{(pH} \mathrm{3.0)}$. The sample was centrifuged and supernatant was kept for analysis.

For the ImmunoPure ${ }^{\circledR}$ Protein-A IgG orientation kit, a total amount of $750 \mu \mathrm{L}$ serum was diluted in 300 $\mu \mathrm{L}$ urea $(6 \mathrm{~mol} / \mathrm{L})$ and $750 \mu \mathrm{L}$ wash buffer was added to the column. After incubation for 90 minutes, the column was washed twice with PBS. Elution was performed with 4 times $1 \mathrm{~mL} 1.0 \mathrm{~mol} / \mathrm{L} \mathrm{glycine-HCl}$ (pH 3.0). Based on the presence of cTnT, fraction 3 was collected for analysis.

Samples were prepared for electrophoresis by adding $20 \mu \mathrm{L}$ sample buffer $(40 \mathrm{mmol} / \mathrm{L}$ Tris, $3.3 \%(\mathrm{w} / \mathrm{v})$ SDS, $50 \%(\mathrm{v} / \mathrm{v})$ glycerol, bromophenolblue) to $80 \mu \mathrm{L}$ eluate. Twenty $\mu \mathrm{L}$ of this mixture was applied to a $4-15 \%$ linear gradient Tris- $\mathrm{HCl}$ polyacrylamide precast gel (Biorad). Precision Plus Protein Standard (BioRad) was used for molecular weight determination. After stacking for 15 minutes at $100 \mathrm{~V}$ and running for 40 minutes at $150 \mathrm{~V}$, blotting was done onto a nitrocellulose membrane (BioRad) at $4{ }^{\circ} \mathrm{C}$ at $100 \mathrm{~V}$ for 60 minutes. Each membrane was blocked for 60 minutes in PBS with $3.3 \mathrm{~g} / 100 \mathrm{~mL}$ non-fat dry milk. The primary anti-cTnT antibody (4C5) was added $1 / 1000$ in wash buffer at $4^{\circ} \mathrm{C}$ overnight. Control experiments with a different anti-cTnT antibody (9G6; mapped epitope: 1 - 60) were also performed (Figure 2-1). The membrane was washed three times in wash buffer and the secondary antibody (peroxidase labeled goat-anti-mouse, Dako) was added 1/5000 in wash buffer for 60 minutes at $4^{\circ} \mathrm{C}$. The membrane was washed 4 times with wash buffer and finally once in PBST. Membranes were developed using Enhanced Chemiluminescence Buffer and captured on Kodak X-Omat Blue film (both from Perkin-Elmer Life Sciences).

To evaluate both methods, we used serum samples that were obtained from a patient with AMI. In addition to a total protein content of $50 \mathrm{~g} / \mathrm{L}$, these samples contained a relatively small amount of CTnT: sample 1 was taken 16 hours after onset of symptoms ( $\mathrm{CTnT}=33.44 \mu \mathrm{g} / \mathrm{L})$ and sample 2 was taken 238 hours after onset of symptoms ( $C T n T=5.53 \mu \mathrm{g} / \mathrm{L}$ ). We tested the sensitivity of our method in a clinical setting and collected serum samples from 63 end stage renal disease (ESRD) patients, currently on hemodialysis. Patients were recruited from the in-hospital dialysis department of the University Hospital Maastricht. Signed informed consent was obtained from all patients. Venous blood samples were collected prior to dialysis, allowed to clot and centrifuged. Samples were stored at $-20^{\circ} \mathrm{C}$ and analyses were performed within one week.

cTnT concentrations were measured with a third-generation cTnT test (Roche, Elecsys 2010). The serum detection limit of this immunoassay, equal to the 99th percentile reference limit, is $<0.010$ 
$\mu \mathrm{g} / \mathrm{L}^{11}$ Between-day variation is $7.9 \%$ and $6.7 \%$ at concentrations of $0.134 \mu \mathrm{g} / \mathrm{L}$ and $2.85 \mu \mathrm{g} / \mathrm{L}$, respectively $(n=89)$.

\section{RESULTS}

\section{Method validation}

Various parameters were checked to determine the optimal conditions. Protein-A Sepharose was preferred over protein-G Sepharose, because the latter showed more background signal in the immunoblots. Temperatures $\left(37,56,65\right.$ and $\left.100^{\circ} \mathrm{C}\right)$ for the elution of $\mathrm{CTnT}$ from the beads showed optimal results at $56^{\circ} \mathrm{C}$. Finally, the difference between goat-anti-mouse and rabbit-anti-mouse secondary horseradish peroxidase labelled antibodies was investigated. The former resulted in slightly higher band intensities (data not shown).

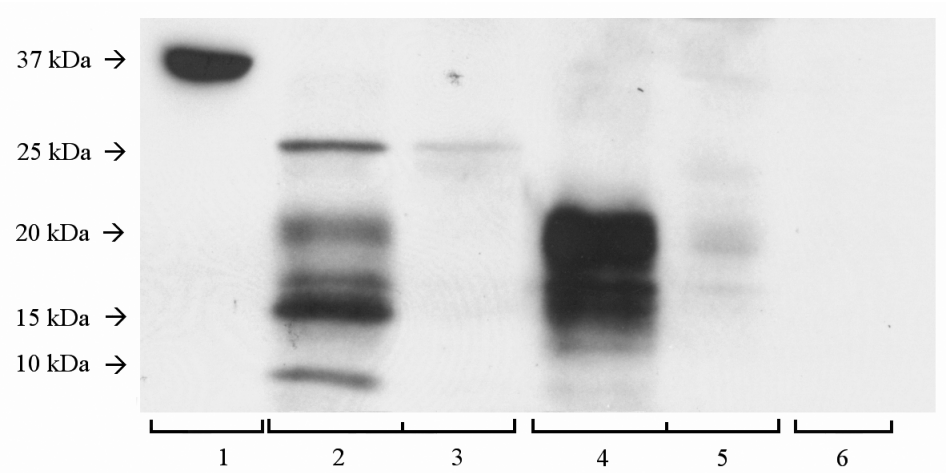

Figure 2-4. Immunoblot analysis of CTnT purified from serum from a patient with AMI visualized with monoclonal antiCTnT antibody 4C5. Lane 1: cTnT negative serum spiked with purified human cTnT. Lanes 2 and 3: serum sample 1 (cTnT: $33.44 \mu \mathrm{g} / \mathrm{L}$ ). Lanes 4 and 5: serum sample 2 (cTnT $5.53 \mu \mathrm{g} / \mathrm{L}$ ). Lane 6: negative control. Samples in lanes 1, 2, 4 and 6 are precipitated with our assay and samples in lanes 3 and 5 are precipitated with the Pierce Protein-A IgG Orientation Kit. Molecular weight standards are indicated on the left.

A positive control (purified CTnT standard in CTnT negative serum) was precipitated to check whether the protein of interest was modified or degraded along the process. This resulted in only one band at $\sim 37 \mathrm{kDa}$ and a small band at $\sim 25 \mathrm{kDa}$ (Figure 2-4 lane 1). A negative control serum was used to check for binding of proteins resulting in non-specific bands: no bands were visible. A comparison between the results of the two methods shows that the commercially available method from Pierce (lanes 3 and 5) results in a lower signal. Although (much) longer exposure times revealed comparable protein bands, indicating similar purifying properties, background noise was becoming too high (data not shown). 


\section{Dialysis patients}

Table 2-1 gives the characteristics of the 63 participants in this study. Patients were relatively old (70 years), most had hypertension ( $71 \%), 51 \%$ had a history of cardiovascular disease and the median time on dialysis was 26 months. Immunoblots were prepared and repeated if necessary. Due to differences in exposure times, band intensities are not comparable between immunoblots (Figure 2-5). All patients showed the presence of immunoreactive cTnT fragments, ranging in size from 8 to $25 \mathrm{kDa}$. The latter fragment was present in all patients, whereas the intact $37 \mathrm{kDa}$ protein could not be detected in any of the samples. Immunoreactive fragments were also detected in samples with cTnT concentrations below the $0.010 \mu \mathrm{g} / \mathrm{L}$ detection limit of the CTnT immunoassay.

\section{Discussion}

Cardiac troponins are low abundance proteins $(\mu \mathrm{g} / \mathrm{L})$ in the circulation. The reference concentration in a normal population has been found to be $0.0002 \pm 0.001 \mu \mathrm{g} / \mathrm{L}$, as measured with the second generation cTnT assay, ${ }^{12}$ although this is questionable looking at the specifications of the assay used. ${ }^{13}$ This poses a difficulty for analysing these proteins.

Using diimidoesters as a cross-linker between antibodies and protein-A Sepharose, we have developed a powerful and highly sensitive immunoprecipitation method for extracting and concentrating low abundance cTnT from human serum. Furthermore, there was minimal interference of high concentrations of total protein, albumin and human immunoglobulins when using this technique in combination with immunoblotting.

Table 2-1. Patient characteristics $(n=63)$. Data are represented as median values (IQR).

\begin{tabular}{|c|c|c|}
\hline Characteristic & Value & Reference value \\
\hline Age (years) & $70(58-76)$ & \\
\hline Gender (male / female) & $53 / 47$ & \\
\hline Smoking (\%) & 35 & \\
\hline Diabetic (\%) & 18 & \\
\hline Hypertension (\%) & 71 & \\
\hline History of cardiac disease (\%) & 51 & \\
\hline Time on dialysis (months) & $26(15-51)$ & \\
\hline Troponin $\mathrm{T}(\mu \mathrm{g} / \mathrm{L})^{+}$ & $0.051(0.027-0.097)$ & $<0.03$ \\
\hline CK-MB mass $(\mu \mathrm{g} / \mathrm{L})$ & $1.85(1.22-2.51)$ & $<4.9$ (men) $<2.9$ (women) \\
\hline Myoglobin $(\mu \mathrm{g} / \mathrm{L})$ & $157(118-204)$ & $28-72$ (men) $25-58$ (women) \\
\hline
\end{tabular}

${ }^{+}$Values below the $0.010 \mu \mathrm{g} / \mathrm{L}$ detection limit of the cTnT immunoassay were arbitrarily replaced by $0.005 \mu \mathrm{g} / \mathrm{L}$.

One important property of our method is that the amount of Sepharose beads can easily be adjusted to the amount of sample available. This has two advantages. First, to prevent contamination, it is best to allow each sample a fresh batch of Sepharose beads. This can easily be done with our method, whereas with the use of (large volume) columns this will be more expensive (in terms of the number of columns and antibodies needed). Also, this requires large sample volumes that are not always readily available. 
Secondly, because of the low volume elution $(50 \mu \mathrm{L})$, proteins remain present at relatively high concentrations. Therefore, this method is extremely suitable for extracting and concentrating low abundance $(\mu \mathrm{g} / \mathrm{L})$ proteins from small sample quantities without the risk of cross-contamination.

Elevated CTnT levels have been reported in many different diseases, including primary systemic amyloidosis, ${ }^{14}$ acute stroke, ${ }^{15}$ idiopathic dilated cardiomyopathy, ${ }^{16}$ congestive heart failure, ${ }^{17}$ myocarditis, ${ }^{18}$ pulmonary embolism, ${ }^{19}$ cardiac surgery, ${ }^{20}$ major vascular surgery, ${ }^{21}$ cardiotoxicity, ${ }^{22}$ sepsis, ${ }^{23}$ patients with chronic kidney disease, ${ }^{24}$ ESRD patients on dialysis, ${ }^{25}$ and many other. ${ }^{26,}{ }^{27}$

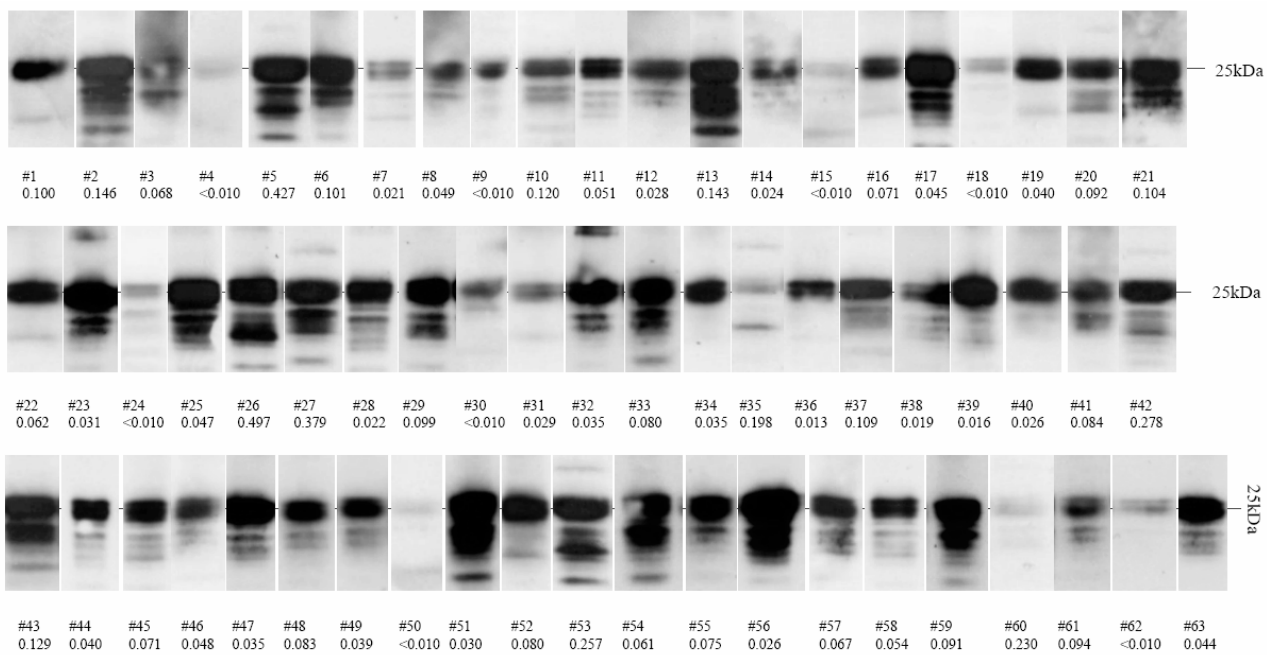

Figure 2-5. Immunoblots of 63 dialysis patients showing the ability of our assay to detect cTnT, even at concentrations below the $0.010 \mu \mathrm{g} / \mathrm{L}$ detection limit of the third generation CTnT assay (Roche). Indicated below the panels are the sample number and the CTnT concentration $(\mu \mathrm{g} / \mathrm{L})$. Immunoblotting was done with monoclonal antibody $4 \mathrm{C5}$ and all immunoblots were aligned at $25 \mathrm{kDa}$. Intensities are not comparable due to different exposure times.

The scientific discussion has focussed mainly on troponin elevations in ESRD patients, because minor CTnT elevation are often seen in this population. Clinicians have difficulties with interpreting these levels in the acute setting, because the concentrations are often around or above the $0.03 \mu \mathrm{g} / \mathrm{L} \mathrm{AMI}$ cut-off level. We showed that the CTnT concentration correlated well with the duration on dialysis. ${ }^{28}$ When we hypothesized that immunoreactive fragments may well be the cause of these minor increases, this was subject of discussion. ${ }^{29}$ The main issue that has been investigated is the prognostic value of cardiac troponins ( $\mathrm{I}$ and $\mathrm{T}$ ) in this population. It has been shown that elevated $\mathrm{CTnT}$ or $\mathrm{CTnI}$ levels have a higher morbidity and mortality rate, compared with ESRD patients without troponin elevations. ${ }^{25,30,31}$ In conclusion, using this highly sensitive method we were the first to detect cTnT fragments in serum samples from dialysis patients, even at concentrations below the $0.010 \mu \mathrm{g} / \mathrm{L}$ detection limit of the third generation CTnT assay. Possibly, these immunoreactive fragments remain in the circulation, despite being small enough to be cleared by the kidney. It is possible these fragments give a positive reaction in the commercially available cTnT immunoassay marketed by Roche. This method allows us to further investigate $\mathrm{CTnT}$ fragmentation and clearance in vivo. 


\section{REFERENCES}

[1] Colantonio DA, Dunkinson C, Bovenkamp DE, Van Eyk JE. Effective removal of albumin from serum. Proteomics 2005; 5: 3831-5.

[2] Steel LF, Trotter MG, Nakajima PB, Mattu TS, Gonye G, Block T. Efficient and specific removal of albumin from human serum samples. Mol Cell Proteomics 2003; 2: 262-70.

[3] Fu Q, Garnham CP, Elliott ST, Bovenkamp DE, Van Eyk JE. A robust, streamlined, and reproducible method for proteomic analysis of serum by delipidation, albumin and IgG depletion, and two-dimensional gel electrophoresis. Proteomics 2005; 5: 2656-64.

[4] Granger J, Siddiqui J, Copeland S, Remick D. Albumin depletion of human plasma also removes low abundance proteins including the cytokines. Proteomics 2005; 5: 4713-8.

[5] Hunter MJ, Ludwig ML. The reaction of imidoesters with proteins and related small molecules. J Am Chem Soc 1962; 84: 3491504.

[6] Levy DE, Eveleigh JW. Reversed immunosorbents: a simple method for specific antibody immobilization. J Immunol Methods 1978; 22: 131-42.

[7] Gersten DM, Marchalonis J]. A rapid, novel method for the solid-phase derivatization of IgG antibodies for immune-affinity chromatography. J Immunol Methods 1978; 24: 305-9.

[8] Schneider C, Newman RA, Sutherland DR, Asser $U$, Greaves MF. A one-step purification of membrane proteins using a high efficiency immunomatrix. J Biol Chem 1982; 257: 107669.

[9] Johnson G, Wu T. Kabat Database and its applications: future directions. Nucleic Acids Res 2001; 29: 205-6.

[10] Sisson TH, Castor CW. An improved method for immobilizing IgG antibodies on protein Aagarose. J Immunol Methods 1990; 127: 21520.

[11] Apple FS, Quist HE, Doyle PJ, Otto AP, Murakami MM. Plasma 99th Percentile Reference Limits for Cardiac Troponin and Creatine Kinase MB Mass for Use with European Society of Cardiology/American College of Cardiology Consensus Recommendations. Clin Chem 2003; 49: 1331-6.

[12] Missov ED, De Marco T. Clinical insights on the use of highly sensitive cardiac troponin assays. Clin Chim Acta 1999; 284: 175-85.

[13] Muller-Bardorff $M$, Hallermayer $K$, Schroder $A$, Ebert C, Borgya A, Gerhardt W, Remppis A, Zehelein J, Katus HA. Improved troponin T ELISA specific for cardiac troponin $\mathrm{T}$ isoform: assay development and analytical and clinical validation. Clin Chem 1997; 43: 458-66.

[14] Dispenzieri A, Kyle RA, Gertz MA, Therneau TM, Miller WL, Chandrasekaran K, McConnell JP, Burritt MF, Jaffe AS. Survival in patients with primary systemic amyloidosis and raised serum cardiac troponins. Lancet 2003; 361: 1787-9.
[15] James $P$, Ellis CJ, Whitlock RM, McNeil AR, Henley J, Anderson NE. Relation between troponin $\mathrm{T}$ concentration and mortality in patients presenting with an acute stroke: observational study. Bmj 2000; 320: 1502-4.

[16] Sato $Y$, Yamada T, Taniguchi R, Nagai $K$, Makiyama $T$, Okada $H$, Kataoka K, Ito $H$, Matsumori A, Sasayama S, Takatsu Y Persistently increased serum concentrations of cardiac troponin $t$ in patients with idiopathic dilated cardiomyopathy are predictive of adverse outcomes. Circulation 2001; 103: 36974.

[17] Bertinchant JP, Combes N, Polge A, FabbroPeray P, Raczka F, Beck L, Cade S, Ledermann $B$. Prognostic value of cardiac troponin $T$ in patients with both acute and chronic stable congestive heart failure: comparison with atrial natriuretic peptide, brain natriuretic peptide and plasma norepinephrine. Clin Chim Acta 2005; 352: 143-53.

[18] Lauer B, Niederau C, Kuhl U, Schannwell M, Pauschinger M, Strauer BE, Schultheiss HP. Cardiac troponin $T$ in patients with clinically suspected myocarditis. J Am Coll Cardiol 1997; 30: 1354-9.

[19] Giannitsis E, Muller-Bardorff M, Kurowski $V$ Weidtmann B, Wiegand U, Kampmann M, Katus HA. Independent prognostic value of cardiac troponin $\mathrm{T}$ in patients with confirmed pulmonary embolism. Circulation 2000; 102: 211-7.

[20] Kathiresan S, Servoss SJ, Newell JB, Trani D, MacGillivray $T E$, Lewandrowski $K$, LeeLewandrowski E, Januzzi JL, Jr. Cardiac troponin $\mathrm{T}$ elevation after coronary artery bypass grafting is associated with increased one-year mortality. Am J Cardiol 2004; 94: 879-81.

[21] Kertai MD, Boersma E, Klein J, Van Urk H, Bax $\mathrm{JJ}$, Poldermans D. Long-term prognostic value of asymptomatic cardiac troponin $\mathrm{T}$ elevations in patients after major vascular surgery. Eur J Vasc Endovasc Surg 2004; 28: 59-66.

[22] Niitsu N, Khori M, Hayama M, Kajiwara K, Higashihara M, Tamaru J. Phase I/II study of the rituximab-EPOCT regimen in combination with granulocyte colony-stimulating factor in patients with relapsed or refractory follicular lymphoma including evaluation of its cardiotoxicity using B-type natriuretic peptide and troponin T levels. Clin Cancer Res 2005; 11: 697-702.

[23] Spies C, Haude V, Fitzner R, Schroder K, Overbeck M, Runkel N, Schaffartzik W. Serum cardiac troponin $\mathrm{T}$ as a prognostic marker in early sepsis. Chest 1998; 113: 1055-63.

[24] Abbas NA, John RI, Webb MC, Kempson ME, Potter AN, Price CP, Vickery S, Lamb EJ. Cardiac Troponins and Renal Function in Nondialysis Patients with Chronic Kidney Disease. Clin Chem 2005; 51: 2059-66.

[25] Khan NA, Hemmelgarn BR, Tonelli M, Thompson $C R$, Levin $A$. Prognostic value of troponin $T$ and I among asymptomatic patients with end-stage renal disease: a meta-analysis. Circulation 2005; 112: 3088-96. 
[26] Panteghini M. The new definition of myocardial infarction and the impact of troponin determination on clinical practice. Int J Cardiol 2006; 106: 298-306.

[27] Roongsritong C, Warraich I, Bradley C. Common causes of troponin elevations in the absence of acute myocardial infarction: incidence and clinical significance. Chest 2004; 125: 1877-84.

[28] Diris JH, Hackeng CM, Kooman JP, Pinto YM, Hermens WT, Van Dieijen-Visser MP. Impaired Renal Clearance Explains Elevated Troponin T Fragments in Hemodialysis Patients. Circulation 2004; 109: 23-5.

[29] Giannitsis E, Katus HA. Troponin T release in hemodialysis patients. Circulation 2004; 110: e25-6; author reply e-6.
[30] Wood GN, Keevil B, Gupta J, Foley R, Bubtana A, McDowell G, Ackrill P. Serum troponin $T$ measurement in patients with chronic renal impairment predicts survival and vascular disease: a 2 year prospective study. Nephrol Dial Transplant 2003; 18: 1610-5.

[31] Havekes $B$, van Manen JG, Krediet RT, Boeschoten EW, Vandenbroucke JP, Dekker FW. Serum troponin $\mathrm{T}$ concentration as a predictor of mortality in hemodialysis and peritoneal dialysis patients. Am J Kidney Dis 2006; 47: 823-9. 



\title{
INVESTIGATION OF RELEASE AND DEGRADATION OF CARDIAC TROPONIN T IN PATIENTS WITH ACUTE MYOCARDIAL INFARCTION
}

\begin{abstract}
Background. Cardiac troponin T (cTnT) degradation after tissue release is still under debate. Because degradation of cTnT might have consequences on clearance of the molecule from the circulation, but also on the assay performance, the aim of this study was to investigate CTnT release and degradation in serum of AMI patients.
\end{abstract}

Methods. Serum samples were collected from 20 patients with AMI diagnosis undergoing rapid revascularization. Intact $\mathrm{CTnT}$ and fragments were detected using a combination of immunoprecipitation, SDS-PAGE and Western blotting.

Results. The intact cTnT protein was detected only during the first 12 hours after the cTnT concentration started to increase above the AMI cut-off value of $0.03 \mu \mathrm{g} / \mathrm{L}$. Thereafter only fragments with molecular weights ranging from 10 - $30 \mathrm{kDa}$ were detected, with two fragments being most prominent (15 and $25 \mathrm{kDa}$ ).

Conclusions. Intact cTnT rapidly disappears from the circulation during the early hours after AMI, but immunoreactive fragments remain present longer. The current cTnT immunoassay detects both intact cTnT and fragments.

Parts of this Chapter have been published:

Clinical Biochemistry 2007; 40:851-5. 


\section{INTRODUCTION}

Cardiac troponin I ( $\mathrm{CTnI}$ ) and $\mathrm{T}$ ( $\mathrm{cTnT}$ ) have been recommended as the biomarkers of choice for diagnosis and prognosis of acute myocardial infarction (AMI) because of their high sensitivity and specificity. ${ }^{1}$ Both proteins are markers of cardiomyocyte necrosis, which is accompanied by increased proteolytic activity. Especially $\mathrm{CTnI}$ has been shown to be highly susceptible to degradation after myocardial infarction..$^{2-5}$ It is likely that degradation of cardiac troponins after AMI can have consequences for both release into and clearance from the circulation. In addition, the immunoreactivity of the intact protein and its degradation products can be different. For cTnI, degradation has been shown to be a key factor in assay-to-assay variation, thereby complicating the standardization of different cTnI assays. ${ }^{5,6}$

Because of an international patent there is only one manufacturer providing commercially available CTnT assays, so that the results between different studies are easier to compare. However, degradation or modification of cTnT (just as CTnI) during and after AMI might influence CTnT immunoreactivity. Therefore, knowledge on the different circulating forms of CTnT is essential for further determination of assay characteristics and accuracy, but also to investigate the influence on release characteristics and clearance from the circulation of the molecule. In addition, this knowledge might shed light on the unexplained CTnT elevations seen in many diseases. ${ }^{7}$

Degradation has been described for both $\mathrm{CTnT}^{2,8}$ and $\mathrm{cTnI}^{2,3}$ in serum of patients with AMI. Also, in an earlier study, we demonstrated degradation of CTnT in serum from patients with end stage renal disease. ${ }^{9}$ In addition to their presence in serum, CTnT fragments have also been detected in human heart tissue homogenates. ${ }^{10,11}$ Contrasting these studies, Fahie-Wilson et al. recently stated that in patients with kidney failure cTnT circulates only in the intact form. ${ }^{12}$ To the best of our knowledge, there have been two reports describing both intact $\mathrm{CTnT}$ and fragments in serum of patients with AMI. The first study used serum samples from three patients and applied these to gel filtration chromatography. ${ }^{8}$ The second study detected one major ( $\left.26 \mathrm{kDa}\right)$ and two minor degradation products with a direct-serum-analysis Western blot technique in serum from one patient. ${ }^{2}$ The latter study clearly indicated a time related difference in the forms of cTnT present in serum.

A possible relation between release characteristics and $\mathrm{CTnT}$ degradation has not been investigated until now. Katus et al. were the first to describe the biphasic release kinetics of CTnT after AMI. ${ }^{13}$ The typical biphasic release kinetics can be seen when early coronary revascularization is achieved. When revascularization is not achieved, the initial rapid rise in CTnT is reduced and only the second peak around 3-4 days after onset of symptoms is found. The rationale behind it is thought to be the intracellular compartmentation of $\mathrm{CTnT} .{ }^{14,15}$ In human myocardium, approximately $6 \%$ of $\mathrm{CTnT}$ is found as an unbound cytosolic fraction that can be released rapidly after cell damage. The remaining CTnT, which is bound to the myofibrils, is released more slowly over a prolonged timespan. The electrophoretic and immunogenic properties of the bound and unbound CTnT forms were found to be similar. ${ }^{14}$

In the present study we investigated for the first time circulating CTnT molecules at different times after AMI, using a highly sensitive immunoprecipitation assay, SDS-PAGE and Western blotting. 


\section{Methods}

\section{Patients}

Serum samples sent to our laboratory for clinical analysis were collected from 20 patients with AMI diagnosis undergoing rapid revascularization. Samples were stored at $-20^{\circ} \mathrm{C}$ and used for immunoprecipitation and Western blotting within 6 months. All consecutive routine samples were collected during hospitalization. Informed consent for analysis of cTnT and its fragments in leftover serum after routine analysis of cardiac markers was obtained. The investigation conforms to the principles outlined in the Declaration of Helsinki. Six patients arrived at the Emergency Department (ED) with a cTnT concentration below the AMI cut-off value of $0.03 \mu \mathrm{g} / \mathrm{L}$. The time after onset of symptoms for these 6 patients was between 2-6 hours. We determined the time where the cTnT concentration was still below the AMI cut-off value as the starting point of the time concentration curve. All individual curves were curve-fitted (Figure 3-1A). In the 14 patients without a sample with a cTnT concentration below the AMI cut-off value the curve was extrapolated. The median time for each consecutive sample in the serum cTnT concentration curve was calculated relative to the starting point of the curve for each individual patient. Based on these release kinetics, the curve was divided into 6 different points (0-5).

A serum pool was prepared from blood of five healthy volunteers with the cTnT concentration below the assay detection limit. This serum pool was used as a negative control and precipitated as described to check for non-specific binding of the antibody. Two commercially available troponin $\mathrm{T}$ standards were spiked into the negative serum pool and used as positive controls in Western blotting: A highly purified (>98\%) human cTnT standard (Advanced ImmunoChemical Inc., Long Beach, USA) and the recently characterised and certified Standard Reference Material (SRM) 2921 for standardization of cardiac troponin I assays, ${ }^{16}$ composed of the human cardiac troponin complex (HyTest Ltd., Turku, Finland).

\section{Analytical methods}

cTnT was measured on an Elecsys 2010 analyzer (Roche Diagnostics, Mannheim, Germany) using the third-generation CTnT immunoassay (capture antibody M11.7 recognizing amino acid residues 136-147 and detection antibody M7 recognizing residues 125-131). ${ }^{10}, 11$ The AMI cut-off concentration is 0.03 $\mu \mathrm{g} / \mathrm{L}$ and the detection limit is $0.01 \mu \mathrm{g} / \mathrm{L} .{ }^{17}$ Between-day variation (expressed as $\mathrm{CV}$ ) is $7.9 \%$ and $6.7 \%$ at concentrations of $0.134 \mu \mathrm{g} / \mathrm{L}$ and $2.85 \mu \mathrm{g} / \mathrm{L}$, respectively $(n=89)$.

\section{Western Blotting}

Serum samples were thawed and CTnT was extracted and concentrated according to the method we described earlier. ${ }^{9}$ In brief, samples were prepared for SDS-PAGE by adding $20 \mu \mathrm{L}$ of sample buffer (40 $\mathrm{mmol} / \mathrm{L}$ Tris, $33 \mathrm{~g} / \mathrm{L}$ SDS, $500 \mathrm{~mL} / \mathrm{L}$ glycerol, and bromophenol blue) to $80 \mu \mathrm{L}$ of concentrated cTnT sample. We applied $20 \mu \mathrm{L}$ of this mixture to a $4-15 \%$ linear gradient Tris- $\mathrm{HCl}$ polyacrylamide precast gel (Biorad, Veenendaal, The Netherlands). The Precision Plus Protein Standard (Biorad) was used as the molecular weight marker. After stacking for 15 minutes at $100 \mathrm{~V}$ and running for 45 minutes at 150 $\mathrm{V}$, the gel was blotted onto a $0.45 \mu \mathrm{m}$ nitrocellulose membrane (Biorad) at $4^{\circ} \mathrm{C}$ at $100 \mathrm{~V}$ for 60 minutes. The membrane was blocked for 60 minutes in PBS containing $33 \mathrm{~g} / \mathrm{L}$ non-fat dry milk (Nutricia, Cuijk, The Netherlands). The primary monoclonal anti-cTnT antibody (4C5, BiosPacific, Emeryville, USA) was added at a 1:1000 dilution in wash buffer (PBS containing $0.2 \mathrm{~mL} / \mathrm{L}$ Tween-20 
and $6.7 \mathrm{~g} / \mathrm{L}$ non-fat dry milk) and incubated overnight at $4^{\circ} \mathrm{C}$. The membrane was washed three times 5 minutes in wash buffer and the secondary antibody (peroxidase-labelled goat-anti-mouse, DAKO, Glostrup, Denmark) was then added at a 1:5000 dilution in wash buffer and incubated for 60 minutes at $4{ }^{\circ} \mathrm{C}$. The membrane was washed four times 5 minutes in wash buffer and finally once in PBS for 10 minutes. The membrane was developed with Enhanced Chemiluminescence Buffer (Perkin-Elmer, Boston, USA) and captured on Kodak X-Omat Blue film.

\section{Statistical analysis}

Values are represented as medians (interquartile range, IQR), unless stated otherwise. Statistical analysis was done with SPSS 11 for Windows. The overall differences between the different points of the serum CTnT time concentration curve were tested with the non-parametric Kruskal-Wallis test. Because there was a significant difference $(p<0.01)$, the non-parametric Wilcoxon signed rank test was used for analysis of differences in the number of fragments and their mean molecular weight at the different points in the curve. Bonferroni correction was used to adjust for multiple testing. A p-value $<0.05$ was considered to indicate a statistically significant difference.

\section{RESULTS}

Release kinetics for CTnT showed a biphasic change in the serum time concentration curve of each individual patient. This was, however, not perfectly clear from the median concentration represented in the combined curve (Figure 3-1A). The median (IQR) CTnT peak concentration of these patients was 9.0 $\mu \mathrm{g} / \mathrm{L}(10 \mu \mathrm{g} / \mathrm{L})$. The median times after the starting point of the curve (point 0$)$ were $8(6), 12(7), 37$ (46), 94 (55) and 169 (116) hours for point 1, 2, 3, 4 and 5 on the curve, respectively. Figure 3-1B shows a Western blot example of one representative patient, clearly showing the time dependent changes. Intact cTnT migrated to approximately $37 \mathrm{kDa}$ on SDS-PAGE. Evidence for the presence of the troponin TIC complex ( $79 \mathrm{kDa}$ ) was not found in any of the patients, likely due to the effects of SDS.

Two researchers independently counted the number of CTnT fragments per sample and determined their mean molecular weight based on the molecular weight markers. These data are represented as individual measurements in Figure 3-2.

Intact cTnT was detected in 15 out of the 20 patients, but only within the first 12 hours after the cTnT concentration started to increase above the AMI cut-off value of $0.03 \mu \mathrm{g} / \mathrm{L}$. This was the part of the curve in which the cTnT concentration increased to the maximum value. In 3 of these 15 patients, the intact protein was the only molecule detected in serum at point 0 , without the presence of fragments. In the other patients fragments were also present at and from point 0 (Figure 3-2B). In blood samples after the cTnT peak concentration at 12 hours, no intact cTnT could be detected and only fragments were identified. 


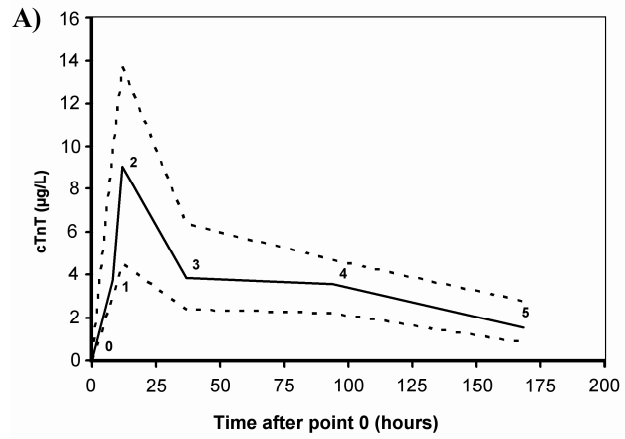

B)

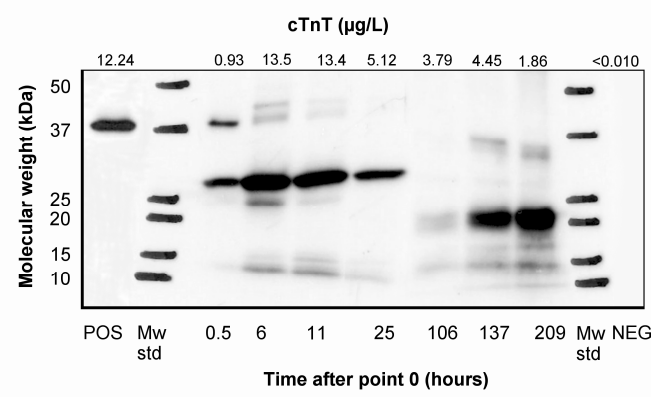

Figure 3-1. Serum cTnT concentration changes after acute myocardial infarction.

A) Combined CTnT time concentration curves of 20 AMI patients with early revascularization. The serum concentration changes are represented as median (line) and interquartile range (dotted lines). Based on these release kinetics, the curve was divided into 6 different points, indicated by the numbers 0-5. B) Representative Western blot analysis of serum from one patient with AMI. Lane 1, positive control with the intact CTnT migrating to approximately $37 \mathrm{kDa}$; lanes 2 and 10, molecular weight markers; lanes 3-9, serum samples at 0.5, 6, 11, 25, 106, 137 and 209 hours after onset of symptoms. Lane 11, serum with CTnT undetectable when measured by the third generation cTnT assay. Cardiac troponin T concentrations are given above the corresponding lanes.
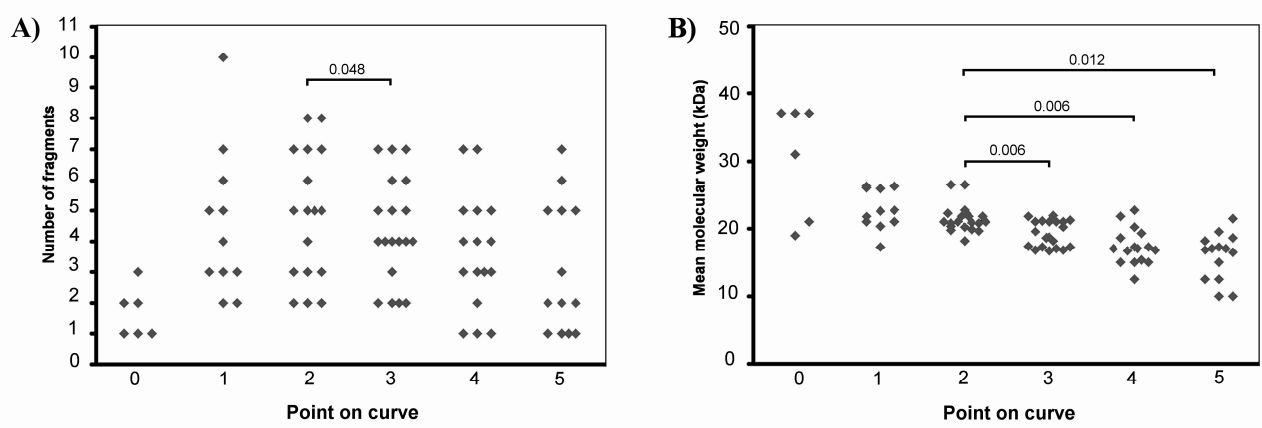

Figure 3-2. The number of cTnT fragments and their mean molecular weight after acute myocardial infarction.

A) The number of cTnT fragments per sample (also including the intact molecule) increased in the first 12 hours (point 0 2) and then decreased slowly with immunoreactive cTnT fragments still present in the circulation at point 5 . B) In 15 patients, intact CTnT was detected, but only within the first 12 hours (point 0-2). In 3 of these 15 patients, intact cTnT (37 kDa) was the only molecule that could be detected at point 0 . In 12 other patients the intact protein was accompanied by smaller fragments from point 0 . The intact protein rapidly disappeared from the circulation, but smaller fragments remained present for up to 169 hours. $\mathrm{N}=6,11,20,20,17$ and 14 at a median of $0,8,12,37,94$ and 169 hours after point 0 , respectively. The non-parametric Wilcoxon signed rank test with Bonferroni correction was used for calculating differences.

Figure 3-2A gives the number of fragments detected in each individual. Figure 3-2B shows the mean molecular weight of all detected fragments (including the intact molecule), which was highest directly after cTnT values started to increase above the AMI cut-off (point 0, $34.0 \mathrm{kDa}$ ). From the peak cTnT 
concentration at 12 hours, the mean molecular weight of all fragments decreased from $21.0 \mathrm{kDa}$ to $19.2 \mathrm{kDa}$ at a median of 37 hours $(p=0.006), 17.0 \mathrm{kDa}$ at a median of 94 hours $(p=0.006)$ and 16.9 $\mathrm{kDa}$ at a median of 169 hours $(\mathrm{p}=0.012)$ after the initial rise of cTnT at point 0 , respectively.

At the peak cTnT concentration the median number of circulating CTnT fragments had increased to 5 , with two fragments of 25 and $15 \mathrm{kDa}$ being most prominent (Figure 3-1B). The prolonged elevation of cTnT concentrations, as determined by the current commercial cTnT assay was still clearly evident at a median of 169 hours after the initial rise of cTnT above the AMI cut-off concentration. Importantly, at this time the intact protein had already disappeared from the circulation. Hence, the positive result in the cTnT assay can therefore only be explained from immunoreactivity of cTnT fragments, indicating that the current commercial assay detects both intact cTnT and its fragments.

\section{Discussion}

In the present study we investigated degradation of circulating cTnT in samples from patients with AMI at different times after cTnT values started to increase above the AMI cut-off. With a highly sensitive immunoprecipitation assay and Western blotting, we were able to detect intact cTnT and up to 10 different fragments in serum from patients diagnosed with AMI. Fragments, ranging in size from 10 $30 \mathrm{kDa}$, were detected in all studied patients. The intact cTnT protein, however, was detected only within the first 12 hours in which the cTnT concentration reached its maximum, but never in later samples. These data indicate that the current commercial cTnT assay measures both intact cTnT and its fragments. These data also suggest a very short half-life for the intact cTnT molecule. This is in accordance with the report by Katus et al. who described the half-life of cTnT in serum to be 120 minutes, and claimed that a persistent serum elevation of cTnT beyond the $5^{\text {th }}$ day after onset of symptoms could not be attributed to slow elimination from the circulation, but indicated ongoing cTnT release during infarct evolution, most likely being the fraction bound to the myofibrils. ${ }^{14}$

The presence of intact cTnT and its fragments in serum of AMI patients has been reported earlier by other groups. ${ }^{2,8}$ In the study by $\mathrm{Wu}$ et al., serum samples from three patients at or around the peak troponin values were used and subjected to gel filtration chromatography analysis. ${ }^{8}$ The different peaks were assigned to the troponin TIC complex, free cTnT and immunoreactive fragments. We were not able to detect the troponin TIC complex due to the effects of SDS. Around the peak cTnT values we also found the intact protein accompanied by several fragments. In a study by Labugger et al. on troponin I and $\mathrm{T}$ degradation, Western blot data with serum from one patient and probed for cTnT showed the intact protein, one major ( $26 \mathrm{kDa})$ fragment detected at 6:40 hours and two additional minor fragments ( $>26 \mathrm{kDa}$ ) at 17:25 hours after the first blood sample was drawn. ${ }^{2}$

Contrasting these studies, Fahie-Wilson et al. recently investigated the nature of circulating cTnT forms, using gel-filtration chromatography or size exclusion chromatography (SEC), combined with off-line measurement of cTnT. The main conclusion of their paper was that cTnT circulates predominantly in the free, intact form in serum of patients with kidney failure and in patients with acute coronary syndrome. ${ }^{12}$ Importantly, however, no secondary proof was provided by either SDS-PAGE or mass spectrometry. Further analysis of their data indicated that these conclusions could, however, be incorrect with part of the immunoreactive molecules present in patients with acute coronary syndrome and in patients on hemodialysis or peritoneal dialysis being immunoreactive cTnT fragments. ${ }^{18-20}$ 
In addition to the presence of $\mathrm{CTnT}$ fragments in serum of patients with $\mathrm{AMI}^{2,}{ }^{8}$ and patients on hemodialysis, ${ }^{9,}{ }^{21}$ fragments have also been detected in healthy human heart tissue homogenate, using the monoclonal antibodies from the third generation Roche cTnT immunoassay. This leads to another relevant question. Does degradation of cTnT (and cTnI) occur inside the cardiomyocyte, or is cTnT degraded after release of the intact protein into the circulation? Our study was not designed to provide this information. In our patients, both the intact protein and its fragments were present in serum early after the initial rise of cTnT, suggesting that fragments may have already been generated inside the cardiomyocyte, before loss of membrane integrity and reperfusion as suggested by Labugger et al., ${ }^{2}$ Van der Laarse also hypothesized that release of troponin and/or troponin fragments is not specific for necrotic myocardium, but may also occur from viable myocardium. ${ }^{22}$ Indeed, there is evidence suggesting degradation of CTnT within the cardiomyocyte by protease activity related to myocardial damage. ${ }^{23}$

Calcium dependent proteases, such as calpain I and II have been shown to be activated due to the intracellular $\mathrm{Ca}^{2+}$ overload that develops during ischemia and early reperfusion. ${ }^{24,} 25$ The specific degradation of CTnT by calpain I has been demonstrated in vitro and in situ in rats ${ }^{26}$ and in guinea pig. ${ }^{27}$ More recently, Bartha et al. showed that activation of calpain I resulted in one cTnT degradation product of $33 \mathrm{kDa}$ using human heart tissue. ${ }^{28}$ Intact cTnT migrated to $44 \mathrm{kDa}$ on SDS-PAGE. In our experimental settings, cTnT migrated to $37 \mathrm{kDa}$ on SDS-PAGE and the main fragment to $25 \mathrm{kDa}$. The intact cTnT to fragment ratio deduced from their data gives $44 / 33=1.33$ and calculations on our data give a ratio of $37 / 27=1.37$, suggesting similarity in detected molecules.

The apoptotic protease caspase- 3 has also been shown to be capable of degrading cTnT in vitro. Communal et al. showed that caspase-3 cleaves cTnT when it is in complex with cTnI and TnC, but not as free cTnT. ${ }^{29}$ Cleavage resulted in a $25 \mathrm{kDa}$ cTnT fragment on Western blot when using an anti-cTnT antibody recognizing the C-terminal part of the molecule. It is possible that after AMI proteases involved in apoptosis and or necrosis degrade structural proteins (including cTnT) before loss of membrane integrity, resulting in the release of fragments, in addition to the intact protein.

Based on the data presented here and the available literature, we believe that the rapid increase of cTnT concentrations in patients with early reperfusion mainly represents release of the intact protein from the cytosolic fraction as already hypothesized by Katus et al. ${ }^{14}$ We hypothesize this fraction is rapidly cleared from the circulation after AMI, which has also been suggested for cTnT clearance after strenuous exercise. ${ }^{30}$ Furthermore, it is likely that the prolonged elevations of cTnT seen after AMI can be ascribed to the formation of immunoreactive cTnT fragments and likely some release of the intact protein. It is possible that these immunoreactive fragments have a different (longer) half life, thereby giving rise to the typical biphasic release curve seen after AMI.

In conclusion, we have shown that the current commercial cTnT assay detects both intact cTnT and several of its fragments. Furthermore, we showed that intact CTnT rapidly disappears from the circulation during the early hours after AMI. 


\section{REFERENCES}

[1] Alpert JS, Thygesen K, Antman E, Bassand JP. Myocardial infarction redefined--a consensus document of The Joint European Society of Cardiology/American College of Cardiology Committee for the redefinition of myocardial infarction. J Am Coll Cardiol 2000; 36: 959-69.

[2] Labugger R, Organ L, Collier C, Atar D, Van Eyk JE. Extensive troponin I and $\mathrm{T}$ modification detected in serum from patients with acute myocardial infarction. Circulation 2000; 102: 1221-6.

[3] Morjana NA. Degradation of human cardiac troponin I after myocardial infarction. Biotechnol Appl Biochem 1998; 28: 105-11.

[4] Katrukha AG, Bereznikova AV, Filatov VL, Esakova TV, Kolosova OV, Pettersson K, Lovgren $T$, Bulargina TV, Trifonov IR, Gratsiansky NA, Pulkki K, Voipio-Pulkki LM, Gusev NB. Degradation of cardiac troponin I: implication for reliable immunodetection. Clin Chem 1998; 44: 2433-40.

[5] Shi Q, Ling $M$, Zhang X, Zhang M, Kadijevic L, Liu S, Laurino JP. Degradation of cardiac troponin I in serum complicates comparisons of cardiac troponin I assays. Clin Chem 1999; 45: 1018-25.

[6] Panteghini M, Pagani F, Yeo KT, Apple FS, Christenson RH, Dati F, Mair J, Ravkilde J, Wu AH. Evaluation of imprecision for cardiac troponin assays at low-range concentrations. Clin Chem 2004; 50: 327-32

[7] Panteghini M. The new definition of myocardial infarction and the impact of troponin determination on clinical practice. Int J Cardiol 2006; 106: 298-306.

[8] Wu AH, Feng YJ, Moore R, Apple FS, McPherson $\mathrm{PH}$, Buechler KF, Bodor G. Characterization of cardiac troponin subunit release into serum after acute myocardial infarction and comparison of assays for troponin $\mathrm{T}$ and $\mathrm{I}$. American Association for Clinical Chemistry Subcommittee on cTnI Standardization. Clin Chem 1998; 44: 1198-208.

[9] Michielsen EC, Diris JH, Hackeng CM, Wodzig WK, Van Dieijen-Visser MP. Highly sensitive immunoprecipitation method for extracting and concentrating low-abundance proteins from human serum. Clin Chem 2005; 51: 222-4.

[10] Ricchiuti V, Voss EM, Ney A, Odland M, Anderson PA, Apple FS. Cardiac troponin T isoforms expressed in renal diseased skeletal muscle will not cause false-positive results by the second generation cardiac troponin $\mathrm{T}$ assay by Boehringer Mannheim. Clin Chem 1998; 44: 1919-24.

[11] Davis GK, Labugger R, Van Eyk JE, Apple FS. Cardiac Troponin $\mathrm{T}$ is not detected in western blots of diseased renal tissue. Clin Chem 2001; 47: 782-3.

[12] Fahie-Wilson MN, Carmichael DJ, Delaney MP, Stevens PE, Hall EM, Lamb EJ. Cardiac Troponin $\mathrm{T}$ Circulates in the Free, Intact Form in Patients with Kidney Failure. Clin Chem 2006; 52: 41420.
[13] Katus HA, Remppis A, Looser S, Hallermeier $\mathrm{K}$, Scheffold T, Kubler W. Enzyme linked immuno assay of cardiac troponin $T$ for the detection of acute myocardial infarction in patients. J Mol Cell Cardiol 1989; 21: 1349-53.

[14] Katus HA, Remppis A, Scheffold T, Diederich $\mathrm{KW}$, Kuebler W. Intracellular compartmentation of cardiac troponin $T$ and its release kinetics in patients with reperfused and nonreperfused myocardial infarction. Am J Cardiol 1991; 67: 1360-7.

[15] Remppis A, Scheffold $T$, Greten J, Haass $M$ Greten $T$, Kubler $W$, Katus HA. Intracellular compartmentation of troponin $\mathrm{T}$ : release kinetics after global ischemia and calcium paradox in the isolated perfused rat heart. $\mathrm{J}$ Mol Cell Cardiol 1995; 27: 793-803.

[16] Bunk DM, Welch MJ. Characterization of a new certified reference material for human cardiac troponin I. Clin Chem 2006; 52: 212-9.

[17] Apple FS, Murakami MM. Serum 99th percentile reference cutoffs for seven cardiac troponin assays. Clin Chem 2004; 50: 1477-9.

[18] Fahie-Wilson MN, Hall EM, Lamb EJ. The authors of the article cited above respond. Clin Chem 2006; 52: 2307-9.

[19] Michielsen EC, Diris JH, Kleijnen VWVC, Wodzig KW, van Dieijen-Visser MP. Size-exclusion chromatography of circulating cardiac troponin T. Clin Chem 2006; 52: 2306-7; author reply 79.

[20] Michielsen EC, Diris JH, Kleijnen VWVC, Wodzig $\mathrm{KW}$, Van Dieijen-Visser MP. Interpretation of cardiac troponin $\mathrm{T}$ behaviour in size-exclusion chromatography. Clin Chem Lab Med 2006; 44: 1422-7.

[21] Diris JH, Hackeng CM, Kooman JP, Pinto YM, Hermens WT, Van Dieijen-Visser MP. Impaired Renal Clearance Explains Elevated Troponin T Fragments in Hemodialysis Patients. Circulation 2004; 109: 23-5.

[22] Van der Laarse A. Hypothesis: troponin degradation is one of the factors responsible for deterioration of left ventricular function in heart failure. Cardiovasc Res 2002; 56: 8.

[23] Lancel S, Joulin O, Favory R, Goossens JF, Kluza J, Chopin C, Formstecher P, Marchetti P, Neviere R. Ventricular myocyte caspases are directly responsible for endotoxin-induced cardiac dysfunction. Circulation 2005; 111: 2596-604.

[24] Tolnai S, Korecky B. Calcium-dependent proteolysis and its inhibition in the ischemic rat myocardium. Can J Cardiol 1986; 2: 42-7.

[25] Atsma DE, Bastiaanse EM, Jerzewski A, Van der Valk LJ, Van der Laarse A. Role of calciumactivated neutral protease (calpain) in cell death in cultured neonatal rat cardiomyocytes during metabolic inhibition. Circ Res 1995; 76: 1071-8. 
[26] Di Lisa F, De Tullio R, Salamino F, Barbato R, Melloni E, Siliprandi N, Schiaffino S, Pontremoli S. Specific degradation of troponin $\mathrm{T}$ and $\mathrm{I}$ by mu-calpain and its modulation by substrate phosphorylation. Biochem J 1995; 308 (Pt 1): 57-61.

[27] Gorza L, Menabo R, Vitadello M, Bergamini CM, Di Lisa F. Cardiomyocyte Troponin T Immunoreactivity Is Modified by Cross-linking Resulting From Intracellular Calcium Overload. Circulation 1996; 93: 1896-904.

[28] Barta J, Toth A, Edes I, Vaszily M, Papp JG, Varro A, Papp Z. Calpain-1-sensitive myofibrillar proteins of the human myocardium. Mol Cell Biochem 2005; 278: 1-8.
[29] Communal C, Sumandea M, de Tombe P, Narula J, Solaro RJ, Hajjar RJ. Functional consequences of caspase activation in cardiac myocytes. Proc Natl Acad Sci U S A 2002; 99: 6252-6.

[30] Neumayr G, Pfister R, Mitterbauer G, Eibl G, Hoertnagl $H$. Effect of competitive marathon cycling on plasma $\mathrm{N}$-terminal pro-brain natriuretic peptide and cardiac troponin $\mathrm{T}$ in healthy recreational cyclists. Am J Cardiol 2005; 96: 732-5. 



\title{
INTERPRETATION OF CARDIAC TROPONIN T BEHAVIOUR IN SIZE- EXCLUSION CHROMATOGRAPHY
}

\begin{abstract}
Background. Knowledge about the presence of intact cardiac troponin $T$ (cTnT) and/or its immunoreactive fragments is of great value for the interpretation of CTnT clearance from the circulation. Until now there has been a lot of controversy on CTnT fragmentation. To provide an answer to the present controversy, we investigated fragmentation of CTnT with size-exclusion chromatography (SEC), and confirmed our data with mass spectrometry.

Methods. A highly purified human CTnT standard, characterized with mass spectrometry as one single peak of $34377 \mathrm{Da}$, and with SDS-PAGE as one single immunoreactive band (37 kDa), was incubated in serum for 0,24 and 48 hours at $37^{\circ} \mathrm{C}$ and analyzed using SEC. A troponin TIC complex standard, used in an earlier study, was also investigated.
\end{abstract}

Results. We demonstrated that, because of its rod like shape, the molecular weight of CTnT cannot be estimated from SEC using the molecular weight of globular proteins as a reference. The Stokes radius of intact CTnT was calculated to be $33.7 \AA$. Incubation of both cardiac troponin standards in troponin free serum resulted in a time dependent decrease of intact cTnT and in a simultaneous increase of smaller immunoreactive fragments $(13.4 \AA$ and $22.4 \AA)$.

Conclusion. CTnT has a Stokes radius of $33.7 \AA$. Compared with globular calibrator proteins, intact CTnT elutes earlier than can be expected based solely on its molecular weight. For non-globular or uncharacterized proteins, stokes radii should be used for correct interpretation of SEC data. By doing so, we were able to clearly demonstrate CTnT fragments.

Parts of this Chapter have been published:

Clinical Chemistry 2006;52:2306-7.

Clinical Chemistry and Laboratory Medicine 2006;44:1422-7. 


\section{INTRODUCTION}

Several studies have discussed the presence of circulating cardiac troponin $T$ (cTnT) fragments in patients with acute myocardial infarction (AMI). The latest contribution to the discussion has been by Fahie-Wilson et al., ${ }^{1}$ who investigated the nature of ${ }^{C T n T}$ reactive molecules in serum samples of dialysis patients and in patients with acute coronary syndrome using gel-filtration chromatography or size-exclusion chromatography (SEC). In this study it was claimed that the circulating CTnT in patients with kidney failure and elevated serum cTnT concentrations was due to the presence of the free, intact molecular form of $\mathrm{CTnT}^{1}$. They also showed that the $\mathrm{cTnT}$ elution profiles of patients that experienced an acute coronary event were identical to the patients with kidney failure which contrasts to the study by Wu et al., who reported the presence of immunoreactive CTnT fragments in serum after AMI using the same technique. ${ }^{2}$

Troponin $\mathrm{T}$ fragments have already been described in the early days of troponin investigation. ${ }^{3,4}$ Although these experiments focused mainly on bovine cardiac troponins, it is reasonable to assume that similar results will be obtained for human troponins. Comparison of the amino acid sequences of human and bovine cardiac troponins in the online SWISS-PROT database indicated $85 \%, 89 \%$ and $99 \%$ homology between bovine and human cardiac troponin T, I and C, respectively. ${ }^{5}$ Similar homology has been described for human and bovine CTnT by others. ${ }^{6}$ More recently, Labugger et al. also demonstrated $\mathrm{CTnT}$ fragments in serum after AMI with the use of a western blot- direct serum analysis protocol. Importantly, they showed a time related change in the composition of the fragments. ${ }^{7}$ Later, Diris et al. ${ }^{8}$ and Michielsen et al. ${ }^{9}$ showed the presence of cTnT fragments in serum of hemodialysis patients.

When investigating proteins with SEC, it is important to realize that CTnT is far from globular. Numerous studies have already addressed the important influence of the hydrodynamic volume / molecular shape of proteins on the chromatographic behaviour in a SEC column. ${ }^{10-15}$ Ideally, the distribution of a molecule into the pores of a SEC column is only a matter of steric interaction or hydrodynamic volume.

The hydrodynamic volume of a protein can be expressed as the Stokes radius $\left(R_{s}\right)$ and is a generally accepted method for data interpretation in SEC. ${ }^{12} \mathrm{~A}$ non-globular protein is known to have a (much) larger $R_{s}$ compared to a globular protein with an equal molecular weight. Several mathematical models have been proposed for the description of the behaviour of non-globular proteins in SEC. ${ }^{11,13}$ Although none of these models are completely correct, there is general agreement that separation of nonglobular proteins in a SEC column is better described using the Stokes radii of the proteins than using their molecular weights. ${ }^{10}$ In contrast, when using sodium dodecyl sulfate polyacrylamide gel electrophoresis (SDS-PAGE) for molecular weight determination, it is possible to directly compare molecular weights with known molecular weight standards. With this technique there is a linear relation between the length of the molecule and the amount of SDS bound to it, and chromatographic behaviour is primarily determined by the negative electrical charge from SDS.

Evidently, when using SEC, the molecular weight of a CTnT molecule, which has a rod like shape, ${ }^{16,17}$ as well as the molecular weight of the troponin TIC complex, cannot be determined directly from a molecular weight calibration curve using globular calibration proteins. The intact cTnT molecule is most likely to elute from the SEC column much earlier than could be expected based on its relatively large Stokes radius. To test this theory for human CTnT, we performed SEC experiments using a Superdex 75 
SEC column, SDS-PAGE and immunoblotting, and mass spectrometry (MS). Further characterization of serum cTnT and/or its fragments was performed using these three techniques.

\section{Methods}

To be able to compare our data with previous findings, we not only used a highly purified ( $>98 \%$ pure) human cTnT standard (Advanced Immunochemical Inc, Long Beach, USA), but also purchased the less well characterized troponin TIC complex standard (SCIPAC, Sittingbourne, England) used by FahieWilson et al. ${ }^{1} \mathrm{MS}$ was used to confirm the molecular weight of all troponin standards. For this purpose, a PBS-IIc time-of-flight mass spectrometer (Ciphergen Biosystems Inc, Freemont, USA) was calibrated in the molecular range of 12-147 kDa. Troponin standards were applied directly to a Matrix Assisted Laser Desorption/Ionization (MALDI) surface $(2 \mu \mathrm{L})$. A saturated sinapinic acid (Ciphergen) solution in $50 \%$ acetonitrile, $0.5 \%$ trifluoracetic acid was used as the energy absorbing matrix (two $1 \mu \mathrm{L}$ additions).

In addition, SDS-PAGE and immunoblotting were performed with monoclonal anti-cTnT antibody $9 \mathrm{G6}$ (HyTest, Turku, Finland), recognizing amino acid residues 1-60. Troponin standards were directly diluted to the appropriate concentrations in Laemmli sample buffer (Biorad, Veenendaal, The Netherlands) before application to the electrophoresis gel. We applied $20 \mu \mathrm{L}$ of this mixture to a $4-15 \%$ linear gradient Tris- $\mathrm{HCl}$ polyacrylamide precast gel (Biorad). The Precision Plus Protein Standard (Biorad) was used as the molecular mass marker. After stacking for 15 minutes at $100 \mathrm{~V}$ and running for 45 minutes at $150 \mathrm{~V}$, the gel was blotted onto a $0.45 \mu \mathrm{m}$ nitrocellulose membrane (Biorad) at $4^{\circ} \mathrm{C}$ at $100 \mathrm{~V}$ for 60 minutes. The membrane was blocked for 60 minutes in PBS containing $33 \mathrm{~g} / \mathrm{L}$ nonfat dry milk (Nutricia, Cuijk, The Netherlands). The primary monoclonal anti-cTnT antibody (9G6) was added at a 1:1000 dilution in wash buffer (PBS containing $0.2 \mathrm{~mL} / \mathrm{L}$ Tween-20 and $6.7 \mathrm{~g} / \mathrm{L}$ nonfat dry milk) and incubated overnight at $4^{\circ} \mathrm{C}$. The membrane was washed three times 5 minutes in wash buffer and the secondary antibody (peroxidase-labeled goat-anti-mouse, DAKO, Glostrup, Denmark) was then added at a 1:5000 dilution in wash buffer and incubated for 60 minutes at $4^{\circ} \mathrm{C}$. The membrane was washed four times 5 minutes in wash buffer and finally once in PBS for 10 minutes. The membrane was developed with Enhanced Chemiluminiscence Buffer (Perkin-Elmer, Boston, USA) and captured on Kodak X-Omat Blue film.

SEC experiments were performed on a Hewlet-Packard 1100 system (Agilent Technologies) equipped with a Superdex 75 10/300 GL SEC column (Pharmacia Biotech) and a diode array detector (210-900 $\mathrm{nm})$. Ammonium bicarbonate $(0.1 \mathrm{~mol} / \mathrm{L})$ was used as running buffer at a flow of $0.25 \mathrm{~mL} / \mathrm{min}$ to facilitate easy transfer to the mass spectrometer. All samples were loaded onto the column with a 200 $\mu \mathrm{l}$ injection loop. Equation 4-1 was used to translate elution volumes into dimensionless theoretical fractional volumes:

$$
K_{a v}=\frac{V_{e}-V_{0}}{V_{t}-V_{0}}
$$


where $\mathrm{K}_{\mathrm{av}}$ is the theoretical fractional volume of the column to which the sample of interest has access, $V_{e}$ is the elution volume, $V_{0}$ is the void volume of the column $(7.55 \mathrm{~mL})$ and $V_{t}$ is the total volume of the column $(25 \mathrm{~mL})$.

The low molecular weight calibration standard (Pharmacia Biotech, cat. no. 17-0442-01) was composed of a mixture of four globular proteins: bovine serum albumin ( $67 \mathrm{kDa}, 35.5 \AA)$, ovalbumin (43 kDa, $30.5 \AA)$, chymotrypsinogen $\mathrm{A}(25 \mathrm{kDa}, 20.9 \AA)$ and ribonuclease $\mathrm{A}(14 \mathrm{kDa}, 16.4 \AA){ }^{18}$. Dextran Blue $\left(2000 \mathrm{kDa}\right.$ ) was used to determine $\mathrm{V}_{0}$ of the column. Between 20 and 100 minutes, fractions of $0.5 \mathrm{~mL}$ were collected every two minutes. cTnT concentrations were measured on an Elecsys 2010 analyzer (Roche Diagnostics) with the third generation CTnT assay, with a serum detection limit of $<0.010 \mu \mathrm{g} / \mathrm{L}$. Between-day variation is $7.9 \%$ and $6.7 \%$ at concentrations of $0.134 \mu \mathrm{g} / \mathrm{L}$ and $2.85 \mu \mathrm{g} / \mathrm{L}$, respectively $(n=89)$. Cardiac troponin I (cTnI) was measured with the Access AccuTnI assay (Beckman Coulter, Inc, Fullerton, USA). Between-day variation is $3.0 \%$ and $4.1 \%$ at concentrations of $0.56 \mu \mathrm{g} / \mathrm{L}$ and 7.31 $\mu \mathrm{g} / \mathrm{L}$, respectively $(\mathrm{n}=120)$.

Pooled serum, obtained from healthy volunteers and negative for both CTnT and cTnI, was spiked with the purified cTnT standard and incubated for 0,24 and 48 hours at $37^{\circ} \mathrm{C}$. The negative control was also incubated for 48 hours. All samples were separated on the SEC column to investigate possible degradation due to protease activity. Identical experiments were done using the troponin TIC complex standard, although incubation times were slightly different (0, 24 and 96 hours).

\section{RESULTS}

\section{Elution profile of globular calibration standards}

Figure 4-1 panel A shows the elution profile of the four globular calibration proteins. The volume at peak maximum was used for calculation of $\mathrm{K}_{\mathrm{av}}$ and construction of the calibration curve. When $\mathrm{K}_{\mathrm{av}}$ was plotted against $\ln \left(R_{s}\right)$, the calibration curve for these experimental settings was obtained (Figure 4-1 panel $B$ ). With the calibration curve, $K_{a v}=-0.278 \ln \left(R_{s}\right)+1.077$ (equation 4-2), it is possible to calculate Stokes radii of uncharacterized proteins. For this Superdex 75 column, the $R_{s}$ separation window ( $K_{a v}$ between 0 and 1) lies between $1.3 \AA$ and $48 \AA$. Any protein with a $R_{s}$ larger than $48 \AA$ will elute at $V_{0}$ $(7.55 \mathrm{~mL})$ and any protein smaller than $1.3 \AA$ at $\mathrm{V}_{\mathrm{t}}(25 \mathrm{~mL})$.

\section{Properties of the cardiac troponin standards}

Figure 4-2 panels $A$ and $B$ show the mass spectra of the two cardiac troponin standards. The purified CTnT standard showed one peak at $\mathrm{m} / \mathrm{z}$ value 34378 , corresponding to the molecular weight of the single protonated intact protein $\left([\mathrm{M}+\mathrm{H}]^{+}\right)$. Also visible was a smaller peak at approximately half the $\mathrm{m} / \mathrm{z}$ value (17307), representing the double protonated $\mathrm{cTnT}$ molecule $[\mathrm{M}+2 \mathrm{H}]^{2+}$. In addition, there was also a peak at $\mathrm{m} / \mathrm{z}$ value 68545 , corresponding to $[2 \mathrm{M}+\mathrm{H}]^{+}$. In contrast, the major component of the troponin TIC complex standard was albumin $\left(\mathrm{m} / \mathrm{z}\right.$ value $\left.66318,[\mathrm{M}+\mathrm{H}]^{+}\right)$. Again, the smaller peak at $\mathrm{m} / \mathrm{z}$ value 33238 represented the double protonated albumin molecule $[\mathrm{M}+2 \mathrm{H}]^{2+}$. This mass spectrum neither showed peaks at the expected $\mathrm{m} / \mathrm{z}$ values of the individual troponin $\mathrm{T}$, I or $\mathrm{C}$ subunits, nor the TIC complex. It is questionable whether CTnT can be detected at all, due to the relatively high concentration of albumin ( $5.6 \mathrm{~g} / \mathrm{L})$, which is known to cause ion suppression. 

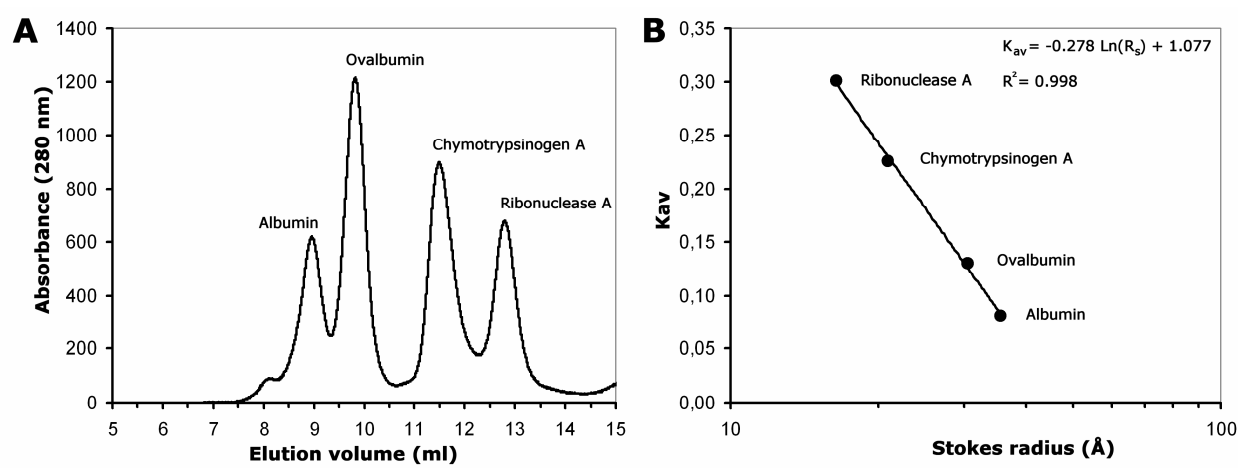

Figure 4-1. Calibration of the Superdex 75 column. (A) Elution profile of four globular proteins. The theoretical fractional volume $\left(\mathrm{K}_{\mathrm{av}}\right)$ was calculated from equation $4-1$. The void volume $\left(\mathrm{V}_{0}\right)$ was determined by elution of Dextran Blue. The total column volume $\left(\mathrm{V}_{\mathrm{t}}\right)$ was obtained from the specifications provided by the manufacturer $\left(\mathrm{V}_{\mathrm{t}}=25 \mathrm{~mL}\right)$. (B) Calibration equation (equation 4-2) used for calculation of the $R_{s}$ of uncharacterized proteins.
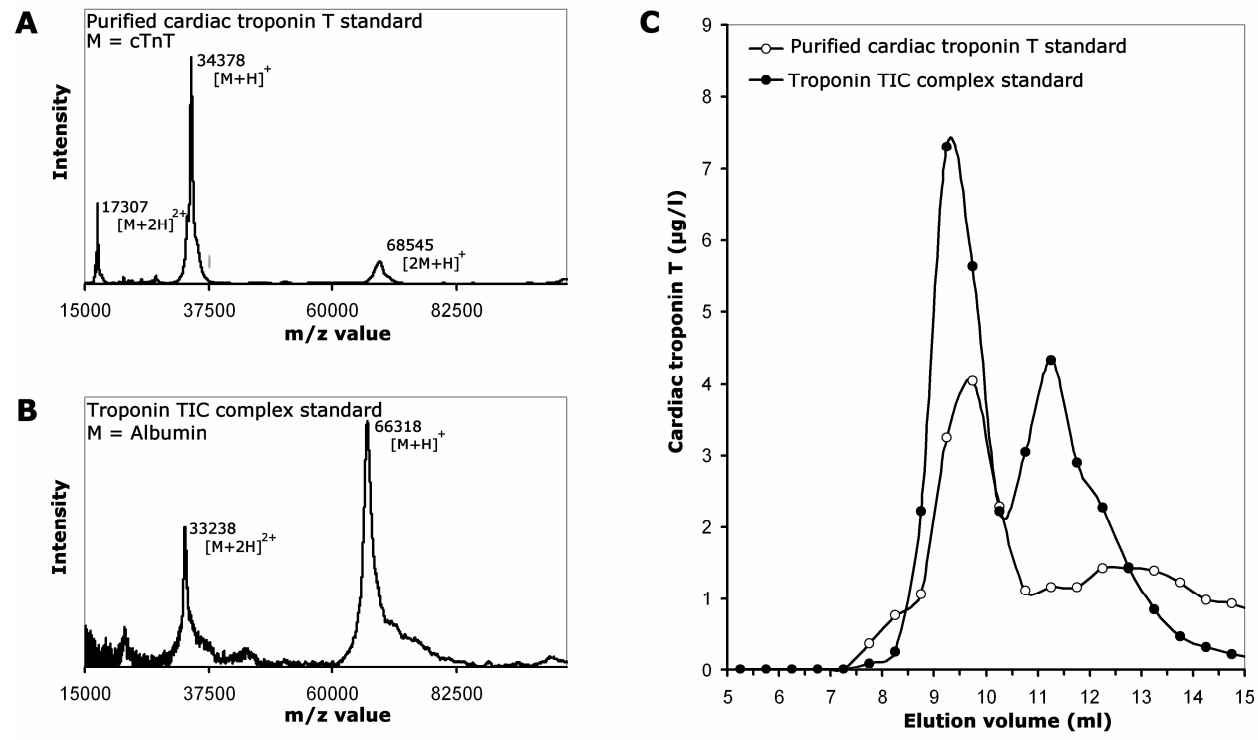

Figure 4-2. Characterization of two cardiac troponin standards. (A) Mass spectrum of a purified cTnT standard showing intact protonated $\mathrm{cTnT}$ at $\mathrm{m} / \mathrm{z}$ value $34378\left([\mathrm{M}+\mathrm{H}]^{+}\right)$. (B) Mass spectrum of a troponin TIC complex standard showing albumin at $\mathrm{m} / \mathrm{z}$ value $66318\left([\mathrm{M}+\mathrm{H}]^{+}\right)$as the major component. (C) Elution profile of both cardiac troponin standards spiked into serum and applied directly to SEC. CTnT was measured with the third generation Roche cTnT immunoassay.

Figure 4-2 panel $C$ shows both standards spiked into serum and applied directly to SEC. The SCIPAC TIC complex standard showed two CTnT reactive peaks, whereas the purified standard showed one peak superimposed on a column artefact (baseline elevation). 


\section{CHAPTER 4}

SDS-PAGE confirmed the presence of the intact protein at $37 \mathrm{kDa}$ in the purified cTnT standard. Although partly obscured by the large amount of albumin, the troponin TIC complex standard also showed the intact protein. However, a cTnT fragment at $\sim 27 \mathrm{kDa}$ was most prominent (Figure 4-3). Albumin removal (ProteoExtract Albumin Removal Kit, Calbiochem) did not yield better results (data not shown).

Table 4-1. Summary of chromatographic data.

\begin{tabular}{|c|c|c|c|c|c|c|}
\hline & $\begin{array}{l}\text { Molecular } \\
(\mathrm{kDa})\end{array}$ & weight & $\begin{array}{l}V_{e} \\
(\mathrm{ml})\end{array}$ & $\mathbf{K}_{\mathrm{av}}$ & $\begin{array}{l}\text { Stokes } \\
(\AA)\end{array}$ & radius \\
\hline \multicolumn{7}{|l|}{ A. Calibration proteins } \\
\hline Ribonuclease A & 13.7 & & 12.79 & 0.301 & 16.4 & \\
\hline Chymotrypsinogen A & 25.0 & & 11.49 & 0.226 & 20.9 & \\
\hline Ovalbumin & 43.0 & & 9.82 & 0.130 & 30.5 & \\
\hline Bovine serum albumin & 67.0 & & 8.96 & 0.081 & 35.5 & \\
\hline \multicolumn{7}{|l|}{ B. cTnT reactive peaks } \\
\hline Peak 1 & $34^{*}$ & & 9.25 & 0.097 & $33.7^{+}$ & \\
\hline Peak 2 & & & 11.25 & 0.212 & $22.4^{+}$ & \\
\hline Peak 3 & & & 13.75 & 0.355 & $13.4^{+}$ & \\
\hline
\end{tabular}

* Molecular weight as confirmed a priori by mass spectrometry; ${ }^{+}$Stokes radius calculated from equation 4-2.

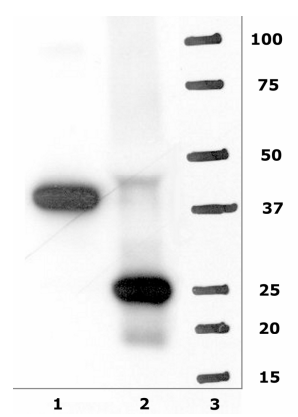

Figure 4-3. Immunoblot of two cardiac troponin standards applied directly to SDS-PAGE. Lane 1, purified cTnT standard. Lane 2, SCIPAC troponin TIC complex standard. Lane 3, Molecular weight marker (kDa). Detection was done with monoclonal anti-cTnT antibody $9 \mathrm{G} 6$ (epitope 1-60, HyTest). The intact protein is partly masked by the large amount of albumin present in the troponin TIC complex standard.

\section{In-vitro incubation of troponin standards in serum}

Figure 4-4 panels $A$ and $4 B$ show the elution profiles of the purified CTnT standard and the troponin TIC complex standard, respectively. Both cardiac troponin standards were spiked into the pooled troponin negative serum and incubated for 0,24 and 48 or 96 hours at $37^{\circ} \mathrm{C}$. The $x$-axis (elution volume) and yaxis (cTnT concentration) have been kept similar for both samples for easier visual comparison. Two major peaks are visible. In time, the amount of troponin T eluting in Peak $1\left(K_{a v}=0.097, R_{s}=33.7 \AA\right)$ decreased, whereas the amount eluting in Peak $2\left(K_{a v}=0.212, R_{s}=22.4 \AA\right)$ increased. Note that Peak 2 , 
because of its later appearance, represents a molecule that is smaller than the first peak with a molecular weight of $34377 \mathrm{Da}$, as confirmed by MS. After 96 hours of incubation, the troponin TIC complex standard showed a third peak (Peak 3, $\mathrm{K}_{\mathrm{av}}=0.355, \mathrm{R}_{\mathrm{s}}=13.4 \AA$ ), indicating an even smaller immunoreactive cTnT molecule. A summary of these chromatographic data is given in Table 4-1.

\section{Discussion}

When using SEC for molecular weight determination of uncharacterized proteins, it is important to realize the molecular mechanism behind the technique. Although the ideal situation can be described quite precisely, laboratory practice has proven to be different. When trying to label a peak with a certain molecular weight, thorough knowledge about the sample, as well as calibrators and standards are of utmost importance.
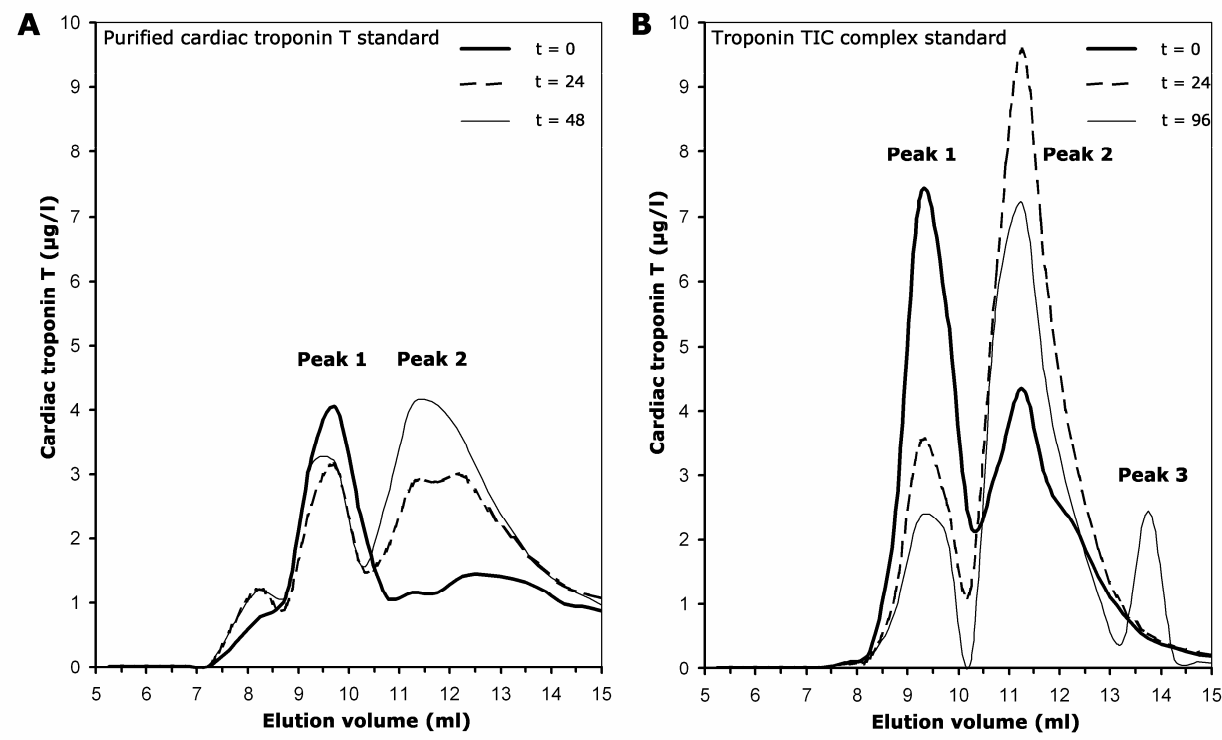

Figure 4-4. Incubation of cardiac troponin standards in serum. (A) Elution profile of the purified CTnT standard incubated in serum for 0,24 and 48 hours. (B) Elution profile of the troponin TIC complex standard incubated in serum for 0, 24 and 96 hours. Both cardiac troponin standards showed a decrease in CTnT concentration for Peak 1 and an increase for Peak 2. The troponin TIC complex standard incubated for 96 hours even showed a third immunoreactive cTnT peak. cTnT was measured with the third generation Roche CTnT immunoassay.

Behavior of proteins in SEC is determined mainly by their hydrodynamic volume (expressed as Stokes radius, $R_{s}$ ). Nonglobular proteins are known to have a larger $R_{s}$ than globular proteins with a comparable molecular weight, and CTnT is far from globular. ${ }^{17}$ Therefore, as is generally agreed, the separation of the nonglobular cTnT protein in an SEC column is better described with the $R_{s}$ than the molecular weight. ${ }^{10}$ The latest contribution to the discussion on CTnT fragmentation was by FahieWilson et al. ${ }^{1}$ The interpretation of these data appeared to be incorrect, as outlined below. 
From the data by Fahie-Wilson et al. ${ }^{1}$ we calculated the $R_{s}$ of the immunoreactive peaks. To do so, we deduced the $K_{a v}$ of the calibrator proteins from Figure 1 (ribonuclease $A, 0.393$; chymotrypsinogen $A$, 0.310 ; ovalbumin, 0.165$)$ and constructed a new calibration curve $\left(K_{a v} v s \ln R_{s}\right)$. To construct this curve we used the Stokes radii of these proteins: $16.4 \AA, 20.9 \AA$, and $30.5 \AA$, respectively. ${ }^{18}$ This calibration curve is represented by equation 4-3:

$K_{a v}=-0.369 \operatorname{Ln}\left(R_{s}\right)+1.427 ; R^{2}=0.999$

The void volume $\left(V_{0}\right)$ of the column was estimated from the reported column volume $\left(V_{t}\right)$ of $75 \mathrm{~mL}$ and

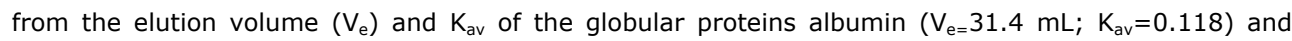
prolactin $\left(\mathrm{V}_{\mathrm{e}}=40.2 \mathrm{~mL} ; \mathrm{K}_{\mathrm{av}}=0.280\right)$. Entering these numbers into the equation for $\mathrm{K}_{\mathrm{av}}: \mathrm{K}_{\mathrm{av}}=\left(\mathrm{V}_{\mathrm{e}}-\mathrm{V}_{0}\right) /\left(\mathrm{V}_{\mathrm{t}}{ }^{-}\right.$ $\mathrm{V}_{0}$ ), yielded a $\mathrm{V}_{0}$ of $25.1 \mathrm{~mL}$ (albumin) and $26.4 \mathrm{~mL}$ (prolactin). The mean of $25.8 \mathrm{~mL}$ was used as an estimate of the true $V_{0}$.

We then calculated the $K_{a v}$ for the $2 \mathrm{cTnT}$ reactive peaks from Figure $2 \mathrm{D}$ (peak $1, \mathrm{~V}_{\mathrm{e}}=30.5$ so $\mathrm{K}_{\mathrm{av}}=0.09$; and for peak 2, $V_{e}=37.0$ so $K_{a v}=0.22$ ). When these $K_{a v}$ were entered into equation 4-3, Stokes radii of $37 \AA$ and $26 \AA$ were obtained. In addition, we used equation 1 to calculate the highest $R_{s}\left(K_{a v}=0\right)$ that could be separated with the column $\left(R_{s, \max }=48 \AA\right)$. We believe these $R_{s}$ do not correspond to the troponin complex and free cTnT. The $R_{s}$ of the troponin complex has been determined to be $57 \AA .{ }^{19}$ Hence, we may conclude that the first peak cannot correspond to the troponin complex, because this would have eluted at $\mathrm{V}_{0}$.

It is plausible, however, that the first peak corresponds to intact free cTnT. Based on the $R_{s}$ of bovine $\operatorname{TnC}(18.4 \mathrm{kDa})$ and CTnI $(23.9 \mathrm{kDa})\left(24 \AA\right.$ and $30 \AA$, respectively, ${ }^{20}$ it is likely that the larger cTnT (34.5 kDa) has an $R_{s}$ of $37 \AA$. The online SWISS-PROT database indicated $85 \%$, $89 \%$, and $99 \%$ homology between bovine and human cardiac troponin $\mathrm{T}$, I, and C, respectively. The second peak would then correspond to an immunoreactive fragment. Interestingly, a small immunoreactive fraction just before $30 \mathrm{~mL}$ is visible in Figure $2 \mathrm{C}$ and corresponds to the first peak from Figure $2 \mathrm{D}{ }^{1}$. This peak could indicate a small amount of the intact protein present in ACS patients. Importantly, because no secondary proof was provided (e.g. SDS-PAGE or amino acid sequencing), the exact identity of the peaks remains unclear.

Regarding our data, the purified CTnT standard showed the presence of only one protein with a molecular weight of $34377 \mathrm{Da}$ as confirmed by MS and similar to the expected mass of intact CTnT (Figure 4-2A). In contrast, the troponin TIC complex standard neither showed a peak at the expected molecular weight of the troponin TIC complex $(77 \mathrm{kDa})$, nor at the expected position of individual subunits T, C and I. This might be attributable to (a) the effects of the MALDI technique that can cause separation of the TIC complex into the 3 individual troponin subunits, combined with (b) the relatively high $(5.6 \mathrm{~g} / \mathrm{L})$ albumin concentration resulting in suppression of the troponin signals. Therefore, the absence of a peak at $\mathrm{m} / \mathrm{z}$ value $\sim 77000$ in Figure $4-2 B$ may not lead to the conclusion that no troponin TIC complex is present. Also, under denaturing conditions, as with SDS-PAGE, protein complexes are likely to be separated into the individual subunits. This might explain why the native TIC complex was not detected in our experiments.

For the bovine cardiac troponin TIC complex, a Stokes radius of $52-57 \AA$ has been found. ${ }^{4,19}$ The online SWISS-PROT database indicated $85 \%, 89 \%$ and $99 \%$ homology between bovine and human $\mathrm{CTnT}^{6}{ }^{6} \mathrm{I}$ and $\mathrm{C}$, respectively. ${ }^{5}$ In our opinion, this justifies application of these bovine data to human troponins. 
The properties of the Superdex 75 column limit the highest Stokes radius that can be determined to 48 $\AA$. Therefore, the intact troponin TIC complex should, if present, elute at $V_{0}\left(K_{a v}=0\right)$.

Separation of the cardiac troponin standards should result in either one peak for the purified cTnT standard (intact cTnT), and one, maybe two peaks for the troponin TIC complex standard (troponin TIC complex, and intact cTnT). Keeping in mind the non-globular shape of cTnT, the actual elution volumes for both intact CTnT and the troponin TIC complex will be shifted towards larger elution volumes. Importantly, the peak of the troponin TIC complex will elute earlier than the peak of the intact cTnT. Surprisingly, when both cardiac troponin standards were loaded onto the column, both showed a similar elution profile (Figure 4-2C), revealing two major peaks. In combination with the data derived from the MS experiments with the purified CTnT standard, this leads to the following conclusions: (a) In the absence of troponin I and C, Peak 1 of the purified cTnT standard (of which the contents has been confirmed by MS) can only be intact cTnT, not the TIC complex; (b) the $R_{\mathrm{s}}$ of Peak 1 (33.7 $\AA$ ) is too small for the earlier reported $R_{S}$ of $52-57 \AA$ for the troponin TIC complex, ${ }^{4,19}$ thus supporting the first conclusion; (c) following conclusion (a), Peak 2 must be an immunoreactive fragment of cTnT, most likely the $\sim 25 \mathrm{kDa}$ fragment described by our group, ${ }^{9}$ and others; ${ }^{7,}{ }^{21}$ (d) based on identical elution volumes, the two peaks of the troponin TIC complex standard can only represent intact cTnT and a smaller immunoreactive fragment; (e) with the current chromatographic conditions, the TIC complex is unstable and disintegrates into its subunits; (f) the $R_{s}$ of intact human cTnT is $33.7 \AA$.

In vitro incubation of both cardiac troponin standards in serum showed a time dependent decrease of Peak 1 and at the same time, an increase of Peak 2. For the troponin TIC complex standard a third, even smaller fragment appeared at $\mathrm{t}=96 \mathrm{~h}$. The small cTnT reactive peak, only present after 24 or $48 \mathrm{~h}$ of incubation of the highly purified cTnT standard (Figure 4-4A) suggests the presence of a molecule with a higher $R_{s}$ than intact cTnT. Possible cTnT aggregation ${ }^{16}$ does not interfere with the measured $R_{s}$ of this fraction (which is only slightly bigger than the $R_{s}$ of the monomer) when it is assumed that the two rod like molecules adhere along the long-axis. Evidently, it cannot be the troponin TIC complex due to the absence of $\mathrm{cTnI}$ and the fact that it would elute at $\mathrm{V}_{0}$. Based on the previous conclusions this degradation of cTnT confirms earlier experiments where in vitro incubation of spiked serum samples showed the appearance of smaller degradation products in time on SDS-PAGE (Figure 1 in the online data supplement of Michielsen et al. ${ }^{9}$ ).

In conclusion, from the fact that comparable Stokes radii were found in our study compared with the results described by Fahie-Wilson et al. ${ }^{1}$ and from the fact that the molecular mass of the purified cTnT standard was independently confirmed by MS and SDS-PAGE, we may conclude that the peaks indicated by Fahie-Wilson et al. ${ }^{1}$ cannot be the troponin TIC complex and free cTnT, but are intact cTnT and an immunoreactive cTnT degradation product (most probably of approximately $25 \mathrm{kDa}$ ). Hence, the correct conclusion from the study by Fahie-Wilson et al. ${ }^{1}$ should have been that in patients on hemodialysis or peritoneal dialysis, no intact free cTnT is present, but a smaller (25 kDa) immunoreactive cTnT fragment is. In patients with acute coronary syndrome a small amount of the intact free protein is present, depending on the time after onset of symptoms. Moreover, this conclusion is strengthened by the fact that incubation of a purified cTnT standard in troponin free serum resulted in a time dependent increase of immunoreactive fragments, which has been demonstrated in this study by SEC chromatography and in an earlier study by our group using SDS-PAGE. ${ }^{9}$ With our current findings we clearly demonstrated that a thorough approach to interpretation of SEC data is of utmost importance. Furthermore, fragmentation of CTnT in serum was clearly demonstrated using different techniques. 


\section{Limitations of the study}

Because of the unavailability of the unlabelled anti CTnT antibodies of the Roche third generation cTnT assay a different anti-cTnT antibody had to be used. Therefore, it should be noted that (quantitative) data from the immunoblots cannot directly be compared to the peak height of the SEC data. 


\section{REFERENCES}

[1] Fahie-Wilson MN, Carmichael DJ, Delaney MP, Stevens PE, Hall EM, Lamb EJ. Cardiac Troponin $\mathrm{T}$ Circulates in the Free, Intact Form in Patients with Kidney Failure. Clin Chem 2006; 52: 41420.

[2] Wu AH, Feng YJ, Moore R, Apple FS, McPherson $\mathrm{PH}$, Buechler KF, Bodor G. Characterization of cardiac troponin subunit release into serum after acute myocardial infarction and comparison of assays for troponin $\mathrm{T}$ and $\mathrm{I}$. American Association for Clinical Chemistry Subcommittee on cTnI Standardization. Clin Chem 1998; 44: 1198-208.

[3] Burtnick LD, McCubbin WD, Kay CM. The isolation and characterization of the tropomyosin binding component (TN-T) of bovine cardiac troponin. Can J Biochem 1976; 54: 546-52.

[4] Byers DM, McCubbin WD, Kay CM. Hydrodynamic properties of bovine cardiac troponin. FEBS Lett 1979; 104: 106-10.

[5] Boeckmann B, Bairoch A, Apweiler R, Blatter MC, Estreicher A, Gasteiger E, Martin MJ, Michoud K, O'Donovan C, Phan I, Pilbout S, Schneider $M$. The SWISS-PROT protein knowledgebase and its supplement TrEMBL in 2003. Nucleic Acids Res 2003; 31: 365-70.

[6] Mesnard L, Samson F, Espinasse I, Durand J, Neveux JY, Mercadier JJ. Molecular cloning and developmental expression of human cardiac troponin T. FEBS Lett 1993; 328: 139-44

[7] Labugger R, Organ L, Collier C, Atar D, Van Eyk JE. Extensive troponin I and $T$ modification detected in serum from patients with acute myocardial infarction. Circulation 2000; 102: 1221-6.

[8] Diris JH, Hackeng CM, Kooman JP, Pinto YM, Hermens WT, Van Dieijen-Visser MP. Impaired Renal Clearance Explains Elevated Troponin T Fragments in Hemodialysis Patients. Circulation 2004; 109: 23-5.

[9] Michielsen EC, Diris JH, Hackeng CM, Wodzig WK, Van Dieijen-Visser MP. Highly sensitive immunoprecipitation method for extracting and concentrating low-abundance proteins from human serum. Clin Chem 2005; 51: 222-4.

[10] Cabre F, Canela EI, Canela MA. Accuracy and precision in the determination of Stokes radii and molecular masses of proteins by gel filtration chromatography. J Chromatogr 1989; 472: 347-56
[11] Potschka M. Universal calibration of gel permeation chromatography and determination of molecular shape in solution. Anal Biochem 1987; 162: 47-64.

[12] Himmel ME, Baker JO, Mitchell DJ. Size Exclusion Chromatography of proteins. In: Wu C-s, ed. Handbook of size exclusion chromatography. Vol 69. New York: Marce Dekker, Inc.; 1995:409-28.

[13] Dubin PL, Principi JM. Failure of universal calibration for size exclusion chromatography of rodlike macromolecules versus random coils and globular proteins. Macromolecules 1989; 22: $1891-6$

[14] Demassieux S, Lachance J-P. Molecular filtration on Sepharose 6B. Empiric relationships between the distribution coefficient and the Stokes radius on the one hand and the molecular weight on the other of proteins of different degrees of asymmetry. Journal of Chromatography 1974; 89: 251-8.

[15] Axelsson I. Characterization of proteins and other macromolecules by agarose gel chromatography. Journal of Chromatography $A$ 1978; 152: 21-32.

[16] Byers DM, Kay CM. Hydrodynamic properties of bovine cardiac troponin-I and troponin-T. J Biol Chem 1983; 258: 2951-4.

[17] Flicker PF, Phillips GN, Jr., Cohen C. Troponin and its interactions with tropomyosin. An electron microscope study. J Mol Biol 1982; 162: 495-501.

[18] Fasman GD. Handbook of biochemistry and molecular biology. Section A: Proteins. 3rd ed. Cleveland, OH: CRC Press; 1976.

[19] Hinkle A, Goranson A, Butters CA, Tobacman LS. Roles for the troponin tail domain in thin filament assembly and regulation. A deletional study of cardiac troponin T. J Biol Chem 1999; 274: 7157-64.

[20] Byers DM, Kay CM. Bovine cardiac troponin subunits: binary complexes and reconstitution of whole troponin. FEBS Lett 1982; 148: 12-6.

[21] Communal C, Sumandea M, de Tombe P, Narula J, Solaro RJ, Hajjar RJ. Functional consequences of caspase activation in cardiac myocytes. Proc Natl Acad Sci U S A 2002; 99: 6252-6. 



\title{
CHAPTER 5
}

\section{CARdiac troponin t ReleAse AFTER PROLOnged StRenUOUS EXERCISE AND RECREATIONAL EXERCISE}

\begin{abstract}
Over the past two decades there has been a large interest in cardiac troponin T (cTnT) elevations, which are often seen following endurance sport events. There have been many reports on this topic, although sometimes with different approaches. We reviewed the available literature on CTnT elevations after prolonged strenuous exercise and found profound differences in the percentage of subjects reported to have elevated CTnT concentrations. This could partly be attributed to differences in immunoassay characteristics, such as cross-reactivity with skeletal troponin $T$, and the use of different cut-off values used in the different studies. The elevations were transient, with levels decreasing to preevent concentrations within 24 to 48 hours. This might be explained by the relatively short half life of CTnT, or water imbalance during and after the event. The release mechanism of CTnT, as well as the long term positive or negative effects, remains unclear. Future research should therefore be aimed at clarifying the release mechanism of cTnT. Furthermore, the benefits and the possible long term negative aspects of prolonged exercise should be evaluated.
\end{abstract}

Parts of this Chapter will be published:

Sports Medicine 2007; Accepted for publication. 


\section{INTRODUCTION}

Healthy food and an active lifestyle are factors that are generally associated with a lower risk of cardiac disease. Many people worldwide participate in a variety of physical activities, some more intense than others. Prolonged exercise, such as training for and participating in a marathon or triathlon, is becoming more popular. On average, participants in these strenuous activities are well-trained individuals pursuing a healthy lifestyle. There is, however controversy on the beneficial effects of prolonged exercise. In the past several years, studies have been published that showed the release of cardiac biomarkers after prolonged exercise in healthy participants. An example of these biomarkers is troponin. Troponins are markers that are used in a clinical setting to detect cardiac tissue damage and to diagnose acute myocardial infarction. ${ }^{1}$ The problem between prolonged exercise and troponin elevations is that it is unknown whether this release indicates reversible or irreversible damage to the heart. The current review aims to summarize all published literature regarding the release of cardiac troponin T (cTnT) after prolonged strenuous exercise to gain insight in the frequency of cTnT elevations and the influence of different immunoassays used for detection.

\section{THE TROPONIN COMPLEX}

The troponin complex is comprised of three subunits and regulates $\mathrm{Ca}^{2+}$ dependent muscle contraction in all striated muscle cells. Troponin $\mathrm{T}$ structurally binds the troponin complex via troponin $\mathrm{C}$ to tropomyosin. Binding of $\mathrm{Ca}^{2+}$ to troponin $\mathrm{C}$ results in increased affinity for troponin I. Troponin I then releases its inhibitory function on actomyosin ATPase, which leads to ATP hydrolysis and muscle contraction (see Farah et al. ${ }^{2}$ for an extensive review). Troponins are present in cardiac and skeletal muscle. The isoforms of troponin I and T, however, are encoded by different genes, yielding immunologically different proteins in cardiac and skeletal muscle. ${ }^{3,4}$ The cardiac muscle isoforms of troponin I and $\mathrm{T}$ ( $\mathrm{CTnI}$ and $\mathrm{CTnT}$, respectively) are highly specific and highly sensitive biomarkers for detecting minor cardiac damage. ${ }^{5}$ Hence, $\mathrm{CTnI}$ and $\mathrm{CTnT}$ are the preferred biomarkers for diagnosis and prognosis of acute coronary syndromes. ${ }^{1,6}$ It was demonstrated that the diagnosis of myocardial injury can be accurately excluded within 6 hours of admission using CTnT at the time of initial presentation, 3 and 6 hours after presentation resulting in sensitivities of $79.7 \%, 95.7 \%$, and $98.4 \%$, respectively. ${ }^{7}$

\section{Prolonged exercise}

The name "marathon" comes from a legend. According to the Greek historian Herodotus in his book "History", the Athenian generals sent Pheidippides, a professional runner, from Athens to Sparta to ask the Spartans to help fight the Persian army, who had arrived by ship at Marathon. Pheidippides completed the 145 mile $(234 \mathrm{~km}$ ) journey, delivered the generals' request, and then returned to Athens with the Spartan's reply - which was that due to religious festivities they could not leave Sparta until the first full moon. Upon receiving this news the generals decided to attack the Persians anyway, the result being Athenian victory against seemingly overwhelming odds in the Battle of Marathon (490 BC). 
The alternative version of the legend says that Pheidippides was sent from the town of Marathon to Athens (about 26 miles, $42 \mathrm{~km}$ ) to announce that the Persians had been miraculously defeated. It is said that he ran the entire distance without stopping. Moments after proclaiming the Greek victory over Persia with the words "We were victorious!", he died on the spot. ${ }^{8,9}$

Fortunately, death is an infrequent occurrence in modern day marathons, ${ }^{10-12}$ but there is debate about the clinical cardiac aspects of prolonged strenuous exercise. Although regular exercise is associated with certain cardiac benefits, ${ }^{13}$ biochemical markers of cardiac tissue damage such as the cardiac troponin isoforms $\mathrm{CTnI}^{14-16}$ and $\mathrm{cTnT}^{15-20}$ have been shown to be elevated immediately after prolonged strenuous exercise. These effects were all transient and returned to normal values within 24 to 48 hours. This review aims to give an overview of the cTnT elevations reported after prolonged strenuous exercise and to discuss the possible role of the different assay generations used for determining cTnT concentrations.

\section{TROPONIN T IMMUNOASSAYS}

Ever since it became apparent that antibodies against the cardiac isoform of troponin $\mathrm{T}$ were able to discriminate between skeletal and cardiac isoforms, immunoassays have been developed and improved. ${ }^{21}$ In 1989 the first generation cTnT immunoassay was released. This was a one step ELISA method, which employed polyclonal goat-anti-human anti-troponin $\mathrm{T}$ antibodies, immobilised on polyvinylchloride test tubes and peroxidase labelled monoclonal anti-troponin $\mathrm{T}$ antibody $1 \mathrm{~B} 10$ for detection. 22 The latter had $12 \%$ cross reactivity to skeletal muscle troponin $\mathrm{T} .{ }^{23,}{ }^{24}$ Overall, the assay displayed $1 \%$ cross reactivity to skeletal $\mathrm{TnT},{ }^{22}$ likely attributable to unspecific binding of skeletal muscle troponin $\mathrm{T}$ to the test tube and detection by the cross-reactive monoclonal antibody $1 \mathrm{~B} 10$ used as label. ${ }^{25,26}$ The detection limit of this assay was $0.04 \mu \mathrm{g} / \mathrm{L}$ and the turnaround time was 90 minutes. Some years later, the assay $\left(\right.$ Enzymun $^{\circledR}$ ) was improved by replacing the capture antibodies with biotin labelled monoclonal capture antibody M7, without significant cross reactivity to skeletal TnT, and antibody $1 \mathrm{~B} 10$ for detection, combined with streptavidin-coated tubes as the solid phase to reduce unspecific binding. ${ }^{23}$

The second generation, a new and more-specific version of the troponin T ELISA, was developed and used a new antibody combination. ${ }^{26}$ The second generation cTnT immunoassay used two cardiac tissue specific monoclonal anti-cTnT antibodies, biotin labelled monoclonal capture antibody M11.7 (recognising amino acid residues 136-147) and horseradish peroxidase labelled monoclonal detection antibody M7 (recognising amino acid residues 125-131). The latter was first used as capture antibody. The detection limit of this assay was lower $(0.0123 \mu \mathrm{g} / \mathrm{L})$, the imprecision was lower and the turnaround time was reduced to 45 minutes. ${ }^{26,27}$ Calibration of the assay was performed with purified bovine cTnT spiked in human serum. For diagnosis of patients with myocardial damage a cut-off of 0.1 $\mu \mathrm{g} / \mathrm{L}$ was proposed. ${ }^{26}$

The third generation assay used recombinant human cTnT as calibration material and had a more linear calibration curve. Thus, linearity problems observed with the second generation assay were eliminated. The assay had high precision, especially at the low end of the measuring range. ${ }^{28}$ The detection limit in serum and heparin plasma is $<0.010 \mu \mathrm{g} / \mathrm{L}$, which is equal to the 99th percentile reference limit in healthy volunteers. ${ }^{29,} 30$ However, heparin was shown to generate markedly decreased concentrations 
compared with serum. ${ }^{31,32}$ Speth et al. concluded that the apparent decrease in cTnT values in heparin plasma was a result of direct molecular interaction between the negatively charged glycosaminoglycan and clusters of basic residues within the cTnT molecule. ${ }^{33}$ For diagnosis of myocardial damage, it has been recommended to use a cut-off value at which the coefficient of variation (CV) is less than or equal to $10 \%$. For the third generation assay this was $0.03 \mu \mathrm{g} / \mathrm{L}$. It was shown to be a valuable marker that allows for rapid and accurate differential diagnosis of patients with suspected acute coronary syndrome, and of patients with other causes of chest pain. ${ }^{34}$ Recently, a study comparing the second and third generation assays showed excellent agreement ( $r=0.99$ Spearman, $p<0.0001, n=135)$ across the analytical range. This correlation was linear in the range from 0.01-0.2 $\mathrm{g} / \mathrm{L}$ and curvilinear above 0.2 $\mu \mathrm{g} / \mathrm{L} .{ }^{35}$ The third generation assay classified $35 \%$ more patients as having AMI, identified a $10 \%$ larger low-risk group, and was superior in identifying patients with signs of very minor myocardial necrosis (cTnT >0.01-0.02 $\mu \mathrm{g} / \mathrm{L}) .{ }^{36}$ The antibodies do not show cross reactivity with skeletal isoforms $(<0.001 \%)$ and may therefore be used to detect cardiac damage in the context of exercise-induced skeletal muscle damage. ${ }^{37,38}$

The fourth generation troponin T assay has recently been tested for analytical and clinical performance. This method differs from the previous generation in the composition of reagent 1 , which has an inhibitor of heparin cationic activity added to make heparin plasma samples suitable for cTnT determination. Although preliminary data suggested a reduction of the lower detection limit with adequate precision, ${ }^{39}$ the manufacturer recently determined the $10 \% \mathrm{CV}$ concentration to be 0.028 $\mu \mathrm{g} / \mathrm{L} .{ }^{40}$ These results were evaluated in a laboratory setting by measuring CTnT in a frozen human serum pool prepared by selecting fresh leftover samples from patients with cTnT concentrations around the selected cut-off for diagnosis of myocardial infarction. This group showed an average total CV (SD) of $9.8 \%(0.7)$ at an overall CTnT mean (SD) concentration of $0.041 \mu \mathrm{g} / \mathrm{L}(0.004) .{ }^{41}$ The fourth generation is now the laboratory standard for analysis of cTnT.

\section{CARDIAC TROPONIN T AND PROLONGED EXERCISE}

It is generally known that participants in endurance sport events can have abnormal laboratory parameters, including electrolytes and biomarkers for cardiac function. ${ }^{42,43}$ An extensive table of modified reference ranges (or expected ranges) for basic biochemical, cardiac, and haematologic laboratory parameters for marathon runners was published recently. ${ }^{43}$ In general, these abnormal values returned to normal within 24 to 48 hours after the strenuous event, suggesting these effects are transient. 


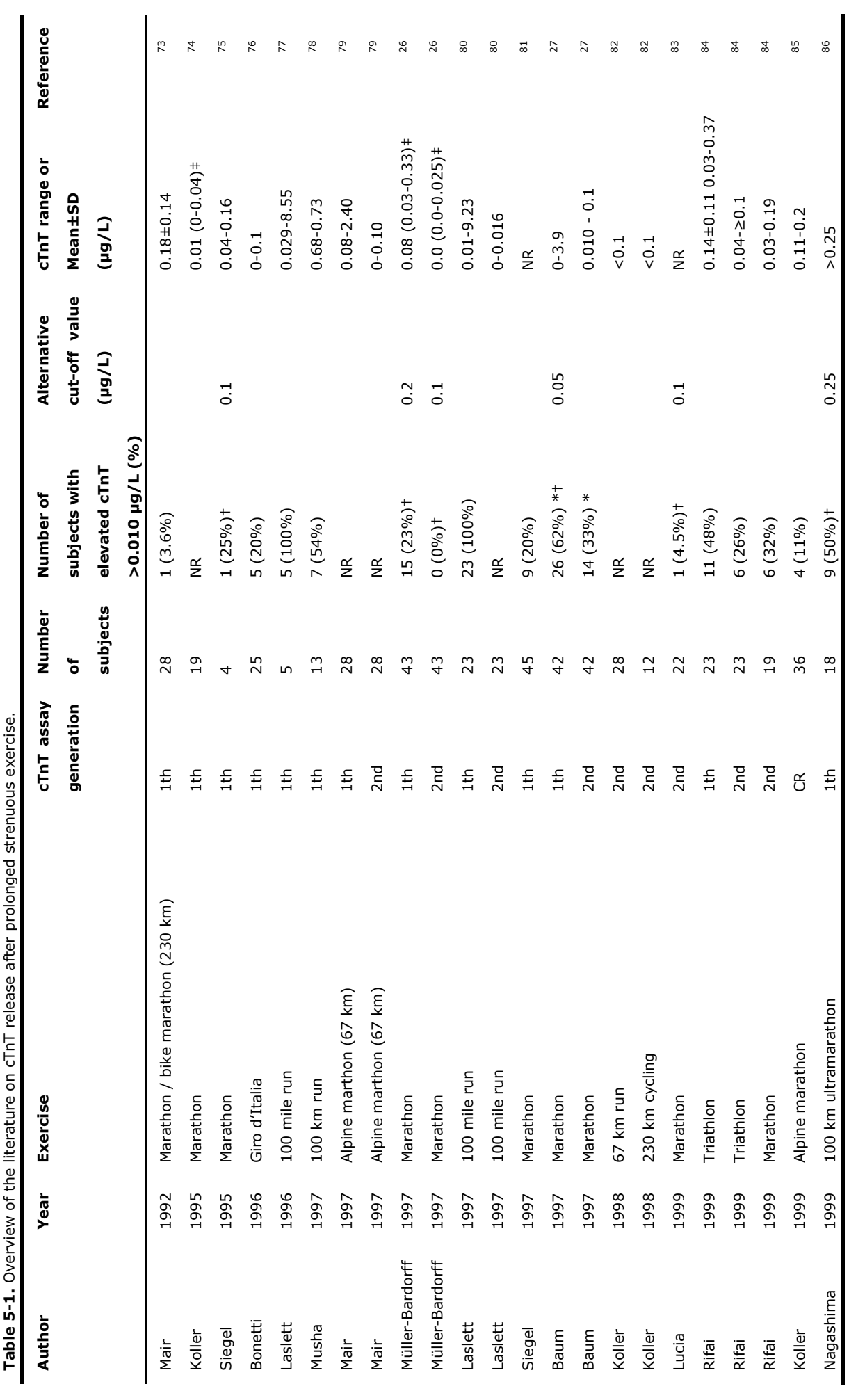




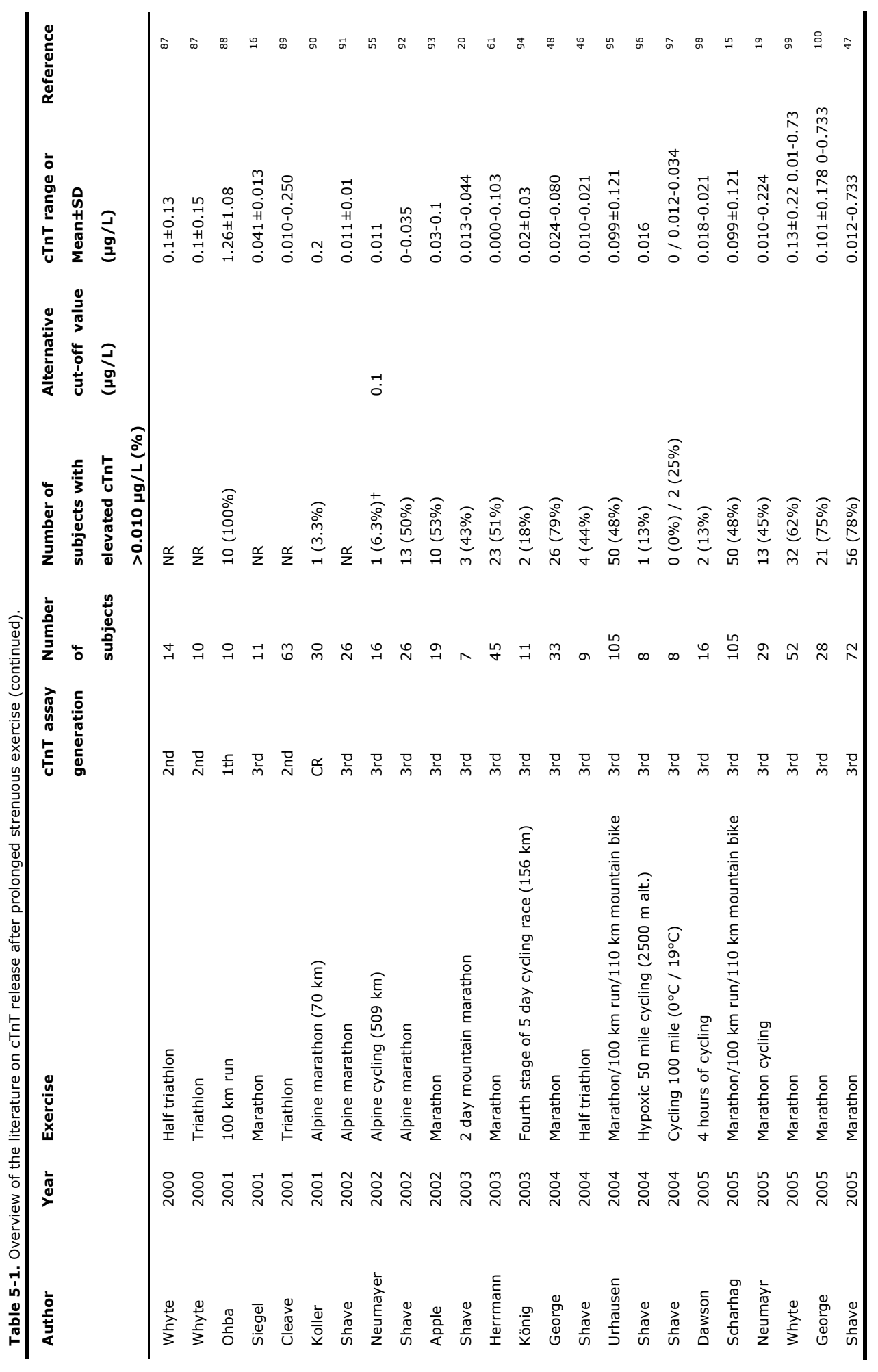




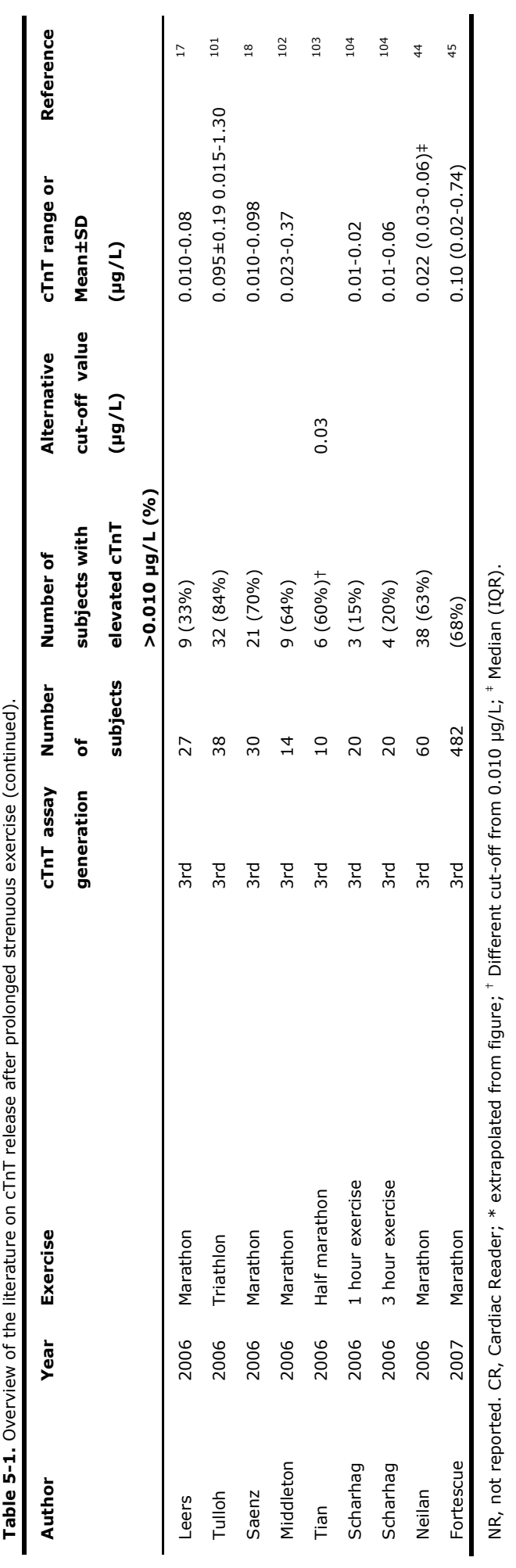


Especially cTnT has been investigated thoroughly in the past two decades (Table 5-1). The data presented in Table 5-2 is a summary of the data presented in Table 5-1. The first generation assay recognised skeletal and cardiac troponin $\mathrm{T}$ in $44 \%$ of the subjects. Subsequent studies using the second generation showed a lower percentage positive subjects $(13 \%)$, possibly because of loss of the skeletal component. Most studies used the third generation cardiac specific assay, which showed cTnT elevations in $59 \%$ of the subjects, likely due to the 10 -fold lower detection limit. We could not detect differences between the kind of exercise (running or cycling, marathon or triathlon) and the severity of cTnT increases in these studies. It has been shown that cTnT elevations correlated inversely with training distance, suggesting that adaptation of the heart to strenuous exercise can decrease cardiac injury. ${ }^{44}$ In contrast to the findings by Fortescue et al. who found that younger age appeared to be associated with cTnT increases, ${ }^{45}$ other groups reported no relation with age. ${ }^{17,46-48}$

At first the difficulty was to differentiate the skeletal isoform from the cardiac isoform of troponin $\mathrm{T}$. When this was achieved with the arrival of the second generation cTnT immunoassay, the scientific discussion focussed more on the short and long term clinical aspects of cTnT elevations. The most important and difficult question to be answered was whether the release of cTnT in healthy athletes after strenuous exercise represents transient and reversible myocardial damage, or subclinical and irreversible myocardial damage. A recent meta-analysis revealed an overall immediate post exercise reduction in the ejection fraction (EF), systolic blood pressure/end systolic volume (SBP/ESV) ratio, and early-to-late diastolic filling (E/A) ratio, suggesting a transient decrease in both systolic function and diastolic filling. ${ }^{49}$ More recently, it was shown in 20 subjects that all the systolic abnormalities had normalised after a marathon race, but that diastolic abnormalities of the left and right ventricle persisted up to 1 month after participation. ${ }^{50}$ It has been argued that, despite the claims of exercise induced damage, the cardiovascular benefits attributable to regular vigorous exercise are the primary prevention strategy for coronary disease. ${ }^{51}$

Table 5-2. cTnT elevations as measured with different Roche cTnT immunoassay generations.

\begin{tabular}{llll}
\hline Assay generation & Number of studies & Number of subjects & $\begin{array}{l}\text { Number of } \\
\text { with cTnT elevation }\end{array}$ \\
\hline 1th generation & 12 & 279 & $122(44 \%)$ \\
2nd generation & 7 & 205 & $27(13 \%)$ \\
3rd generation & 26 & 1290 & $759(59 \%)$ \\
Cardiac Reader & 2 & 66 & $5(8 \%)$ \\
\hline
\end{tabular}

${ }^{*}$ Different cut-off values have been used in different studies.

\section{TROPONIN RELEASE}

Although the exact mechanism of release remains to be clarified, it has been hypothesised that these elevations most likely reflect (reversible) myocardial stunning and/or true (irreversible) ischemic cell injury and even cell death. ${ }^{18,52}$ Transient elevations could represent loss of cTnT from the cytosolic pool due to membrane damage induced by oxidative stress, ${ }^{53}$ hypoxia, ${ }^{54}$ or transient ischemia. ${ }^{52}$ Regarding this, exercise has been shown to induce overload of free oxygen radicals leading to increased membrane leakage. ${ }^{55,56}$ The majority of the total intracellular cTnT content is bound to the myofibrils in 
complex with cTnI and troponin C. Marked differences in release kinetics of cTnT have been described in patients with reperfusion after acute myocardial infarction, compared to patients with a permanent occlusion. Rapid reperfusion (> 3.5 hours), resulted in a typical biphasic cTnT time-concentration curve. ${ }^{57,58}$ The early rapid rise (first peak) in serum concentrations was ascribed to release of cTnT from the unbound cytosolic fraction and the persistent elevation (second peak) of cTnT for more than 180 hours after onset of symptoms to ongoing cTnT release from myofibrils. ${ }^{57}$ From the biphasic release curve it is apparent that the half-life of the cytosolic fraction is considerably shorter than the half-life of the second, bound fraction. It was hypothesised that the return of elevations observed directly after exercise to pre-race levels can be ascribed to the relatively short (120 minutes) half life of cTnT. ${ }^{19}$ It is also possible that cTnT concentrations after one day are below the detection limit of the current routine Roche immunoassay due to water imbalance. It has been shown that during and shortly after a marathon race plasma volume is decreased, which resulted in a loss of body weight and an increase of serum albumin. ${ }^{59}$ It is likely that cTnT is also concentrated due to a lower plasma volume. In addition, a significant increase in plasma volume was noted at 24 and 48 hours after running a treadmill marathon. ${ }^{60}$ The increase in plasma volume results in dilution and this might explain why elevations of cTnT decrease below the detection limit 24-48 hours after a race.

The other cardiac specific isoform of troponin (cTnI) has also been shown to be elevated after prolonged strenuous exercise. ${ }^{15,55,61,62}$ Proteolysis and degradation of cTnI have been extensively investigated. ${ }^{63,64} \mathrm{~A}$ recent study showed that degradation of $\mathrm{CTnI}$ in human myocardium might impair diastolic function, whereas systolic function was largely preserved. ${ }^{65}$

The cellular release mechanism of troponin is likely different from that after myocardial infarction. A possible role of catecholamine-induced myocardial injury after exercise has been proposed. ${ }^{66}$ In addition, it was shown that the cardiovascular response to dobutamine was abnormal with attenuated heart rate, blood pressure and left ventricular contractility, suggesting it may be due, in part, to altered $\beta$-receptor function. ${ }^{67}$

\section{SHORT EXERCISE}

Neilan et al. recently reported an intriguing paper, confirming signs of myocardial injury of Boston Marathon participants, showing an inverse correlation between decreased cardiac function and elevated biomarkers such as cardiac troponin $\mathrm{T}$ (cTnT) and $\mathrm{N}$-terminal pro-brain natriuretic peptide (NTproBNP). ${ }^{68} \mathrm{CTnT}$ was elevated above the 99 th percentile of normal $(>0.01 \mathrm{ng} / \mathrm{ml})$ in $>60 \%$ of marathon participants, while $40 \%$ of the studied participants had cTnT levels above the limit for acute myocardial infarction $(\geq 0.03 \mu \mathrm{g} / \mathrm{L})$. Since the authors excluded participants with a previous history of cardiovascular disease, a relatively healthy population was studied. The accompanying editorial stated that it is important to study the long term sequelae of prolonged exercise among minimally trained runners. ${ }^{69}$

In this light, our recently collected data contain a message that may be even more disturbing. We studied serum cardiac biomarkers in 127 participants in a 4 mile health run/walk before and after the event, which was an activity to promote a healthy life style and physical activity in the general population. The study was approved by the local medical ethics committee. Venous blood samples were collected $0,5-2,5 \mathrm{~h}$ before the event, and $0,5-2,5 \mathrm{~h}$ post-event for the determination of cTnT and NT- 


\section{CHAPTER 5}

proBNP (Roche Diagnostics). Subjects were required to fill in a questionnaire and had their blood pressure measured in order to calculate the risk score according to the PROCAM study (Table 5-3). ${ }^{70}$

Mean age was $53 \pm 11$ years. NT-proBNP was elevated above the age-adjusted optimal cut-off for heart failure71 pre-event in one subject (178 pmol/L), with post-event levels being elevated in this subject (280 pmol/L) and one other subject (118 pmol/L). Troponin levels were elevated above the 99th percentile of normal in 3 subjects post-event, and in two subjects even above the cut-off for myocardial infarction $(0.011 ; 0.036$ and $0.102 \mu \mathrm{g} / \mathrm{L})$, whereas pre-event cTnT levels were undetectable. These subjects had PROCAM risk scores of $10.4,0.8$ and $7.8 \%$, and post-event NT-proBNP levels of 43,22 and $20 \mathrm{pmol} / \mathrm{L}$, respectively. The mean PROCAM risk score for all participants was $7.0 \pm 11 \%$, the mean NT-proBNP pre and post-event were $13 \pm 19$ and $18 \pm 29 \mathrm{pmol} / \mathrm{L}$, respectively.

Table 5-3. Characteristics of 127 participants with a post-race blood sample.

\begin{tabular}{lccc}
\hline Characteristic & All $(\mathbf{n = 1 2 7})$ & Male $(\mathbf{n = 6 3})$ & Female $(\mathbf{n = 6 4 )}$ \\
\hline Age & $55(13-75)$ & $55(13-73)$ & $55(14-75)$ \\
Systolic blood pressure (mmHg) & $137(110-189)$ & $135(110-189)$ & $140(110-177)$ \\
Cholesterol (mmol/L) & $5.5(3.3-9.4)$ & $5.5(3.3-9.4)$ & $5.6(3.3-8.8)$ \\
HDL (mmol/L) & $1.2(0.6-2.5)$ & $1.1(0.6-2.3)$ & $1.5(0.7-2.5)^{\mathrm{a}}$ \\
LDL (mmol/L) & $3.7(1.8-6.4)$ & $3.9(2.1-6.4)$ & $3.6(1.8-6.3)$ \\
Triglycerides (mmol/L) & $1.0(0.3-3.7)$ & $1.1(0.4-3.7)$ & $0.9(0.3-2.6)$ \\
Glucose (mmol/L) & $5.7(4.6-9.5)$ & $5.8(5.0-9.5)$ & $5.6(4.6-7.7)$ \\
Pre-race NT-proBNP (pmol/L) & $7.7(0.6-178)$ & $6.0(0.6-178)$ & $9.0(1.9-91)^{a}$ \\
Post-race NT-proBNP (pmol/L) & $10(0.6-280)$ & $7.8(0.6-280)$ & $12(1.3-118)^{\mathrm{b}}$ \\
Pre-race cTnT ( $\mu \mathrm{g} / \mathrm{L})$ & $0.010(0.010-0.010)$ & $0.010(0.010-0.010)$ & $0.010(0.010-0.010)$ \\
Post race cTnT ( $\mu \mathrm{gg} / \mathrm{L})$ & $0.010(0.010-0.102)$ & $0.010(0.010-0.102)$ & $0.010(0.010-0.011)$ \\
PROCAM Risk score (\%) & $3.6(0.1-88)$ & $2.9(0.1-88)$ & $4.8(0.2-59)^{\mathrm{b}}$ \\
History of smoking (no/yes) (\%) & $106 / 20(84 / 16)$ & $46 / 16(74 / 26)$ & $60 / 4(94 / 6)^{\mathrm{a}}$ \\
History of MI in family (no/yes) (\%) & $84 / 42(67-33)$ & $40 / 22(65 / 35)$ & $44 / 20(69 / 31)$ \\
\hline
\end{tabular}

Data are represented as median (minimum - maximum). CTnT measurements below $0.010 \mu \mathrm{g} / \mathrm{L}$ are represented as $0.010 \mu \mathrm{g} / \mathrm{L} .{ }^{\mathrm{a}} \mathrm{p}<0.01,{ }^{\mathrm{b}} \mathrm{p}<0.05$

\section{Conclusions}

There has been ongoing research on the clinical aspects of cTnT elevations sometimes seen in participants following endurance events such as marathons, ultra-runs, or triathlons. Based on the available literature we conclude that many groups have reported cTnT elevations after prolonged strenuous exercise in the past two decades. In these reports different cTnT immunoassays (with different characteristics) were used. Together with the use of different cut-off values, this clearly influenced the percentage of athletes reported to have cTnT elevations post-event. Using the third generation CTnT immunoassay, elevations above the detection limit of $0.010 \mu \mathrm{g} / \mathrm{L}$ occurred in $59 \%$ of professional and recreational athletes. The mechanism of release and the clinical long term effects remain to be clarified. Clinicians dealing with these athletes should always measure a second cTnT 3 to 6 hours after the initial blood sample when the person is suspected of having mild ischemia or even a 
myocardial infarction. ${ }^{7,} 72$ We also conclude that elevation in serum cardiac biomarkers can occur in a subset of subjects after a short exercise, especially when untrained. These data support the notion that careful preparation is not only crucial to prevent the release of cardiac biomarkers from the heart for extensive endurance races like a marathon, but may also be essential for exercise levels that are performed by millions of individuals around the world everyday. 


\section{REFERENCES}

[1] Alpert JS, Thygesen K, Antman E, Bassand JP. Myocardial infarction redefined--a consensus document of The Joint European Society of Cardiology/American College of Cardiology Committee for the redefinition of myocardial infarction. J Am Coll Cardiol 2000; 36: 959-69.

[2] Farah CS, Reinach FC. The troponin complex and regulation of muscle contraction. Faseb J 1995; 9: 755-67.

[3] Townsend PJ, Farza H, MacGeoch C, Spurr NK, Wade R, Gahlmann R, Yacoub MH, Barton PJ. Human cardiac troponin $\mathrm{T}$ : identification of fetal isoforms and assignment of the TNNT2 locus to chromosome 1q. Genomics 1994; 21: 311-6.

[4] Vallins WJ, Brand NJ, Dabhade N, ButlerBrowne G, Yacoub MH, Barton PJ. Molecular cloning of human cardiac troponin I using polymerase chain reaction. FEBS Lett 1990; 270: $57-61$.

[5] Giannitsis E, Katus HA. Comparison of cardiac troponin $\mathrm{T}$ and troponin I assays--implications of analytical and biochemical differences on clinical performance. Clin Lab 2004; 50: 521-8.

[6] Newby LK, Goldmann BU, Ohman EM. Troponin: an important prognostic marker and riskstratification tool in non-ST-segment elevation acute coronary syndromes. J Am Coll Cardiol 2003; 41: 31S-6S.

[7] Engel G, Rockson SG. Rapid diagnosis of myocardial injury with troponin $\mathrm{T}$ and CK-MB relative index. Mol Diagn Ther 2007; 11: 10916.

[8] Grogan R. Run, Pheidippides, Run! The story of the Battle of Marathon. Br J Sports Med 1981; 15: 186-9.

[9] Kinsey TE. Pheidippides and the Marathon run $\mathrm{Br}$ J Sports Med 1981; 15: 285-6.

[10] Maron BJ, Shirani J, Poliac LC, Mathenge R, Roberts WC, Mueller FO. Sudden death in young competitive athletes. Clinical, demographic, and pathological profiles. Jama 1996; 276: 199-204.

[11] Rich MW. Risk for sudden cardiac death associated with marathon running. J Am Coll Cardiol 1997; 29: 224

[12] Maron BJ, Poliac LC, Roberts WO. Risk for sudden cardiac death associated with marathon running. J Am Coll Cardiol 1996; 28: 428-31.

[13] Morris CK, Froelicher VF. Cardiovascular benefits of improved exercise capacity. Sports Med 1993; 16: 225-36.

[14] Vidotto C, Tschan H, Atamaniuk J, Pokan R, Bachl N, Muller MM. Responses of $\mathrm{N}$-terminal pro-brain natriuretic peptide (NT-proBNP) and cardiac troponin I (cTnI) to competitive endurance exercise in recreational athletes. Int J Sports Med 2005; 26: 645-50.

[15] Scharhag J, Herrmann M, Urhausen A, Haschke M, Herrmann W, Kindermann W. Independent elevations of $\mathrm{N}$-terminal pro-brain natriuretic peptide and cardiac troponins in endurance athletes after prolonged strenuous exercise. Am Heart J 2005; 150: 1128-34.
[16] Siegel AJ, Lewandrowski EL, Chun KY, Sholar $\mathrm{MB}$, Fischman AJ, Lewandrowski KB. Changes in cardiac markers including B-natriuretic peptide in runners after the Boston marathon. Am J Cardiol 2001; 88: 920-3.

[17] Leers MP, Schepers R, Baumgarten R. Effects of a long-distance run on cardiac markers in healthy athletes. Clin Chem Lab Med 2006; 44: 999-1003.

[18] Saenz AJ, Lee-Lewandrowski E, Wood MJ, Neilan TG, Siegel AJ, Januzzi JL, Lewandrowski KB. Measurement of a plasma stroke biomarker panel and cardiac troponin $T$ in marathon runners before and after the 2005 Boston marathon. Am J Clin Pathol 2006; 126: 185-9.

[19] Neumayr G, Pfister R, Mitterbauer G, Eibl G, Hoertnagl $H$. Effect of competitive marathon cycling on plasma $\mathrm{N}$-terminal pro-brain natriuretic peptide and cardiac troponin $\mathrm{T}$ in healthy recreational cyclists. Am J Cardiol 2005; 96: 732-5.

[20] Shave RE, Dawson E, Whyte PG, George K, Ball $D$, Gaze CD, Collinson P. Cardiac troponin T in female athletes during a two-day mountain marathon. Scott Med J 2003; 48: 41-2.

[21] Rosalki SB, Roberts R, Katus HA, Giannitsis E, Ladenson JH, Apple FS. Cardiac biomarkers for detection of myocardial infarction: perspectives from past to present. Clin Chem 2004; 50: 2205-13.

[22] Katus HA, Remppis A, Looser S, Hallermeier K, Scheffold T, Kubler W. Enzyme linked immuno assay of cardiac troponin $T$ for the detection of acute myocardial infarction in patients. J Mol Cell Cardiol 1989; 21: 1349-53.

[23] Katus HA, Looser S, Hallermayer K, Remppis A, Scheffold T, Borgya A, Essig U, Geuss U. Development and in vitro characterization of a new immunoassay of cardiac troponin T. Clin Chem 1992; 38: 386-93.

[24] Wu AH, Valdes R, Jr., Apple FS, Gornet T, Stone MA, Mayfield-Stokes $S$, Ingersoll-Stroubos AM, Wiler B. Cardiac troponin-T immunoassay for diagnosis of acute myocardial infarction. Clin Chem 1994; 40: 900-7.

[25] Collinson PO, Stubbs PJ, Rosalki SB. Cardiac troponin T in renal disease. Clin Chem 1995; 41: 1671-3.

[26] Muller-Bardorff $M$, Hallermayer $K$, Schroder $A$, Ebert C, Borgya A, Gerhardt W, Remppis A, Zehelein $\mathrm{J}$, Katus HA. Improved troponin $T$ ELISA specific for cardiac troponin $T$ isoform: assay development and analytical and clinical validation. Clin Chem 1997; 43: 458-66.

[27] Baum H, Braun S, Gerhardt W, Gilson G, Hafner G, Muller-Bardorff M, Stein W, Klein G, Ebert C, Hallermayer K, Katus HA. Multicenter evaluation of a second-generation assay for cardiac troponin T. Clin Chem 1997; 43: 1877-84.

[28] Hallermayer K, Klenner D, Vogel R. Use of recombinant human cardiac Troponin $T$ for standardization of third generation Troponin $T$ methods. Scand J Clin Lab Invest Suppl 1999; 230: 128-31. 
[29] Apple FS, Murakami MM. Serum 99th percentile reference cutoffs for seven cardiac troponin assays. Clin Chem 2004; 50: 1477-9.

[30] Apple FS, Quist HE, Doyle PJ, Otto AP Murakami MM. Plasma 99th Percentile Reference Limits for Cardiac Troponin and Creatine Kinase MB Mass for Use with European Society of Cardiology/American College of Cardiology Consensus Recommendations. Clin Chem 2003; 49: 1331-6.

[31] Gerhardt W, Nordin G, Herbert AK, Linaker Burzell B, Isaksson A, Gustavsson E, Haglund S, Muller-Bardorff M, Katus HA. Troponin T and I Assays Show Decreased Concentrations in Heparin Plasma Compared with Serum: Lower Recoveries in Early than in Late Phases of Myocardial Injury. Clin Chem 2000; 46: 817-21.

[32] Stiegler $H$, Fischer $Y$, Vazquez-Jimenez JF, Graf J, Filzmaier K, Fausten B, Janssens U, Gressner $A M$, Kunz D. Lower cardiac troponin $T$ and $I$ results in heparin-plasma than in serum. Clin Chem 2000; 46: 1338-44.

[33] Speth M, Seibold K, Katz N. Interaction between heparin and cardiac troponin $\mathrm{T}$ and troponin $\mathrm{I}$ from patients after coronary bypass surgery. Clin Biochem 2002; 35: 355-62.

[34] Collinson PO, Stubbs PJ, Kessler AC. Multicentre evaluation of the diagnostic value of cardiac troponin T, CK-MB mass, and myoglobin for assessing patients with suspected acute coronary syndromes in routine clinical practice. Heart 2003; 89: 280-6.

[35] Gaze DC, Collinson PO. Clinical effect of recalibration of the roche cardiac troponin $T$ assay. Med Princ Pract 2006; 15: 29-32.

[36] Jernberg $T$, Venge $P$, Lindahl $B$. Comparison between second and third generation troponin $T$ assay in patients with symptoms suggestive of an acute coronary syndrome but without ST segment elevation. Cardiology 2003; 100: 2935 .

[37] Shave R, Dawson E, Whyte G, George K, Ball D, Collinson P, Gaze D. The cardiospecificity of the third-generation CTnT assay after exerciseinduced muscle damage. Med Sci Sports Exerc 2002; 34: 651-4.

[38] Roth HJ, Leithauser RM, Doppelmayr $H_{\text {, }}$ Doppelmayr M, Finkernagel $H$, von Duvillard SP, Korff S, Katus HA, Giannitsis E, Beneke R. Cardiospecificity of the $3(\mathrm{rd})$ generation cardiac troponin $\mathrm{T}$ assay during and after a $216 \mathrm{~km}$ ultra-endurance marathon run in Death Valley. Clin Res Cardiol 2007; 96: 359-64.

[39] Giannitsis E, Katus HA. 99th Percentile and Analytical Imprecision of Troponin and Creatine Kinase-MB Mass Assays: An Objective Platform for Comparison of Assay Performance. Clin Chem 2003; 49: 1248-9.

[40] Hermsen D, Apple F, Garcia-Beltran L, Jaffe A, Karon B, Lewandrowski E, Mühlbacher A, Müller R, Ordóñez J, Pagani F, Panteghini M, Plecko T, Jarausch J. Results from a multicenter evaluation of the 4th generation Elecsys $\AA$ Troponin T assay. Clin Chem 2006; 52: A130.

[41] Dolci A, Dominici R, Luraschi P, Panteghini M. $10 \% \mathrm{CV}$ concentration for the fourth generation Roche cardiac troponin $\mathrm{T}$ assay derived from Internal Quality Control data. Clin Chem Lab Med 2006; 44: 1495-6.
[42] Almond CS, Shin AY, Fortescue EB, Mannix RC, Wypij D, Binstadt BA, Duncan CN, Olson DP, Salerno $A E$, Newburger JW, Greenes DS. Hyponatremia among runners in the Boston Marathon. N Engl J Med 2005; 352: 1550-6.

[43] Kratz A, Lewandrowski KB, Siegel AJ, Chun KY, Flood JG, Van Cott EM, Lee-Lewandrowski E. Effect of marathon running on hematologic and biochemical laboratory parameters, including cardiac markers. Am J Clin Pathol 2002; 118: 856-63.

[44] Neilan TG, Januzzi JL, Lee-Lewandrowski E, Ton-Nu TT, Yoerger DM, Jassal DS, Lewandrowski KB, Siegel AJ, Marshall JE, Douglas PS, Lawlor D, Picard MH, Wood MJ. Myocardial Injury and Ventricular Dysfunction Related to Training Levels Among Nonelite Participants in the Boston Marathon. Circulation 2006; 114: 2325-33.

[45] Fortescue EB, Shin AY, Greenes DS, Mannix RC Agarwal $\mathrm{S}$, Feldman $\mathrm{BJ}$, Shah MI, Rifai $\mathrm{N}$ Landzberg MJ, Newburger JW, Almond CS. Cardiac troponin increases among runners in the Boston Marathon. Ann Emerg Med 2007; 49: $137-43,43$ e1

[46] Shave R, Dawson E, Whyte G, George K, Gaze $D$, Collinson P. Altered cardiac function and minimal cardiac damage during prolonged exercise. Med Sci Sports Exerc 2004; 36: 1098103.

[47] Shave RE, Whyte GP, George K, Gaze DC, Collinson PO. Prolonged exercise should be considered alongside typical symptoms of acute myocardial infarction when evaluating increase in cardiac troponin T. Heart 2005; 91: 1219-20.

[48] George K, Whyte G, Stephenson C, Shave R, Dawson E, Edwards B, Gaze D, Collinson P. Postexercise left ventricular function and CTnT in recreational marathon runners. Med Sci Sports Exerc 2004; 36: 1709-15.

[49] Middleton N, Shave R, George K, Whyte G, Hart

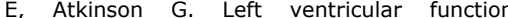
immediately following prolonged exercise: A meta-analysis. Med Sci Sports Exerc 2006; 38: 681-7.

[50] Neilan TG, Yoerger DM, Douglas PS, Marshall JE, Halpern EF, Lawlor D, Picard MH, Wood MJ. Persistent and reversible cardiac dysfunction among amateur marathon runners. Eur Heart J 2006; 27: 1079-84.

[51] Koller A. Exercise-induced increases in cardiac troponins and prothrombotic markers. Med Sc Sports Exerc 2003; 35: 444-8.

[52] $\mathrm{Wu} \mathrm{AH}$, Ford L. Release of cardiac troponin in acute coronary syndromes: ischemia or necrosis? Clin Chim Acta 1999; 284: 161-74.

[53] Venditti P, Di Meo S. Antioxidants, tissue damage, and endurance in trained and untrained young male rats. Arch Biochem Biophys 1996; 331: 63-8.

[54] Ogawa S, Gerlach H, Esposito C, PasagianMacaulay A, Brett J, Stern D. Hypoxia modulates the barrier and coagulant function of cultured bovine endothelium. Increased monolayer permeability and induction of procoagulant properties. J Clin Invest 1990; 85: 1090-8. 
[55] Neumayr G, Pfister R, Mitterbauer G, Maurer A, Gaenzer H, Sturm W, Hoertnagl H. Effect of the "Race Across The Alps" in elite cyclists on plasma cardiac troponins I and T. Am J Cardiol 2002; 89: 484-6.

[56] Chen Y, Serfass RC, Mackey-Bojack SM, Kelly $\mathrm{KL}$, Titus JL, Apple FS. Cardiac troponin $\mathrm{T}$ alterations in myocardium and serum of rats after stressful, prolonged intense exercise. ] Appl Physiol 2000; 88: 1749-55.

[57] Katus HA, Remppis A, Scheffold T, Diederich $\mathrm{KW}$, Kuebler W. Intracellular compartmentation of cardiac troponin $\mathrm{T}$ and its release kinetics in patients with reperfused and nonreperfused myocardial infarction. Am J Cardiol 1991; 67: 1360-7.

[58] Mair J, Thome-Kromer B, Wagner I, Lechleitner $P$, Dienstl $F$, Puschendorf $B$, Michel $G$. Concentration time courses of troponin and myosin subunits after acute myocardial infarction. Coron Artery Dis 1994; 5: 865-72.

[59] Leal-Cerro A, Garcia-Luna PP, Astorga R, Parejo J, Peino R, Dieguez C, Casanueva FF. Serum leptin levels in male marathon athletes before and after the marathon run. J Clin Endocrinol Metab 1998; 83: 2376-9.

[60] Pastene J, Germain M, Allevard AM, Gharib C, Lacour JR. Water balance during and after marathon running. Eur J Appl Physiol Occup Physiol 1996; 73: 49-55.

[61] Herrmann M, Scharhag J, Miclea M, Urhausen A, Herrmann W, Kindermann W. Post-race kinetics of cardiac troponin $\mathrm{T}$ and $\mathrm{I}$ and $\mathrm{N}$-terminal probrain natriuretic peptide in marathon runners. Clin Chem 2003; 49: 831-4.

[62] Denvir MA, Galloway PJ, Meighan AS, Blyth M, Alexander C, Fleming $C$, Frame F. Changes in skeletal and cardiac muscle enzymes during the Scottish Coast to Coast Triathlon. Scott Med J 1999; 44: 49-51.

[63] Madsen LH, Christensen G, Lund T, Serebruany VL, Granger CB, Hoen I, Grieg Z, Alexander JH, Jaffe AS, Van Eyk JE, Atar D. Time Course of Degradation of Cardiac Troponin I in Patients With Acute ST-Elevation Myocardial Infarction. The ASSENT-2 Troponin Substudy. Circ Res 2006; 99: 1141-7.

[64] Labugger R, Organ L, Collier C, Atar D, Van Eyk JE. Extensive troponin $\mathrm{I}$ and $\mathrm{T}$ modification detected in serum from patients with acute myocardial infarction. Circulation 2000; 102: 1221-6.

[65] Narolska NA, Piroddi N, Belus A, Boontje NM, Scellini B, Deppermann S, Zaremba R, Musters RJ, dos Remedios C, Jaquet K, Foster DB, Murphy AM, van Eyk JE, Tesi C, Poggesi C, van der Velden J, Stienen GJ. Impaired diastolic function after exchange of endogenous troponin I with C-terminal truncated troponin I in human cardiac muscle. Circ Res 2006; 99: 1012-20.

[66] Rowe WJ. Extraordinary unremitting endurance exercise and permanent injury to normal heart. Lancet 1992; 340: 712-4.

[67] Welsh RC, Warburton DE, Humen DP, Taylor DA, McGavock J, Haykowsky MJ. Prolonged strenuous exercise alters the cardiovascular response to dobutamine stimulation in male athletes. J Physiol 2005; 569: 325-30.
[68] Neilan TG, Januzzi JL, Lee-Lewandrowski E, Ton-Nu TT, Yoerger DM, Jassal DS, Lewandrowski KB, Siegel AJ, Marshall JE, Douglas PS, Lawlor D, Picard MH, Wood MJ. Myocardial injury and ventricular dysfunction related to training levels among nonelite participants in the Boston marathon. Circulation 2006; 114: 2325-33.

[69] Thompson PD, Apple FS, Wu AH. Marathoner's heart? Circulation 2006; 114: 2306-8.

[70] Assmann G, Schulte H. The Prospective Cardiovascular Munster (PROCAM) study: prevalence of hyperlipidemia in persons with hypertension and/or diabetes mellitus and the relationship to coronary heart disease. Am Heart J 1988; 116: 1713-24.

[71] Januzzi JL, Jr., Camargo CA, Anwaruddin S, Baggish $A L$, Chen AA, Krauser DG, Tung $R$ Cameron R, Nagurney JT, Chae CU, Lloyd-Jones DM, Brown DF, Foran-Melanson S, Sluss PM, Lee-Lewandrowski $\mathrm{E}$, Lewandrowski KB. The Nterminal Pro-BNP investigation of dyspnea in the emergency department (PRIDE) study. Am J Cardiol 2005; 95: 948-54.

[72] Collinson PO, Gaze DC, Morris F, Morris B, Price A, Goodacre S. Comparison of biomarker strategies for rapid rule out of myocardial infarction in the emergency department using ACC/ESC diagnostic criteria. Ann Clin Biochem 2006; 43: 273-80.

[73] Mair J, Wohlfarter T, Koller A, Mayr M, ArtnerDworzak E, Puschendorf B. Serum cardiac troponin $\mathrm{T}$ after extraordinary endurance exercise. Lancet 1992; 340: 1048.

[74] Koller A, Mair J, Mayr M, Calzolari C, Larue C, Puschendorf $B$. Diagnosis of myocardial injury in marathon runners. Ann N Y Acad Sci 1995; 752: 234-5.

[75] Siegel AJ, Lewandrowski KB, Strauss HW, Fischman AJ, Yasuda T. Normal post-race antimyosin myocardial scintigraphy in asymptomatic marathon runners with elevated serum creatine kinase $M B$ isoenzyme and troponin $\mathrm{T}$ levels. Evidence against silent myocardial cell necrosis. Cardiology 1995; 86: 451-6.

[76] Bonetti A, Tirelli F, Albertini R, Monica C, Monica $M$, Tredici G. Serum cardiac troponin $T$ after repeated endurance exercise events. Int J Sports Med 1996; 17: 259-62.

[77] Laslett L, Eisenbud E, Lind R. Evidence of myocardial injury during prolonged strenuous exercise. Am J Cardiol 1996; 78: 488-90.

[78] Musha H, Nagashima J, Awaya T, Oomiya K, Takada H, Murayama M. Myocardial injury in a 100-km ultramarathon. CURR THER RES 1997; 58: 587-93.

[79] Mair J, Schobersberger W, Koller A, Bialk P, Villiger B, Frey W, Puschendorf B. Risk for exercise-induced myocardial injury for athletes performing prolonged strenuous endurance exercise. Am J Cardiol 1997; 80: 543-4.

[80] Laslett L, Eisenbud E. Lack of detection of myocardial injury during competitive races of 100 miles lasting 18 to 30 hours. Am J Cardiol 1997; 80: 379-80. 
[81] Siegel AJ, Sholar M, Yang J, Dhanak E, Lewandrowski KB. Elevated serum cardiac markers in asymptomatic marathon runners after competition: is the myocardium stunned? Cardiology 1997; 88: 487-91.

[82] Koller A, Mair J, Schobersberger W, Wohlfarter T, Haid C, Mayr M, Villiger B, Frey W, Puschendorf $B$. Effects of prolonged strenuous endurance exercise on plasma myosin heavy chain fragments and other muscular proteins. Cycling vs running. J Sports Med Phys Fitness 1998; 38: 10-7.

[83] Lucia A, Serratosa L, Saborido A, Pardo J, Boraita A, Moran M, Bandres F, Megias A, Chicharro JL. Short-term effects of marathon running: no evidence of cardiac dysfunction. Med Sci Sports Exerc 1999; 31: 1414-21.

[84] Rifai N, Douglas PS, O'Toole M, Rimm E, Ginsburg GS. Cardiac troponin $\mathrm{T}$ and $\mathrm{I}_{\text {, }}$ echocardiographic [correction of electrocardiographic] wall motion analyses, and ejection fractions in athletes participating in the Hawaii Ironman Triathlon. Am J Cardiol 1999; 83: $1085-9$.

[85] Koller A, Summer P, Moser H. Regular exercise and subclinical myocardial injury during prolonged aerobic exercise. Jama 1999; 282: 1816.

[86] Nagashima J, Musha H, Takada H, Ohmiya K, Awaya $T$, Oba $H$, Nobuoka $S$, Murayama M. Myocardial injury after an ultramarathon: echocardiographic assessment during isometric exercise and serum cardiac troponin T level. Int J Sports Cardiol 1999; 8: 77-82.

[87] Whyte GP, George K, Sharma S, Lumley S, Gates P, Prasad K, McKenna WJ. Cardiac fatigue following prolonged endurance exercise of differing distances. Med Sci Sports Exerc 2000; 32: 1067-72.

[88] Ohba $H$, Takada $H$, Musha $H$, Nagashima J, Mori $\mathrm{N}$, Awaya T, Omiya K, Murayama M. Effects of prolonged strenuous exercise on plasma levels of atrial natriuretic peptide and brain natriuretic peptide in healthy men. Am Heart J 2001; 141: 751-8.

[89] Cleave P, Boswell TD, Speedy DB, Boswell DR. Plasma cardiac troponin concentrations after extreme exercise. Clin Chem 2001; 47: 608-10.

[90] Koller A, Mertelseder S, Moser H. Is exerciseinduced myocardial injury self-abating? Med Sci Sports Exerc 2001; 33: 850-1.

[91] Shave R, Dawson E, Whyte G, George K, ball D. Markers of cardiac damage after 2 days of prolonged endurance exercise. J Sport Sci 2002; 20: 58.

[92] Shave RE, Dawson E, Whyte G, George K, Ball D, Gaze DC, Collinson PO. Evidence of exerciseinduced cardiac dysfunction and elevated CTnT in separate cohorts competing in an ultraendurance mountain marathon race. Int ] Sports Med 2002; 23: 489-94.

[93] Apple FS, Quist HE, Otto AP, Mathews WE, Murakami MM. Release characteristics of cardiac biomarkers and ischemia-modified albumin as measured by the albumin cobalt-binding test after a marathon race. Clin Chem 2002; 48: 1097-100.
[94] Konig D, Schumacher YO, Heinrich L, Schmid A, Berg A, Dickhuth HH. Myocardial stress after competitive exercise in professional road cyclists. Med Sci Sports Exerc 2003; 35: 167983.

[95] Urhausen A, Scharhag J, Herrmann M, Kindermann W. Clinical significance of increased cardiac troponins $\mathrm{T}$ and $\mathrm{I}$ in participants of ultra-endurance events. Am J Cardiol 2004; 94: 696-8.

[96] Shave RE, Dawson E, Whyte G, George K, Gaze $D$, Collinson P. Effect of prolonged exercise in a hypoxic environment on cardiac function and cardiac troponin $\mathrm{T}$. Br J Sports Med 2004; 38: 86-8.

[97] Shave R, Dawson E, Whyte G, George K, Nimmo M, Layden J, Collinson P, Gaze D. The impact of prolonged exercise in a cold environment upon cardiac function. Med Sc Sports Exerc 2004; 36: 1522-7.

[98] Dawson EA, Shave R, George K, Whyte G, Ball D, Gaze D, Collinson P. Cardiac drift during prolonged exercise with echocardiographic evidence of reduced diastolic function of the heart. Eur J Appl Physiol 2005; 94: 305-9.

[99] Whyte G, George K, Shave R, Dawson E, Stephenson C, Edwards B, Gaze D, Oxborough $D$, Forster J, Simspon R. Impact of marathon running on cardiac structure and function in recreational runners. Clin Sci (Lond) 2005; 108: 73-80.

[100] George K, Oxborough D, Forster J, Whyte G, Shave R, Dawson E, Stephenson C, Dugdill L, Edwards B, Gaze D. Mitral annular myocardial velocity assessment of segmental left ventricular diastolic function after prolonged exercise in humans. J Physiol 2005; 569: 30513.

[101] Tulloh L, Robinson D, Patel A, Ware A Prendergast C, Sullivan D, Pressley L. Raised troponin $\mathrm{T}$ and echocardiographic abnormalities after prolonged strenuous exercise--the Australian Ironman Triathlon. $\mathrm{Br}$ J Sports Med 2006; 40: 605-9.

[102] Middleton N, Shave R, George K, Whyte G, Forster J, Oxborough D, Gaze D, Collinson P. Novel application of flow propagation velocity and ischaemia-modified albumin in analysis of postexercise cardiac function in man. Exp Physiol 2006; 91: 511-9.

[103] Tian Y, Nie J, Tong TK, Cao J, Gao Q, Man J, Shi $\mathrm{Q}$, Liu W. Changes in serum cardiac troponins following a 21-km run in junior male runners. J Sports Med Phys Fitness 2006; 46: 481-8.

[104] Scharhag J, Urhausen A, Schneider G, Herrmann $M$, Schumacher $K$, Haschke $M$, Krieg A, Meyer T, Herrmann W, Kindermann W. Reproducibility and clinical significance of exercise-induced increases in cardiac troponins and $\mathrm{N}$-terminal pro brain natriuretic peptide in endurance athletes. Eur J Cardiovasc Prev Rehabil 2006; 13: 388-97. 



\title{
RELEASE KINETICS OF INTACT AND DEGRADED TROPONIN I AND T AFTER IRREVERSIBLE CARDIOMYOCYTE DAMAGE
}

\begin{abstract}
Background. For the diagnosis of acute myocardial infarction (AMI) activity assays of enzymes like lactate dehydrogenase (LDH) and creatine kinase (CK) have been replaced by mass assays of CK-MB, cardiac troponin I (cTnI) and cardiac troponin T (cTnT). This study characterized whether the release kinetics of cardiac troponin I (cTnI) and T (cTnT) differ from each other in cardiomyocytes before and after the transition from reversible to irreversible cell damage, as assessed by the release of lactate dehydrogenase (LDH).
\end{abstract}

Methods. Cultures of cardiomyocytes were exposed to metabolic inhibition by treatment with sodium azide $(1 \mathrm{mmol} / \mathrm{L})$ to induce a necrotic cell death process that is characterized by a reversible $(0-12 \mathrm{~h})$ and irreversible phase $(12-30 \mathrm{~h})$. At various time intervals cells and media were collected and analyzed for LDH activity, intact CTnI and CTnT, and their degradation products.

Results. During the first $12 \mathrm{~h}$ of metabolic inhibition, cell viability was unchanged with no release of intact CTnI and cTnT nor their degradation products. Between 12 and $30 \mathrm{~h}$ of azide treatment, cardiomyocytes showed progressive cell death accompanied by release of intact cTnI (29 kDa), intact cTnT (39 kDa), four cTnI degradation products of 26, 20, 17 and $12 \mathrm{kDa}$, and three cTnT degradation products of 37, 27 and $14 \mathrm{kDa}$. Possibly due to degradation, there is progressive loss of cTnI and cTnT protein that is obviously undetected by the antibodies used.

Conclusions. Mild metabolic inhibition of cardiomyocytes induces a parallel release of intact cTnI and cTnT and their degradation products, starting only after onset of irreversible cardiomyocyte damage.

Submitted for publication. 


\section{INTRODUCTION}

Cardiac troponin I and T (cTnI and CTnT) are highly sensitive and specific markers of myocardial injury in patients with acute myocardial infarction (AMI) ${ }^{1,2}$ Within a few hours after onset of AMI, troponins are released from necrotic cardiomyocytes into the circulation. Typically, troponin levels peak at 16-18 $\mathrm{h}$, and remain elevated for several weeks after AMI, long after levels of most other markers have normalized. ${ }^{1,3,4}$ Despite the high cardiac specificity, several studies have demonstrated that the appearance of troponins in serum of patients with AMI is delayed compared with the release of CK$\mathrm{MB}_{\text {activity }}$ and $\mathrm{CK}-\mathrm{MB}_{\text {mass }}{ }^{5-8}$ suggesting that troponins and $\mathrm{CK}-\mathrm{MB}$ do not share identical release kinetics, and that troponins may not be ideal early markers for ruling out AMI. Previously, we investigated the release kinetics of intact cTnI and lactate dehydrogenase (LDH) from cultured neonatal cardiomyocytes exposed to severe metabolic inhibition using sodium cyanide, which induces necrosis over a time period of 3-3.5 hours. ${ }^{9}$ We found that the release of intact CTnI from irreversibly damaged cardiomyocytes was partial and delayed as compared with the release of LDH. This delay can theoretically be explained by (1) slow dissociation of cTnI molecules from the myofilaments as only $3-8 \%$ of $\mathrm{cTnI}$ is free in the cytoplasmic pool, ${ }^{10}$ or (2) the early formation of CTnI degradation products that remained undetected by the specific ELISA that is used, as detection of CTnI degradation products is antibody dependent. ${ }^{11,12}$ Troponins are susceptible to proteolytic degradation by intracellular proteases, such as calpain-I, caspases, or matrix metalloproteinase-2 (MMP-2). ${ }^{13-16}$ Degradation products of troponins are detected in serum of patients with AMI, and the release pattern of these degradation products changes in the days following onset of AMI. ${ }^{14,17-19}$

In addition to troponin degradation during irreversible cell damage, several studies have suggested that proteolysis of troponin may also occur in reversibly damaged cardiomyocytes. ${ }^{20-22}$

In the present study we investigated the release kinetics of cardiac troponins from cultured neonatal cardiomyocytes undergoing metabolic inhibition by sodium azide. Azide is an inhibitor of cytochrome $c$ oxidase and induces cell death that, at $1 \mathrm{mmol} / \mathrm{L}$, develops slower compared to cyanide at 5-10 $\mathrm{mmol} / \mathrm{L}$. Chen et al. have demonstrated that cultured neonatal rat cardiomyocytes exposed to azide showed a transition from reversible to irreversible cell damage after 6-12 hours. ${ }^{23}$ The purpose of the present study was to characterize the release kinetics of intact CTnI, intact CTnT, and degradation products of $\mathrm{CTnI}$ and $\mathrm{CTnT}$, in relation to $\mathrm{LDH}$, the golden standard for cell death, from azide-treated cardiomyocytes before and after the transition from reversible to irreversible cell damage.

\section{Methods}

\section{Primary cultures of neonatal cardiomyocytes}

Primary cultures of cardiomyocytes were prepared from the ventricles of 2-day old Wistar rats as described previously. ${ }^{24}$ Briefly, ventricles were minced and cells were isolated enzymatically using collagenase type I (CLS, Worthington, Lakewood, NJ, USA) at $37^{\circ} \mathrm{C}$. The cell suspension was centrifuged and the cell pellet was resuspended in growth medium. Cells were seeded in Primaria ${ }^{\circledR}$-coated plastic culture dishes ( $\varnothing 6.0 \mathrm{~cm}$, Falcon, Becton Dickinson, Etten-Leur, The Netherlands), and after $45 \mathrm{~min}$ non-adherent cells, i.e. the cardiomyocytes, were collected and plated in Primaria ${ }^{\circledR}$-coated plastic 
culture dishes at a density of $\approx 3 \times 10^{6}$ cells per well. Cardiomyocytes were incubated in a humidified incubator at $37^{\circ} \mathrm{C}$ and $5 \% \mathrm{CO}_{2}$ and culture medium was refreshed after $20 \mathrm{~h}$ and $48 \mathrm{~h}$. After three days, a monolayer of spontaneously beating cardiomyocytes had formed. The investigations had the approval of the Animal Experiments Committee of the LUMC, according to Dutch law.

\section{Metabolic inhibition of cardiomyocytes}

Three days after isolation, cardiomyocyte cultures were washed in HEPES-buffered salt solution (HBSS), containing (in mmol/L) $\mathrm{NaCl}(125), \mathrm{KCl}$ (5), $\mathrm{MgSO}_{4}$ (1), $\mathrm{KH}_{2} \mathrm{PO}_{4}$ (1), $\mathrm{CaCl}_{2}$ (2.5), $\mathrm{NaHCO}_{3}$ (10), sodium pyruvate (5), and HEPES (20), pH 7.4 at $37^{\circ} \mathrm{C}$. In each experiment, six cultures of neonatal rat ventricular myocytes were exposed to metabolic inhibition by incubation in $3 \mathrm{~mL}$ HBSS containing sodium azide ( $1 \mathrm{mmol} / \mathrm{L})$ for $0,6,12,18,24$ and $30 \mathrm{~h}$ at $37^{\circ} \mathrm{C}$.

At the end of a period of metabolic inhibition, medium was separated from the cells, cells were collected in $1.5 \mathrm{ml}$ ice-cold lysis buffer containing (in mmol/L) Tris- $\mathrm{HCl}$ (20), $\mathrm{NaCl}(100)$, EDTA (5), 1\% (v/v) Triton X-100, and $10 \%(\mathrm{v} / \mathrm{v})$ glycerol, $\mathrm{pH} 7.5$, and both cell and medium samples were kept on ice awaiting assay of LDH activity at the same day. Aliquots of cell and medium samples were stored at $20^{\circ} \mathrm{C}$ until cTnI and cTnT assays.

\section{LDH activity assay}

Necrotic cell death was quantified by assay of LDH activity released from cells into medium, according to Wroblewski and Ladue. ${ }^{25}$ After various periods of metabolic inhibition ( 0 to $30 \mathrm{~h}$ ), LDH activities in medium and cell samples were determined using a spectrophotometer (Ultrospec 3000, Pharmacia, Roosendaal, The Netherlands) at $25^{\circ} \mathrm{C}$. Per culture tested, the $\mathrm{LDH}$ activities in medium and cell extract were calculated after volume correction. The percentage activity of LDH released from each culture was $\left[\mathrm{LDH}_{\text {medium }} /\left(\mathrm{LHD}_{\text {medium }}+\mathrm{LDH}_{\text {cells }}\right)\right] \times 100 \%$. The detection limit of the LDH assay was $5 \mathrm{U} / \mathrm{L}$. Inter-assay variability was $12 \%$ at $\mathrm{LDH}$ activity of $110 \mathrm{U} / \mathrm{L}$. The intra-assay variability was $3 \%$ and $6 \%$ at $\mathrm{LDH}$ activity of $110 \mathrm{U} / \mathrm{L}$ and $48 \mathrm{U} / \mathrm{L}$, respectively.

\section{Troponin-I ELISA}

Purified human heart cTnI (Calbiochem, LaJolla, CA, USA) was dissolved in urea/Tris buffer according to the manufacturer's instructions. Monoclonal mouse anti-cTnI clone $19 \mathrm{C7}$ (recognizing amino acid residues (a.a.r.) 40-50) and monoclonal mouse anti-cTnI clone 6F9 (recognizing a.a.r. 189-195) were purchased from HyTest (Turku, Finland). The ELISA was based on the sandwich principle as described previously. $^{9}$ The percentage $\mathrm{CTnI}$ released from each culture equalled $\left[\mathrm{TnI}_{\text {medium }} /\left(\mathrm{TnI}_{\text {medium }}+\right.\right.$ $\left.\left.\mathrm{TnI}_{\text {cells }}\right)\right]^{* 100 \%}$. The detection limit of the assay was $6 \mu \mathrm{g} / \mathrm{L}$. Inter-assay variability was $6 \%$ and $10 \%$, at cTnI concentrations of $200 \mu \mathrm{g} / \mathrm{L}$ and $25 \mu \mathrm{g} / \mathrm{L}$, respectively. The intra-assay variability was $6 \%$ at TnI concentration of $100 \mu \mathrm{g} / \mathrm{L}$.

\section{Detection of troponin-I degradation products in autolytic myocardium and medium}

\section{Testing the antibody}

The detection of intact cTnI and cTnI degradation products is antibody dependent. ${ }^{11,12,26}$ Therefore we tested whether cTnI degradation products in rat heart tissue undergoing ischemic autolysis could be 
detected by a specific anti-cTnI antibody (clone K83085G, Biodesign, Saco, Maine, USA) recognizing a.a.r. 27-40. Hearts from anesthetized 2-day old Wistar male rats were rapidly dissected, and washed in a solution containing (in mmol/L) $\mathrm{NaCl}(137), \mathrm{KCl}(5.4), \mathrm{Na}_{2} \mathrm{HPO}_{4}(0.34), \mathrm{KH}_{2} \mathrm{PO}_{4}(0.44)$, D-glucose (5.6), HEPES (20), and $0.02 \%$ Phenol Red, $\mathrm{pH} 7.4$. Subsequently, ventricular myocardium (46 $\pm 7 \mathrm{mg}$ tissue) was incubated for $0,2,4,6,8$ and $10 \mathrm{~h}$ in a petri dish $(\varnothing 1.5 \mathrm{~cm})$ that was placed into another petri dish $(\varnothing 3.5 \mathrm{~cm})$ containing water at $37^{\circ} \mathrm{C}$. After incubation, cardiac tissue was snap-frozen in liquid nitrogen, freeze-dried for at least $24 \mathrm{~h}$, and homogenized in a buffer containing $0.1 \mathrm{~mol} / \mathrm{L}$ Tris$\mathrm{HCl}$ and $0.1 \%(\mathrm{v} / \mathrm{v})$ Tween-20 pH 7.5, using a Potter tube (Kimble/Kontes, Vineland, NJ, USA). Homogenates were stored in aliquots at $-80^{\circ} \mathrm{C}$. Protein concentrations were determined by bicinchonic acid (BCA) protein assay (Pierce, Etten-Leur, the Netherlands). In autolysing myocardium intact cTnI was detected by ELISA and Western blotting, and cTnI degradation products were detected by Western blotting.

\section{Western blotting}

Homogenates of heart tissue and medium samples of control and azide-treated cardiomyocyte cultures (10x concentrated by freeze-drying for $18 \mathrm{~h}$ ) were size-fractionated on NuPage Novex $12 \%$ Bis-Tris gels (Invitrogen) and transferred to Hybond PVDF membranes (Amersham Biosciences, Roosendaal, The Netherlands). After blocking non-specific binding sites, membranes were incubated for $1 \mathrm{~h}$ with the anti-TnI antibody (K83085G, Biodesign), recognizing a.a.r. 27-40, and for $1 \mathrm{~h}$ with the horseradish peroxidase-labelled secondary antibody (rabbit anti-goat IgG, Santa Cruz Biotechnology, Heidelberg, Germany). Chemiluminescence was induced by ECL Advance Detection reagent (Amersham Biosciences) and detected by exposure to Hyperfilm ECL (Amersham Biosciences).

\section{Troponin-T assay}

cTnT concentrations in cell and medium samples of control and azide-treated cardiomyocytes were measured using the Elecsys 2010 (fourth-generation troponin-T test, Roche, Mannheim, Germany). Monoclonal human anti-cTnT clone M11.7 (recognizing a.a.r. 136-147) and monoclonal human anticTnT clone M7 (recognizing a.a.r. 125-131) purchased from Hytest were used as capture and detection antibody, respectively. The detection limit for human CTnI in serum is $0.01 \mu \mathrm{g} / \mathrm{L}$. The inter-assay variability was $8 \%$ and $7 \%$ at concentrations of $0.134 \mu \mathrm{g} / \mathrm{L}$ and $2.85 \mu \mathrm{g} / \mathrm{L}$, respectively $(n=89)$.

\section{Detection of troponin-T degradation products}

Intact cTnT and its degradation products in medium samples of control and azide-treated cardiomyocytes were detected by a novel immunoprecipitation assay. ${ }^{27,} 28$ Briefly, a mixture of four anti-cTnT antibodies (clones 9G6, 7F4, 7A9, and 1C11, a kind gift from Hytest) recognizing specific epitopes throughout the CTnT molecule were used to detect as many degradation products as possible. These antibodies were covalently immobilized on protein-A sepharose (GE Healthcare Europe, Diegem, Belgium) using dimethylpimelimidate (DMP, Sigma, Zwijndrecht, The Netherlands) as a cross-linking agent. Media of cardiomyocyte cultures were incubated with the sepharose beads to extract cTnT and its degradation products. Next, the beads were washed and incubated in sample buffer (40 mmol/L Tris, $33 \mathrm{~g} / \mathrm{L}$ sodium dodecyl sulphate (SDS), $500 \mathrm{~mL} / \mathrm{L}$ glycerol, and bromophenol blue). Samples were separated by SDS-PAGE on a Tris- $\mathrm{HCl} 4-15 \%$ polyacrylamide gradient gel (BioRad, Veenendaal, the Netherlands) and transferred to nitrocellulose $(0.45 \mu \mathrm{m}$, BioRad) before incubation with a mixture of 
the same monoclonal mouse anti-cTnT antibodies. A peroxidase-conjugated goat anti-mouse antibody (Dako, Glostrup, Denmark) was used for visualization by chemoluminescence (Perkin-Elmer Life Sciences, Waltham, MA, USA). Blots were captured on Kodak X-Omat blue film (Perkin-Elmer Life Sciences).

\section{Statistics}

Results are expressed as means \pm SD. Statistical analysis was performed by Student's t-test. Differences were regarded as statistically significant if $p<0.05$. SPSS14 for Windows (SPSS Inc, Chicago, IL, USA) was used for statistical analysis.

\section{Results}

\section{Detection of cardiac TnI degradation products in autolytic myocardium}

At baseline, the mean cTnI content in neonatal rat heart tissue was $0.72 \mu \mathrm{g} / \mathrm{mg}$ tissue (100\%). After 10 $\mathrm{h}$ of incubation, intact CTnI (29 kDa) was progressively reduced to $\approx 40 \%$ (Figure $6-1 \mathrm{a}$ and b), and three cTnI degradation products of 26, 24, $20 \mathrm{kDa}$ were formed (Figure 6-1b). At baseline $(\mathrm{t}=0 \mathrm{~h})$, a weak $26 \mathrm{kDa}$ band was observed, being roughly 10 times smaller than the $29 \mathrm{kDa}$ band (intact cTnI). This $26 \mathrm{kDa}$ band represents a degradation product of cTnI. The intensity of this band increased during the first $4 \mathrm{~h}$, followed by a decrease in the next $6 \mathrm{~h}$ of incubation, compatible with the formation and subsequent further degradation of a CTnI degradation product.

Table 6-1. Total LDH, intact CTnI and cTnT per cardiomyocyte culture (cells+medium) treated with azide determined at $\mathrm{t}=0,6,12,18,24$ and $30 \mathrm{~h}$ and expressed as percentage of activity or concentration present at $\mathrm{t}=0$.

\begin{tabular}{llll}
\hline Time $(\mathrm{h})$ & Total LDH $(\mathrm{n}=12)$ & Total cTnI $(\mathrm{n}=9)$ & Total cTnT $(\mathrm{n}=3)$ \\
\hline 0 & 100 & 100 & 100 \\
6 & $95 \pm 24$ & $92 \pm 21$ & $105 \pm 19$ \\
12 & $96 \pm 17$ & $74 \pm 12^{*}$ & $70 \pm 6^{*}$ \\
18 & $97 \pm 22$ & $40 \pm 26^{*}$ & $45 \pm 19^{*}$ \\
24 & $86 \pm 17^{*}$ & $34 \pm 21^{*}$ & $39 \pm 25^{*}$ \\
30 & $89 \pm 19^{*}$ & $21 \pm 7^{*}$ & $39 \pm 28^{*}$ \\
\hline
\end{tabular}

$* \mathrm{p}<0.05$ versus $\mathrm{t}=0$

\section{LDH release during metabolic inhibition}

The mean LDH activity of 10 cultures at $t=0$ was $2.00 \pm 0.43 \mathrm{U}$ per culture. When incubated in HBSS, cardiomyocytes released $\approx 15 \%$ of total LDH in $30 \mathrm{~h}$ (Figure 6-2a), which confirms previous findings of cell death of cultured cardiomyocytes in serum-free medium. ${ }^{29}$ At times 0,6 and $12 \mathrm{~h}$, release of LDH from azide-treated cardiomyocytes equalled the $\mathrm{LDH}$ release of control cardiomyocytes, indicating no cardiomyocyte necrosis in the first $12 \mathrm{~h}$. However, from 12 to $30 \mathrm{~h}$, a prominent LDH release from azide-treated cardiomyocytes (up to $90 \%$ of total LDH) was demonstrated, indicating that necrotic cell death started after $12 \mathrm{~h}$ and was nearly complete at $30 \mathrm{~h}$ (Figure 6-2a). 
A)

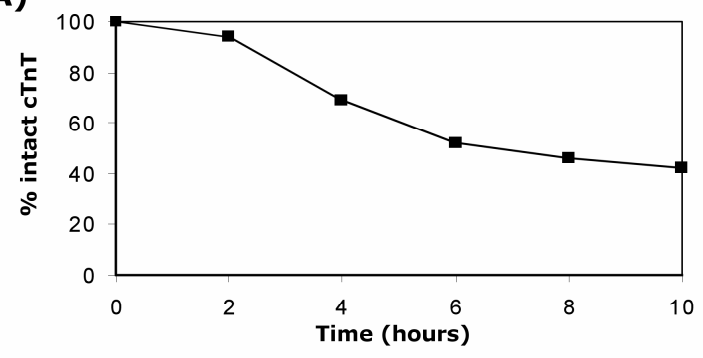

B)

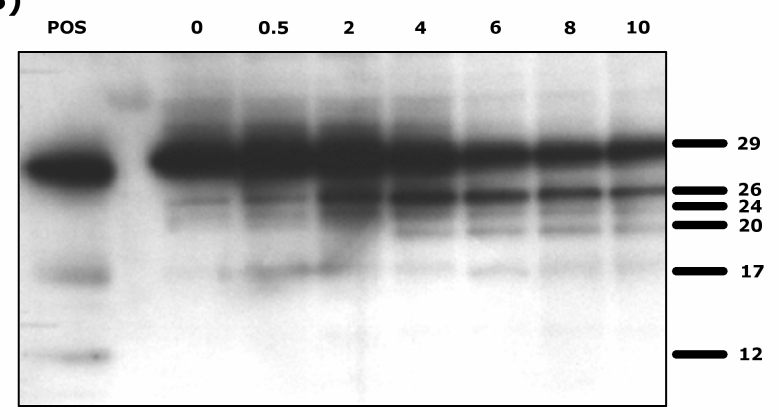

Figure 6-1. (A) Degradation of intact $\mathrm{CTnI}$ in neonatal rat heart tissue undergoing autolysis for $0-10 \mathrm{~h}$ at $37^{\circ} \mathrm{C}$, detected by ELISA. The mean CTnI content at $\mathrm{t}=0(100 \%)$ was $0.72 \mu \mathrm{g} / \mathrm{mg}$ tissue. (B) Formation of cTnI degradation products in neonatal rat heart tissue undergoing autolysis for $0-10 \mathrm{~h}$ at $37^{\circ} \mathrm{C}$, detected by Western blotting. Purified human heart CTnI was used as a positive control (POS).

\section{Release of CTnI during metabolic inhibition}

Intact cTnI assessed by ELISA. The mean content of intact cTnI in 10 cultures at $\mathrm{t}=0$ was $1.2 \pm 0.7 \mu \mathrm{g}$ per culture. Control cardiomyocytes had released $\approx 9 \%$ of total cTnI after $30 \mathrm{~h}$, which is most likely the result of cell death $(\approx 15 \%)$ when incubated for $30 \mathrm{~h}$ in serum-free medium. The release of intact cTnI from azide-treated cardiomyocytes equalled that of control cardiomyocytes at time 0, 6 and $12 \mathrm{~h}$, not exceeding 3\%. At $18 \mathrm{~h}$ of azide treatment, cTnI release started to exceed control values (Figure 6-2b). At $30 \mathrm{~h}$, cTnI release had increased to $51 \pm 16 \%$, indicating a less abundant release of intact cTnI compared with the release of LDH. Secondly, during 12-30 h of azide treatment, the total amount of intact cTnI per culture was significantly reduced compared to that at $\mathrm{t}=0(100 \%)($ Table $6-1)$. 

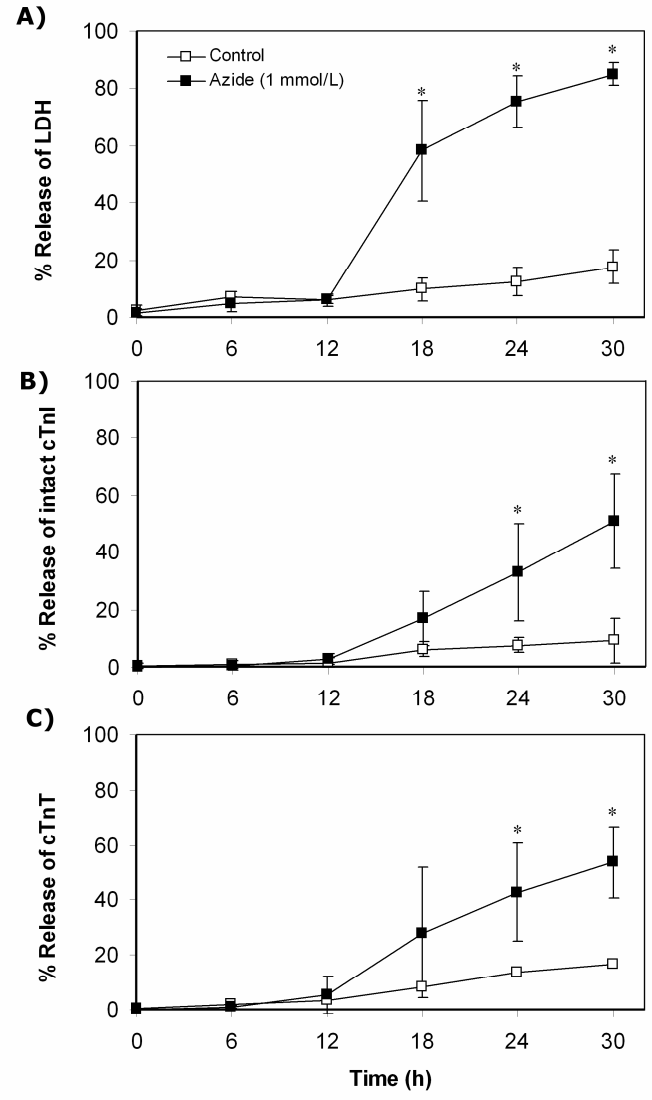

Figure 6-2. (A) Release of LDH ( $n=12)$, (b) release of intact cTnI $(n=9)$, and (C) release of $c \operatorname{TnT}(n=3)$ from control and azide-treated $(1 \mathrm{mmol} / \mathrm{L})$ cardiomyocytes between 0 and $30 \mathrm{~h}$. At $\mathrm{t}=0(100 \%)$, the mean content of LDH, cTnI and cTnT was $2.00 \pm 0.34 \mathrm{U} /$ culture, $1.2 \pm 0.7 \mu \mathrm{g}$ /culture, and $0.23 \pm 0.08 \mu \mathrm{g} /$ culture, respectively. Control cardiomyocytes are indicated by $\square$ and azide-treated cardiomyocytes by $\mathbf{m}$. $* 0<0.05$ versus control.

\section{cTnI degradation products assessed by western blotting}

To investigate whether a less abundant release of intact cTnI compared with that of LDH can be explained by the early formation of undetected cTnI degradation products, cTnI degradation products from control and azide-treated cardiomyocytes were studied by Western blotting (Figure 6-3a). In the first $12 \mathrm{~h}$, only a relatively low quantity of intact cTnI was released that is consistent with the ELISA results. This intact cTnI is probably derived from the small proportion of necrotic cells (6-7\%) in serumfree medium, as this band is also observed in medium of control cardiomyocytes (Figure 6-3a). At $18 \mathrm{~h}$, the intensity of intact cTnI (29 kDa) released from azide-treated cardiomyocytes had increased progressively and was accompanied by release of a $26 \mathrm{kDa}$ band, indicating cTnI degradation (Figure 63a). Enhanced degradation of CTnI was demonstrated at 24 and $30 \mathrm{~h}$. In total four degradation 


\section{Chapter 6}

products of 26, 20, 17 and $12 \mathrm{kDa}$ were detected in medium of azide-treated cardiomyocytes, and only after extensive cell death. In cell extracts of azide-treated cardiomyocytes, no degradation products of cTnI were detected during metabolic inhibition (data not shown).

Figure 6-3. (A) Western blot of intact CTnI (29 kDa) and its degradation products in medium of control (LEFT) and
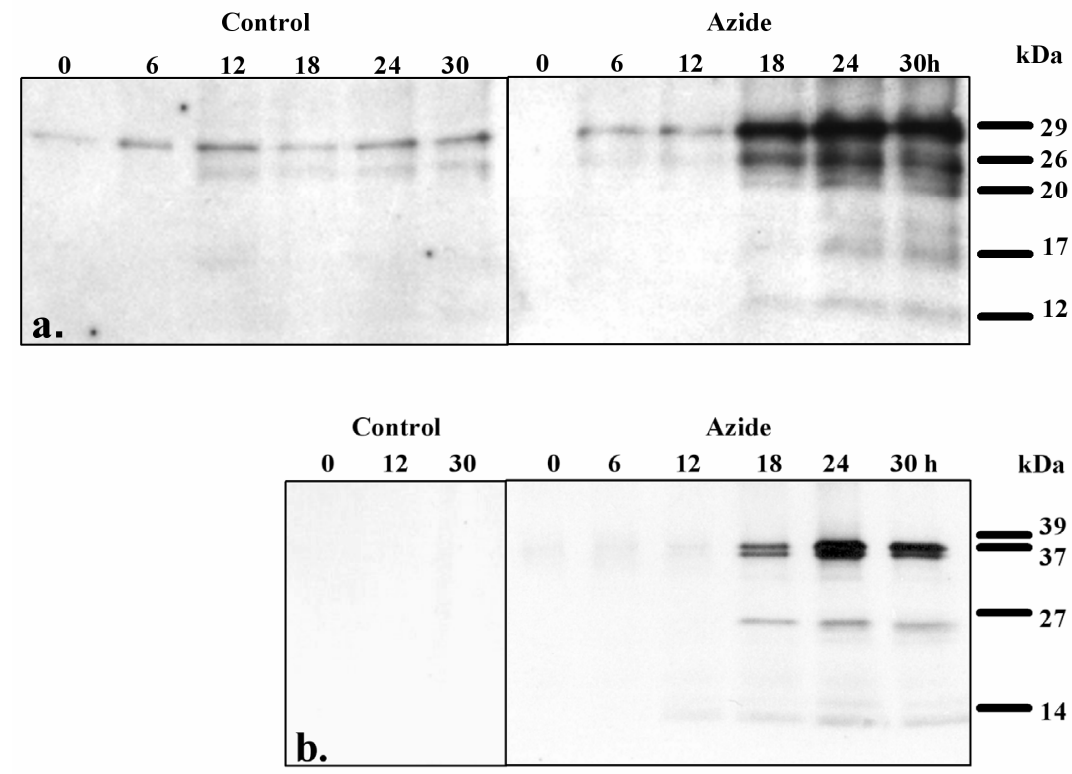

azide-treated cardiomyocytes (right). (B) Western blot of intact CTnT (39 kDa) and its degradation products in medium of control (left) and azide-treated cardiomyocytes (right).

\section{Release of cTnT during metabolic inhibition}

\section{cTnT assessed by immunoassay}

The mean content of $\mathrm{cTnT}$ in five cultures at $\mathrm{t}=0$ was $0.23 \pm 0.08 \mu \mathrm{g}$ per culture. Control cardiomyocytes had released $\approx 16 \%$ of cTnT after $30 \mathrm{~h}$ in serum free-medium. The release of cTnT from azide-treated cardiomyocytes equalled that of control cardiomyocytes at 0, 6, and $12 \mathrm{~h}$, not exceeding $5 \%$. At $18 \mathrm{~h}$ of azide treatment, cTnT release exceeded control values (Figure 6-2c). At $30 \mathrm{~h}, \mathrm{cTnT}$ release had increased to $54 \pm 13 \%$, which is comparable with the release of cTnI and less abundant compared to that of LDH. During 12-30 h of azide treatment also the total amount of cTnT per culture was significantly reduced compared with that at $\mathrm{t}=0(100 \%)($ Table $6-1)$.

\section{cTnT degradation products assessed by western blotting}

In medium of control cardiomyocytes no intact or degraded cTnT was detected between 0 and $30 \mathrm{~h}$ (Figure 6-3b). In medium of azide-treated cardiomyocytes, no intact or degraded cTnT was detected in the first $12 \mathrm{~h}$, but at $18 \mathrm{~h}$ and later, release of intact cTnT (39 kDa) was observed and the intensity of this band increased after 24 and $30 \mathrm{~h}$ (Figure 6-3b). In total three cTnT degradation products of 37, 27, and $14 \mathrm{kDa}$ were detected and only after extensive cell death. In cell extracts of azide-treated 
cardiomyocytes, no degradation products of cTnT were observed during metabolic inhibition (data not shown).

\section{Discussion}

The main findings of the present study are (1) release of cTnI or cTnT from energy-deprived cardiomyocytes does not occur before necrosis sets in, (2) cTnI and cTnT from necrotic cardiomyocytes are both released as intact protein and as degradation products, (3) the release kinetics of cTnI and cTnT from necrotic cardiomyocytes are comparable, and (4) the percentage release of troponins from necrotic cardiomyocytes remained lower than the percentage release of LDH.

Myocardial ischemia causes extensive proteolytic damage to the myocardium and the plasma concentrations of cardiac proteins are used as biochemical markers of cardiac injury. Proteins released upon cardiac necrosis include $\mathrm{LDH}^{25}$ a-hydroxybutyrate dehydrogenase (aHBDH), ${ }^{30} \mathrm{CK}^{31}$ the $\mathrm{MB}$ isoenzyme of $\mathrm{CK}(\mathrm{CK}-\mathrm{MB}),{ }^{32} \mathrm{CTnI}^{2}$ and $\mathrm{CTnT},{ }^{1}$ and these biochemical markers differ in sensitivity and specificity and vary in release kinetics. ${ }^{33,34} \mathrm{LDH}, \mathrm{aHBDH}$ and $\mathrm{CK}$ are predominantly cytosolic proteins and not cardiac specific. Both troponins are highly cardiac specific and are bound, via tropomyosin, to actin filaments of sarcomeres, whereas only a small proportion of cTnT (6-8\%) and cTnI (3-8\%) is found in the soluble cytoplasmic pool. ${ }^{10}$

Several studies have reported that the release of cTnI and CTnT in plasma of patients with AMI starts later than the release of $\mathrm{CK}-\mathrm{MB}^{5-8}$ suggesting that troponins are not ideal early markers for ruling out AMI. Vice versa, other studies have suggested that troponin release may also occur from reversibly damaged cardiomyocytes before necrosis sets in. ${ }^{20-22}$ Elevated troponin levels have been observed in patients without coronary syndromes who had normal CK-MB mass or CK-MBactivity levels, ${ }^{35,} 36$ indicating that under particular conditions circulating troponins may be present in the absence of necrotic cardiomyocyte death.

The present study demonstrates that the first $12 \mathrm{~h}$ of mild metabolic inhibition did not cause necrosis. A sharp decline in cell viability was observed between 12 and $18 \mathrm{~h}$ and extensive cell death was demonstrated at 24 and $30 \mathrm{~h}$. These results are consistent with a previous study of Chen et al., who defined the first 6-12 $\mathrm{h}$ of azide treatment $(1 \mathrm{mmol} / \mathrm{L})$ as a reversible phase, because wash-off experiments revealed that cardiomyocytes could regain full viability if azide was removed within the first $12 \mathrm{~h}$. The reversible phase was followed by an irreversible phase $(12-30 \mathrm{~h})$ with progressive cell death. ${ }^{23}$

Release of both intact and degraded cTnI or cTnT did not occur from reversibly damaged cardiomyocytes (0-12 h), but was associated with irreversible cell damage at $\mathrm{t} \geq 18 \mathrm{~h}$ (Figs. 2 and 3 ). The release of intact cTnI and cTnT from necrotic cardiomyocytes was accompanied by the release of several degradation products (Figure 6-3). Four degradation products of cTnI (26, 20, 17 and 12kDa) and three degradation products of $\mathrm{CTnT}(37,27$ and $14 \mathrm{kDa}$ ) were observed when cardiomyocytes became irreversibly damaged. These results are in contrast with results reported by Kositprapa et al., who showed that metabolic inhibition of neonatal cardiomyocytes by azide treatment ( $1 \mathrm{mmol} / \mathrm{L})$ caused degradation of CTnI in irreversibly damaged cardiomyocytes, whereas cTnT remained unaffected. ${ }^{37}$ The discrepancy between Kositprapa's results and ours may be explained by the use of different cTnT antibodies. In the present study we used an immunoprecipitation method and western 
blotting with several cTnT antibodies that recognized specified epitopes throughout the cTnT molecule to detect as many degradation products as possible, whereas Kositprapa et al. detected cTnT with only one cTnT antibody. ${ }^{37}$

In the present study, release of intact cTnI and CTnT from irreversibly damaged cardiomyocytes showed similar kinetics (Figure 6-2b and Figure 6-2c). Nevertheless, the release of LDH from cardiomyocytes that become necrotic is more pronounced than the release of both troponins during 12-30 $\mathrm{h}$ azidetreatment (Figure 6-2). The quantity of LDH released at $18 \mathrm{~h}$ was $\approx 60 \%$, whereas the quantity of intact CTnI and CTnT was $18-28 \%$. After $30 \mathrm{~h}$, a maximal LDH release of $\approx 90 \%$ was associated with a CTnI and CTnT release of $50-55 \%$, and these results confirmed our previous study. ${ }^{9}$ Although azide-treatment (1 $\mathrm{mmol} / \mathrm{L})$ is less severe than metabolic inhibition induced by cyanide $(5-10 \mathrm{mmol} / \mathrm{L}), 3 \mathrm{~h}$ of cyanide treatment resulted in a maximal LDH release $(80-90 \%)^{9,38}$ that was also associated with a cTnI release of $\approx 50 \%{ }^{9}$

The mean content of total $\mathrm{CTnI}$ at $\mathrm{t}=0$ was $1.2 \pm 0.7 \mu \mathrm{g}$ per culture, whereas the mean content of $\mathrm{cTnT}$ at $\mathrm{t}=0$ was $0.23 \pm 0.08 \mathrm{\mu g}$ per culture. This difference might be explained by immunoassay characteristics. The fourth-generation CTnT assay has been developed and optimized for measurement of human cTnT and utilizes anti-human CTnT antibodies. Although rat CTnT is highly homologous to human $\mathrm{CTnT}$, this might result in lower recoveries. In the CTnI ELISA, developed by our group, ${ }^{9}$ we used human anti-cTnI antibodies for the capture and detection of rat intact cTnI, but these antibodies demonstrated a comparable cross reactivity for rat cTnI compared with human cTnI.

The cTnI ELISA that was used in the present study as well as in the previous study only detects full length cTnI (211 a.a.r.). ${ }^{9}$ Thus any CTnI degradation product that does not contain the two antigenic sites (a.a.r. 40-50 and a.a.r 198-195) will not be detected. Metabolic inhibition of cardiomyocytes induces the release of several degradation products of both cTnI and CTnT (Figure 6-3), which remained undetected by the immunoassays (Figure 6-2). During 12-30 h of azide treatment, total quantity of both intact cTnI and cTnT per culture (cells+medium) was significantly reduced compared with the total quantity at $\mathrm{t}=0(100 \%)$, whereas total LDH activity was hardly reduced during azide treatment (Table 1). These results indicate a loss of both intact cTnI and CTnT during metabolic inhibition. Degradation of intact troponins may be responsible for this reduction in total troponin per culture, as the immunoassay only detects intact troponin. However, troponin degradation products in medium of azide-treated cardiomyocytes detected by western blotting (Figure 6-3) may partially explain this reduction but do not explain a reduction by $60-80 \%$ (Table 1 ). In addition, there is no evidence for intracellular degradation of intact troponins, as degradation products were not observed in cell extracts of azidetreated cardiomyocytes (data not shown). Therefore, these results suggest that also the antibodies used for western blotting may not be able to detect all troponin degradation products formed during metabolic inhibition.

Undetected quantities of total intact cTnI and CTnT during azide treatment may be the result of posttranslational modifications of intact troponin. Post-translational modifications such as phosphorylation, oxidation or nitrosylation may result in an impaired binding capacity of the capture and/or detection antibody, leading to a reduced detection of intact troponin.

The present study demonstrates that the detection of cardiac troponins depends on the formation of troponin degradation products and the immunoreactivity of the currently available antibodies for these degradation products. Released troponin degradation products may influence the result of the diagnostic assay. Whether the extent of irreversible cell damage after AMI is underestimated by the presence of troponin degradation products remains to be studied. Therefore further research is needed 
to identify troponin degradation products in vivo and to develop methods to detect these fragments quantitatively.

\section{CONCLUSIONS}

Mild metabolic inhibition of neonatal rat cardiomyocytes induces parallel release of intact CTnI and cTnT and their degradation products, starting after onset of irreversible cardiomyocyte damage.

In this study release kinetics of intact and degraded CTnI and cTnT were assessed by immunoassays and western blotting using currently available antibodies. If troponin degradation products do not contain the epitope for specific antibodies, they remain undetected. These limitations even apply to commercially available plasma troponin assays to be used for diagnosis of AMI. 


\section{REFERENCES}

[1] Katus HA, Remppis A, Neumann FJ, Scheffold T, Diederich KW, Vinar G, Noe A, Matern G, Kuebler W. Diagnostic efficiency of troponin T measurements in acute myocardial infarction. Circulation 1991; 83: 902-12.

[2] Mair J, Genser N, Morandell D, Maier J, Mair $P$, Lechleitner P, Calzolari C, Larue C, Ambach E, Dienstl F, Pau B, Puschendorf B. Cardiac troponin I in the diagnosis of myocardial injury and infarction. Clin Chim Acta 1996; 245: 1938.

[3] Kragten JA, Hermens WT, van Dieijen-Visser MP. Cardiac troponin T release into plasma after acute myocardial infarction: only fractional recovery compared with enzymes. Ann Clin Biochem 1996; 33 (Pt 4): 314-23.

[4] $\mathrm{Wu} A \mathrm{H}$, Feng $\mathrm{YJ}$, Contois JH, Pervaiz S. Comparison of myoglobin, creatine kinase-MB, and cardiac troponin I for diagnosis of acute myocardial infarction. Ann Clin Lab Sci 1996; 26: 291-300.

[5] De Winter RJ, Koster RW, Schotveld JH, Sturk A, van Straalen JP, Sanders GT. Prognostic value of troponin $\mathrm{T}$, myoglobin, and CK-MB mass in patients presenting with chest pain without acute myocardial infarction. Heart 1996; 75: 235-9.

[6] Jernberg T, Lindahl B, James S, Ronquist G, Wallentin $L$. Comparison between strategies using creatine kinase-MB(mass), myoglobin, and troponin $T$ in the early detection or exclusion of acute myocardial infarction in patients with chest pain and a nondiagnostic electrocardiogram. Am J Cardiol 2000; 86: 1367-71, A5.

[7] Polanczyk CA, Johnson PA, Cook EF, Lee TH. A proposed strategy for utilization of creatine kinase-MB and troponin I in the evaluation of acute chest pain. Am J Cardiol 1999; 83: 11759.

[8] Polanczyk CA, Lee TH, Cook EF, Walls R, Wybenga $D$, Printy-Klein $G$, Ludwig $L$, Guldbrandsen G, Johnson PA. Cardiac troponin I as a predictor of major cardiac events in emergency department patients with acute chest pain. J Am Coll Cardiol 1998; 32: 8-14.

[9] Li L, Hessel M, van der Valk L, Bax M, van der Linden I, van der Laarse A. Partial and delayed release of troponin-I compared with the release of lactate dehydrogenase from necrotic cardiomyocytes. Pflugers Arch 2004; 448: 14652.

[10] Bleier J, Vorderwinkler KP, Falkensammer J, Mair P, Dapunt O, Puschendorf B, Mair J. Different intracellular compartmentations of cardiac troponins and myosin heavy chains: a causal connection to their different early release after myocardial damage. Clin Chem 1998; 44: 1912-8.

[11] Bodor GS, Porter S, Landt Y, Ladenson JH, Adams JEd, Bodor GS, Davila Roman VG, Delmez JA, Apple FS, Ladenson JH, Jaffe AS. Development of monoclonal antibodies for an assay of cardiac troponin-I and preliminary results in suspected cases of myocardial infarction. Clin Chem 1992; 38: 2203-14.
[12] Katrukha AG, Bereznikova AV, Filatov VL, Esakova TV, Kolosova OV, Pettersson K, Lovgren $T$, Bulargina TV, Trifonov IR, Gratsiansky NA, Pulkki K, Voipio-Pulkki LM, Gusev NB. Degradation of cardiac troponin I: implication for reliable immunodetection. Clin Chem 1998; 44: 2433-40.

[13] Wang W, Schulze CJ, Suarez-Pinzon WL, Dyck JR, Sawicki G, Schulz R. Intracellular action of matrix metalloproteinase-2 accounts for acute myocardial ischemia and reperfusion injury. Circulation 2002; 106: 1543-9.

[14] Labugger R, Organ L, Collier C, Atar D, Van Eyk JE. Extensive troponin $\mathrm{I}$ and $\mathrm{T}$ modification detected in serum from patients with acute myocardial infarction. Circulation 2000; 102: 1221-6.

[15] Di Lisa F, De Tullio R, Salamino F, Barbato R, Melloni E, Siliprandi N, Schiaffino S, Pontremoli S. Specific degradation of troponin $\mathrm{T}$ and $\mathrm{I}$ by mu-calpain and its modulation by substrate phosphorylation. Biochem J 1995; 308 (Pt 1): 57-61.

[16] Communal C, Sumandea M, de Tombe P, Narula J, Solaro RJ, Hajjar RJ. Functional consequences of caspase activation in cardiac myocytes. Proc Natl Acad Sci U S A 2002; 99: 6252-6.

[17] Morjana NA. Degradation of human cardiac troponin I after myocardial infarction. Biotechnol Appl Biochem 1998; 28: 105-11.

[18] Wu AH, Feng YJ, Moore R, Apple FS, McPherson $\mathrm{PH}$, Buechler KF, Bodor G. Characterization of cardiac troponin subunit release into serum after acute myocardial infarction and comparison of assays for troponin $\mathrm{T}$ and $\mathrm{I}$. American Association for Clinical Chemistry Subcommittee on cTnI Standardization. Clin Chem 1998; 44: 1198-208.

[19] Michielsen EC, Diris JH, Kleijnen VW, Wodzig $\mathrm{KW}$, van Dieijen-Visser MP. Investigation of release and degradation of cardiac troponin $\mathrm{T}$ in patients with acute myocardial infarction. Clin Biochem 2007; 40: 851-5

[20] Feng J, Schaus BJ, Fallavollita JA, Lee TC, Canty $\mathrm{JM}$, Jr. Preload induces troponin I degradation independently of myocardial ischemia. Circulation 2001; 103: 2035-7.

[21] Ricchiuti V, Sharkey SW, Murakami MM, Voss EM, Apple FS. Cardiac troponin I and T alterations in dog hearts with myocardial infarction: correlation with infarct size. Am J Clin Pathol 1998; 110: 241-7.

[22] Van der Laarse A. Hypothesis: troponin degradation is one of the factors responsible for deterioration of left ventricular function in heart failure. Cardiovasc Res 2002; 56: 8.

[23] Chen SJ, Bradley ME, Lee TC. Chemical hypoxia triggers apoptosis of cultured neonatal rat cardiac myocytes: modulation by calciumregulated proteases and protein kinases. Mol Cell Biochem 1998; 178: 141-9. 
[24] Persoon-Rothert M, Egas-Kenniphaas JM, van der Valk-Kokshoorn EJ, Mauve I, van der Laarse A. Prevention of cumene hydroperoxide induced oxidative stress in cultured neonatal rat myocytes by scavengers and enzyme inhibitors. J Mol Cell Cardiol 1990; 22: 1147-55.

[25] Wroblewski F, LaDue JS. Lactic dehydrogenase activity in blood. Proc Soc Exp Biol Med 1955; 90: 210-3.

[26] Shi Q, Ling M, Zhang X, Zhang M, Kadijevic L, Liu S, Laurino JP. Degradation of cardiac troponin I in serum complicates comparisons of cardiac troponin I assays. Clin Chem 1999; 45: 1018-25.

[27] Diris JH, Hackeng CM, Kooman JP, Pinto YM, Hermens WT, Van Dieijen-Visser MP. Impaired Renal Clearance Explains Elevated Troponin T Fragments in Hemodialysis Patients. Circulation 2004; 109: 23-5.

[28] Michielsen EC, Diris JH, Hackeng CM, Wodzig WK, Van Dieijen-Visser MP. Highly sensitive immunoprecipitation method for extracting and concentrating low-abundance proteins from human serum. Clin Chem 2005; 51: 222-4

[29] Persoon-Rothert M, van der Wees KG, van der Laarse A. Mechanical overload-induced apoptosis: a study in cultured neonatal ventricular myocytes and fibroblasts. Mol Cell Biochem 2002; 241: 115-24.

[30] Elliott BA, Wilkinson JH. Serum "alphahydroxybutyric dehydrogenase" in myocardial infarction and in liver disease. Lancet 1961; 1 : 698-9.
[31] Dreyfus JC, Schapira G, Resnais J, Scebat L. [Serum creatine kinase in the diagnosis of myocardial infarct]. Rev Fr Etud Clin Biol 1960; 5: 386-7.

[32] Van der Veen KJ, Willebrands KF. Isoenzymes of creatine phosphokinase in tissue extracts and in normal and pathological sera. Clin Chim Acta 1966; 13: 312-6.

[33] Apple FS. Acute myocardial infarction and coronary reperfusion. Serum cardiac markers for the 1990s (review). Am J Clin Pathol 1992; 97: 217-26.

[34] Mair J, Wagner I, Jakob G, Lechleitner P, Dienst F, Puschendorf B, Michel G. Different time courses of cardiac contractile proteins after acute myocardial infarction. Clin Chim Acta 1994; 231: 47-60.

[35] Missov E, Calzolari C, Pau B. Circulating cardiac troponin I in severe congestive heart failure. Circulation 1997; 96: 2953-8.

[36] Nunes JP. Cardiac troponin I in systemic diseases. A possible role for myocardial strain. Rev Port Cardiol 2001; 20: 785-8.

[37] Kositprapa C, Zhang B, Berger S, Canty JM, Jr., Lee TC. Calpain-mediated proteolytic cleavage of troponin I induced by hypoxia or metabolic inhibition in cultured neonatal cardiomyocytes. Mol Cell Biochem 2000; 214: 47-55.

[38] Atsma DE, Bastiaanse EM, Jerzewski A, Van der Valk LJ, Van der Laarse A. Role of calciumactivated neutral protease (calpain) in cell death in cultured neonatal rat cardiomyocytes during metabolic inhibition. Circ Res 1995; 76: 1071-8. 



\title{
THE DIAGNOSTIC VALUE OF SERUM AND URINARY NT-PROBNP FOR HEART FAILURE
}

\begin{abstract}
Background. Serum B-type natriuretic peptide (BNP) and the amino-terminal cleavage product of the prohormone (NT-proBNP) have been shown to be valuable parameters for diagnosis of heart failure $(\mathrm{HF})$ in the general population. Urinary BNP and NT-proBNP have also been suggested for diagnosis of HF. The present study investigated the diagnostic value of both serum and urinary NT-proBNP in selected groups of controls and patients diagnosed with HF.
\end{abstract}

Methods. Creatinine clearance, and serum and urinary NT-proBNP were measured in 76 controls and in 47 patients diagnosed with HF. Echocardiography was used to exclude cardiac dysfunction in the control population by the combined normality of left ventricular ejection fraction, e/a ratio, deceleration time, and left ventricular mass index. All patients diagnosed with HF had left ventricular ejection fractions $<40 \%$.

Results. NT-proBNP measurements in urine samples are subject to high variability. Receiver operating characteristic area under the curve for serum, urinary NT-proBNP, and their product were 0.94, 0.72, and 0.93, respectively. Correction of urinary NT-proBNP for urinary creatinine content improved the area under the curve from 0.72 to 0.80 . Negative predictive values for ruling out HF were 0.94, 0.67, and 0.89 , respectively. Linear regression analysis revealed that creatinine clearance was more important in determining serum NT-proBNP levels than age.

Conclusions. Serum NT-proBNP is the best parameter to rule out HF. The product of the serum and urinary NT-proBNP concentrations has equal value. In contrast, urinary NT-proBNP alone performs rather poorly. Renal function influences NT-proBNP levels more than age in this selected population.

Parts of this Chapter will be published

Annals of Clinical Biochemistry 2007; Accepted for publication. 


\section{INTRODUCTION}

Heart failure (HF) is a major public health problem of increasing relevance. ${ }^{1-3}$ It is important to realise that $\mathrm{HF}$ is the final stage of a variety of diseases affecting the heart. Hence, the population of $\mathrm{HF}$ patients is highly heterogeneous. Diagnosis of HF is based mainly on historical features (e.g. myocardial infarction), symptoms (e.g. dyspnoea), physical examination (e.g. third heart sound, leg oedema), chest radiography (e.g. interstitial oedema), and electrocardiography (e.g. atrial fibrillation). ${ }^{4}$ Additional laboratory analyses can include B-type natriuretic peptide (BNP) and the $\mathrm{N}$-terminal cleavage product (NT-proBNP), which have become well established biochemical markers for diagnosis and prognosis of $\mathrm{HF}^{5-8}$

BNP (amino acid 77-108) and NT-proBNP (amino acid 1-76) are derived from proBNP (108 amino acids) by cleavage through the proteases furin, ${ }^{9}$ and corin. ${ }^{10}$ proBNP itself is derived from pre-proBNP (134 amino acids) by cleavage of a signal peptide ( 26 amino acids). ${ }^{11,12}$ Both peptides are released into the circulation from the cardiac ventricle in equimolar amounts. Release is induced by increased wall stretch, either mechanically or by volume overload. ${ }^{13}$

NT-proBNP $(8.5 \mathrm{kDa})$ is a low molecular weight peptide that is filtered by the glomerulus. It is unclear whether it has any biological activity. In contrast, the smaller and biologically active BNP ( $3.5 \mathrm{kDa}$ ) acts as an antagonist of the renin angiotensine aldosterone system, and protects the body from plasma overload by inducing diuresis, natriuresis, and vasodilatation. ${ }^{12}$ In addition to renal clearance, BNP is also cleared from the circulation through binding to natriuretic peptide receptor $C$ (NPR-C). This complex is then internalised and BNP is enzymatically degraded. The receptor is externalised again to the outside of the cell membrane. The third mechanism involves neutral endopeptidase 24.11 (NEP), which also degrades circulating BNP. ${ }^{14,}{ }^{15}$ Both mechanisms were shown to contribute equally to the clearance of BNP. ${ }^{16}$ These two additional mechanisms might explain the longer half life of NT-proBNP, compared with BNP. ${ }^{17}$

Recently it was suggested to use the combined measurement of serum and urinary NT-proBNP in screening for left ventricular systolic dysfunction (LVSD) in the general population. ${ }^{18,19}$ The aims of this study were to evaluate the Roche NT-proBNP immunoassay for measurement of urine samples and to investigate the diagnostic value of serum and urinary NT-proBNP in patients diagnosed with HF and in controls without cardiac abnormalities, as determined by stringent echocardiographic criteria.

\section{MethodS}

\section{Study population}

This study was approved by the Medical Ethical Committee of the University Hospital Maastricht. All patients had echocardiography, blood sampling and 24 hours urine collection. The control group consisted of 76 patients who had no history of cardiac disease and were hospitalised for non-cardiac causes. Controls had normal echocardiography based on the following stringent and combined criteria: left ventricular ejection fraction (LVEF) $>45 \%$, e/a ratio $>1.0$ for patients $<55$ years and $>0.8$ for patients $\geq 55$ years, deceleration time $<220 \mathrm{~ms}$, and left ventricular mass index (LVMI) $\leq 116 \mathrm{~g} / \mathrm{m}^{2}$ in males and $\leq 104 \mathrm{~g} / \mathrm{m}^{2}$ in females. In addition, 47 patients hospitalised for HF were recruited based on 
diminished LVEF $(<45 \%)$ as determined by echocardiographic examination of the heart. A total of 121 serum and 89 urinary samples were analyzed.

\section{Laboratory analysis}

Serum samples were analysed for NT-proBNP and creatinine. Creatinine clearance and a 24-hour urine collection were used to estimate the glomerular filtration rate (GFR) as a parameter of renal function. NT-proBNP was measured on the Elecsys 2010 immunoassay system (Roche Diagnostics, Mannheim, Germany) with a sandwich immunoassay. The serum detection limit of the NT-proBNP immunoassay is $0.6 \mathrm{pmol} / \mathrm{L}$. Between-day variation is $2.4 \%$ and $2.2 \%$ at concentrations of $51.2 \mathrm{pmol} / \mathrm{L}$ and $800 \mathrm{pmol} / \mathrm{L}$, respectively $(n=60)$. The reference values for the identification and exclusion of acute coronary heart failure were shown to be age dependent: $53 \mathrm{pmol} / \mathrm{L}$ ( $<50$ years) and $106 \mathrm{pmol} / \mathrm{L}\left(>=50\right.$ years) ${ }^{20,21}$ NT-proBNP concentrations are expressed in pmol/L, for conversion to $\mathrm{pg} / \mathrm{mL}$ multiply by 8.457 .

Serum and urinary creatinine concentrations were measured on the Synchron LX-20 system (Beckman Coulter, Fullerton, USA) with the Jaffe method using alkaline picrate. Between-day variation of serum creatinine is $2.2 \%$ and $0.93 \%$ at concentrations of $86.9 \mu \mathrm{mol} / \mathrm{L}$ and $401 \mu \mathrm{mol} / \mathrm{L}$, respectively $(n=93)$. The reference values are 71-110 $\mu \mathrm{mol} / \mathrm{L}$ for men and 53-97 $\mu \mathrm{mol} / \mathrm{L}$ for women.

\section{Urinary NT-proBNP}

Data on measurement of NT-proBNP in urine with the Roche immunoassay have not been published yet. $\mathrm{Ng}$ et al. ${ }^{18,19}$ used an immunoluminometric assay (ILMA) with rabbit polyclonal antibodies for the detection of urinary NT-proBNP, ${ }^{22}$ whereas the Roche immunoassay utilises two sheep polyclonal antibodies recognising amino acid residues 10-21 and 39-50 of the molecule.

Recombinant human NT-proBNP (rhNT-proBNP; 1-76) was kindly supplied by Roche (Mannheim, Germany) and was added to serum and urine samples, in which the NT-proBNP concentration was below the detection limit of the immunoassay. Concentrations were measured in the range 32-294 pmol/L. Stability of NT-proBNP in urine was tested by measuring NT-proBNP during a 48 hour time span with aliquots of urine samples stored at different temperatures. The influence of urinary $\mathrm{pH}$ was tested by measuring urinary NT-proBNP before and after $\mathrm{pH}$ adjustment to a value of 7.4.

\section{Echocardiography}

One experienced cardiologist performed echocardiography for all subjects according to the standard clinical protocol used in our hospital. Data were collected on LVEF, LVSD, LV mass, LV mass index, and e/a ratio. The deceleration time was obtained from the electrocardiogram.

\section{Statistical analysis}

The Mann-Whitney $U$ test was used for testing for differences between groups for continuous variables and the $\mathrm{X}^{2}$ test was used for categorical variables. The Spearman correlation coefficient $\left(R_{s}\right)$ was used as a measure of correlation. The receiver operating characteristic (ROC) area under the curve (AUC) and the associated $95 \%$ confidence intervals were estimated. Optimal cut-off levels were calculated with combined highest sensitivity and specificity. Data are presented as medians with interquartile ranges (IQR) and $\mathrm{P}<0.05$ was considered statistically significant. The SPSS version 11.0.1 for Windows (SPSS, Chicago, USA) statistical software package was used for statistical analyses. 
Table 7-1. Patient characteristics.

\begin{tabular}{|c|c|c|c|}
\hline & All $(n=123)$ & Control $(n=76)$ & HF $(n=47)$ \\
\hline Men/ women & $65 / 58$ & $35 / 41$ & $30 / 17$ \\
\hline Age, years & $58(21)$ & $55(20)$ & $70(18)^{*}$ \\
\hline Creatinine clearance, $\mathrm{ml} / \mathrm{min}$ & $86(81)$ & $103(46)$ & $24(37) *$ \\
\hline Serum NT-proBNP, pmol/L & $18(157)$ & $6.9(14)$ & 359 (1408)* \\
\hline Serum creatinine, $\mu \mathrm{mol} / \mathrm{L}$ & $95(87)$ & $81(37)$ & $190(185)^{*}$ \\
\hline Urinary volume, $\mathrm{ml} / 24 \mathrm{~h}$ & $1700(900)$ & $1755(880)$ & $1660(1050)^{*}$ \\
\hline Urinary creatinine, $\mu \mathrm{mol} / \mathrm{L}$ & $6.2(4.3)$ & $7.0(5.1)$ & $4.4(4.0)^{*}$ \\
\hline Urinary NT-proBNP, pmol/L & $5.3(21)$ & $4.5(4.0)$ & $13(515)^{*}$ \\
\hline Urinary NT-proBNP, pmol/24h & $6.9(26)$ & $5.1(5.6)$ & $26(361)^{*}$ \\
\hline Urinary NT-proBNP and creatinine quotient, $\mathrm{pmol} / \mathrm{\mu mol}$ & $0.75(6.4)$ & $0.41(0.51)$ & $5.2(105)^{*}$ \\
\hline Serum and urine NT-proBNP product, (pmol/L)2 & $106(7954)$ & $19(33)$ & $4776(709977) *$ \\
\hline LVEF, \% & $61(15)$ & $64(5)$ & $42(25)^{*}$ \\
\hline LV mass, g & $182(77)$ & $163(39)$ & $261(137)^{*}$ \\
\hline LV massindex, g/m2 & $91(24)$ & $87(16)$ & $139(65)^{*}$ \\
\hline E/A ratio & $1.1(0.5)$ & $1.1(0.45)$ & $0.80(0.73)^{+}$ \\
\hline Deceleration time, ms & $180(210)$ & $180(38)$ & $170(120)$ \\
\hline
\end{tabular}

Data are represented as median (interquartile range). The Mann-Whitney test was used for differences between controls and patients with HF. $* \mathrm{p}<0.0001 ;{ }^{\dagger} \mathrm{p}<0.05$.

\section{Results}

\section{Assay feasibility}

Feasibility of the NT-proBNP immunoassay for the determination of urinary NT-proBNP was checked by addition of rhNT-proBNP to urine samples of different subjects. Figure 7-1 shows the standard curves for NT-proBNP measurements in two representative serum and urine samples using the Roche immunoassay in the range $32-293 \mathrm{pmol} / \mathrm{L}$. In contrast to the $108 \%$ recovery found in serum samples, addition of rhNT-proBNP to urine resulted in lower recovery (16-55\%). This was shown to be at least partly dependent on the urinary protein content of the sample (data not shown). The measurements were linear in the range tested.

Storage of serum and urine samples at room temperature for up to 48 hours did not influence the concentration of NT-proBNP as measured by the Roche immunoassay. Urinary pH did not significantly influence NT-proBNP concentrations (after $\mathrm{pH}$ correction $=0.8267 \mathrm{x}-2.5583 ; \mathrm{R}^{2}=0.994$ ). 


\section{Urinary NT-proBNP}

Table 7-1 shows the characteristics of all subjects who participated in this study, 47 patients diagnosed with HF and 76 controls. HF patients and controls were not age matched $(P<0.0001)$ and $\mathrm{HF}$ patients had lower creatinine clearance $(P<0.0001)$. As expected, HF patients had significantly higher serum and urinary NT-proBNP values $(P<0.0001)$.

Table 7-2. Receiver operating characteristic area under the curve analysis for ruling out HF.

\begin{tabular}{|c|c|c|c|c|c|c|c|}
\hline & AUC & $95 \%$ CI & Cut-off & Sensitivity & Specificity & PPV & NPV \\
\hline $\begin{array}{lll}\text { Serum } & \text { NT } & \text { proBNP } \\
(\mathrm{pmol} / \mathrm{L}) & & \end{array}$ & 0.940 & $0.884-0.996$ & 33.5 & $91 \%$ & $92 \%$ & $88 \%$ & $94 \%$ \\
\hline $\begin{array}{lll}\text { Urinary } & \text { NT } & \text { proBNP } \\
(\mathrm{pmol} / \mathrm{L}) & & \end{array}$ & 0.721 & $0.610-0.831$ & 10.5 & $53 \%$ & $98 \%$ & $96 \%$ & $67 \%$ \\
\hline $\begin{array}{l}\text { Serum and urinary NT } \\
\text { proBNP product }(\mathrm{pmol} / \mathrm{L})^{2}\end{array}$ & 0.927 & $0.868-0.986$ & 115 & $89 \%$ & $93 \%$ & $93 \%$ & $89 \%$ \\
\hline $\begin{array}{l}\text { Urinary NT proBNP and } \\
\text { creatinine } \\
(\mathrm{pmol} / \mathrm{mmol})\end{array}$ & 0.804 & $0.713-0.896$ & 0.962 & $67 \%$ & $86 \%$ & $83 \%$ & $72 \%$ \\
\hline
\end{tabular}

AUC, Area under the curve; CI, confidence interval; PPV, positive predictive value; NPV, negative predictive value.

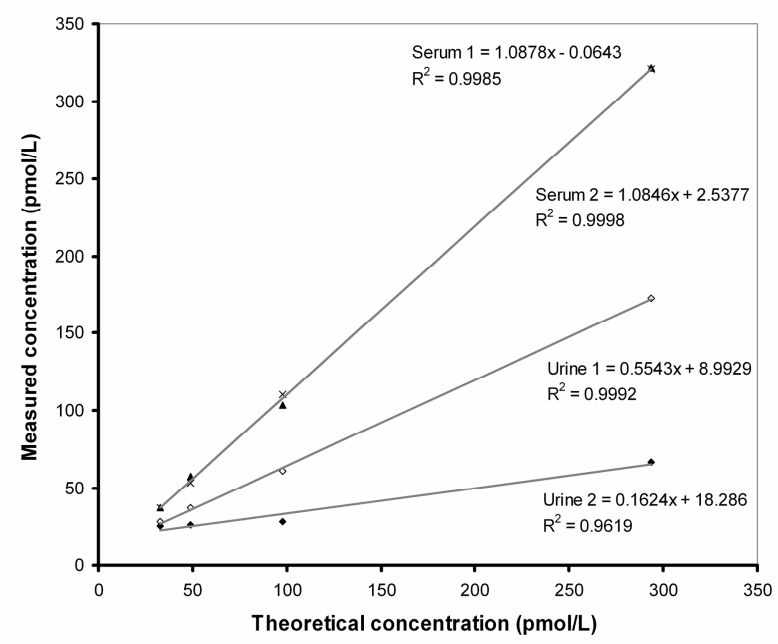

Figure 7-1. Standard curves for NT-proBNP measurement in serum and urine. rhNT-proBNP was spiked into two serum and two urine samples. The analytical response of the immunoassay was linear across the range from 32-294 pmol/L, independent of the matrix.

In Figure 7-2 the relation between serum and urinary NT-proBNP is shown. There was a statistically significant correlation between urinary and serum NT-proBNP concentrations $\left(R_{s}=0.561, P<0.01\right)$. 


\section{Chapter 7}

Figure 7-3 shows the relation between serum and urinary NT-proBNP and age and creatinine clearance for both controls and patients diagnosed with HF. As calculated in the control population, serum NTproBNP increased significantly with age $\left(R_{s}=0.616, P<0.01\right)$, as did urinary NT-proBNP. The latter, however, with a lower correlation coefficient $\left(R_{s}=0.414, P<0.01\right)$. Serum NT-proBNP showed an inverse correlation with creatinine clearance $\left(R_{s}=-0.777, P<0.01\right)$. Urinary NT-proBNP was also inversely correlated with creatinine clearance, but with a lower correlation coefficient $\left(R_{s}=-0.524\right.$, $\mathrm{P}<0.01)$.

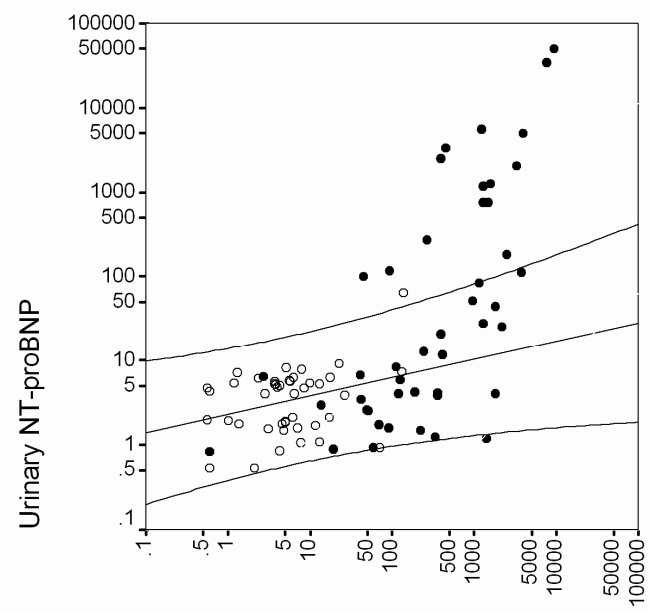

Serum NT-proBNP

Figure 7-2. Relation of serum and urinary NT-proBNP. Open circles represent controls and closed circles represent HF patients. Spearman correlation and $95 \% \mathrm{CI}$ intervals were calculated with controls.

Figure 7-4 shows the ROC curves for serum and urinary NT-proBNP, their product and the urinary NTproBNP corrected for urinary creatinine for diagnosis of HF. Table 7-2 shows the ROC AUC analysis for serum and urinary NT-proBNP for diagnosis of HF with corresponding sensitivity, specificity, and positive and negative predictive values. Serum NT-proBNP had the highest AUC (0.940) and urinary NTproBNP had the lowest $(0.721)$. Correction for the urinary creatinine concentration increased the AUC to 0.804. The sensitivity of urinary NT-proBNP was only $53 \%$, but the specificity was $98 \%$. Urinary NTproBNP had the highest PPV $(96 \%)$ at a cut-off value of $10.5 \mathrm{pmol} / \mathrm{L}$. Serum NT-proBNP had a sensitivity of $91 \%$, a specificity of $92 \%$, and a PPV of $88 \%$ at a concentration of $33.5 \mathrm{pmol} / \mathrm{L}$. The serum and urinary NT-proBNP product performed equal to, but was not superior to serum NT-proBNP alone. 


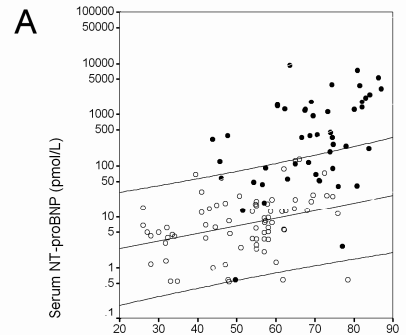

Age

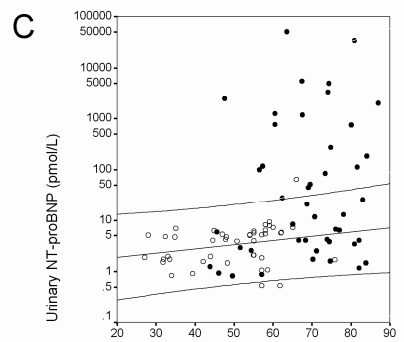

Age

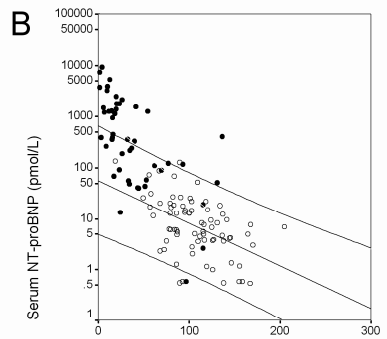

Creatinine clearance $(\mathrm{mL} / \mathrm{min})$

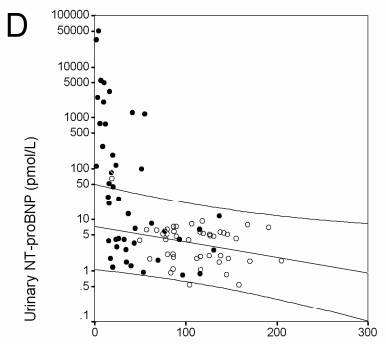

Creatinine clearance $(\mathrm{mL} / \mathrm{min})$

Figure 7-3. Serum and urinary NT-proBNP in relation to age and creatinine clearance. Open circles represent controls and closed circles represent HF patients. Spearman correlation and $95 \% \mathrm{CI}$ intervals were calculated with controls.

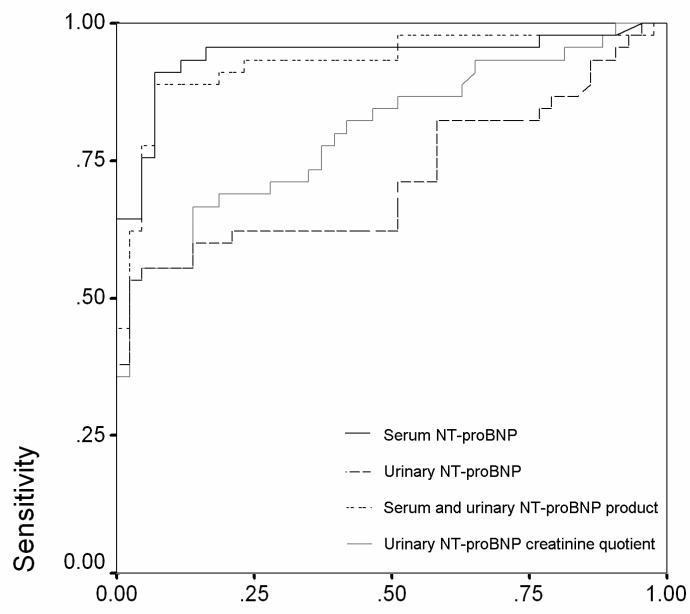

1 - Specificity

Figure 7-4. Receiver operating characteristic area under the curve for the detection of HF for serum NT-proBNP, urinary NT-proBNP, the product of both, and the urinary NT-proBNP corrected for urinary creatinine. 


\section{Discussion}

Circulating BNP and NT-proBNP have been widely accepted and are now used by clinicians as biomarkers for assessing cardiac function. ${ }^{5-8}$ Several papers reported the use of plasma or serum NTproBNP measurements, but not urinary NT-proBNP measurements. Recent reports on the use of urinary NT-proBNP did not use the commercially available electrochemiluminescence immunoassay on the Elecsys 2010 platform that is marketed by Roche Diagnostics ${ }^{18,19}$, except for one. ${ }^{23}$ The ILMA, originally evaluated with plasma samples was used for the detection of urinary NT-proBNP. ${ }^{22}$ Unfortunately, no details were provided on assay performance in urine samples. The first studies of this group reported that urinary NT-proBNP had diagnostic accuracy comparable with plasma NT-proBNP, and that urinary NT-proBNP may be suitable for diagnosis of HF. ${ }^{18}$ In the second study it was concluded that the most cost-effective strategy would be to apply these tests sequentially, using the urinary NT-proBNP test first to rule out LVSD and then subjecting the urine-positive cases to plasma testing. ${ }^{19}$ Cortés et al. reported good diagnostic value for urinary NT-proBNP for diagnosing HF with a ROC AUC value of $0.96 \pm 0.02$ $(p<0.0001)$, compared with $0.98 \pm 0.01$ for serum NT-proBNP. The conclusion was that urinary NTproBNP could be a simple non-invasive test for diagnosing HF.

In the present study we evaluated the feasibility of the Roche NT-proBNP immunoassay for the determination of NT-proBNP in urine samples. First we investigated the stability of NT-proBNP in urine samples and found that samples were stable for up to 48 hours at room temperature. This is an important issue because patients have to collect 24 hours urine samples and it may take longer than 48 hours before these samples can be analysed or frozen in the laboratory. When we analysed rhNTproBNP spiked in urine samples, the recoveries were rather low and varied substantially between 16$55 \%$. In contrast, serum samples had a mean recovery of $108 \%$ as determined within the same concentration range. The results in urine were, however, linear in the range 32-294 pmol/L. This might indicate an effect of the urine matrix, resulting in lower recovery, which might, at least partly, explain the lower diagnostic value of urinary NT-proBNP compared with serum NT-proBNP that was found. The analytical performance and diagnostic accuracy of this assay in serum samples have been evaluated elsewhere and these studies found excellent characteristics. ${ }^{24,25}$

Urinary NT-proBNP increased with increasing levels of serum NT-proBNP. This is to be expected because NT-proBNP is filtered by the kidneys. From Figure 7-2 it can be argued that there seems to be a threshold value of serum NT-proBNP of approximately $100 \mathrm{pmol} / \mathrm{L}$ before it starts to appear in urine. This phenomenon can be explained by limited renal resorption with increasing serum concentrations. The increase in serum NT-proBNP with decreasing renal function can be explained by diminished renal filtration. Impaired renal function, however, implies a lower filtering capacity of the kidneys. This is in contrast with the increasing urinary NT-proBNP when renal function becomes impaired. Possibly, NTproBNP is still small enough to be filtered, but this needs further investigation.

We then investigated the diagnostic value of serum and urinary NT-proBNP for diagnosis of HF. The results from this study are in line with earlier studies that showed the effectiveness of serum NTproBNP for diagnosing HF in a variety of patient groups. ${ }^{5,26-28}$

In a recent study among 20,536 patients that measured NT-proBNP according to the method described by Karl et al., ${ }^{29}$ NT-proBNP levels were strongly predictive for HF and other major vascular events. ${ }^{30}$ 


\section{Conclusions}

The results from this study are in line with earlier data showing that serum NT-proBNP is most effective in ruling out HF. However, with the Roche NT-proBNP immunoassay, the use of urinary NT-proBNP did not show the high values reported by others. ${ }^{18,19}$ Using serum NT-proBNP is the most easy to use method with least variability. We recommend the use of serum and not urine for measurements of NTproBNP for the diagnosis of heart failure. 


\section{REFERENCES}

[1] Jessup $M$, Brozena S. Heart failure. N Engl J Med 2003; 348: 2007-18.

[2] Levy D, Kenchaiah S, Larson MG, Benjamin EJ, Kupka MJ, Ho KK, Murabito JM, Vasan RS. Longterm trends in the incidence of and survival with heart failure. N Engl J Med 2002; 347: 1397402.

[3] Redfield MM. Heart failure--an epidemic of uncertain proportions. N Engl J Med 2002; 347: 1442-4.

[4] Wang CS, FitzGerald JM, Schulzer M, Mak E, Ayas NT. Does this dyspneic patient in the emergency department have congestive heart failure? Jama 2005; 294: 1944-56.

[5] Januzzi JL, van Kimmenade R, Lainchbury J, Bayes-Genis A, Ordonez-Llanos J, Santalo-Bel M, Pinto YM, Richards M. NT-proBNP testing for diagnosis and short-term prognosis in acute destabilized heart failure: an international pooled analysis of 1256 patients: the International Collaborative of NT-proBNP Study. Eur Heart J 2006; 27: 330-7.

[6] Maisel AS, Krishnaswamy P, Nowak RM, McCord J, Hollander JE, Duc P, Omland T, Storrow AB, Abraham WT, Wu AH, Clopton P, Steg PG, Westheim A, Knudsen CW, Perez A, Kazanegra R, Herrmann HC, McCullough PA. Rapid measurement of $B$-type natriuretic peptide in the emergency diagnosis of heart failure. $\mathrm{N}$ Engl J Med 2002; 347: 161-7.

[7] Januzzi J, James L., Camargo CA, Anwaruddin $S$, Baggish AL, Chen AA, Krauser DG, Tung $R$ Cameron R, Nagurney JT. The N-terminal ProBNP Investigation of Dyspnea in the Emergency department (PRIDE) study. The American Journal of Cardiology 2005; 95: 948-54.

[8] McCullough PA, Nowak RM, McCord J, Hollander JE, Herrmann HC, Steg PG, Duc P, Westheim A, Omland $T$, Knudsen $C W$, Storrow $A B$, Abraham WT, Lamba S, Wu AH, Perez A, Clopton $P$, Krishnaswamy P, Kazanegra R, Maisel AS. Btype natriuretic peptide and clinical judgment in emergency diagnosis of heart failure: analysis from Breathing Not Properly (BNP) Multinational Study. Circulation 2002; 106: 416-22.

[9] Sawada $Y$, Suda M, Yokoyama H, Kanda $T$, Sakamaki T, Tanaka S, Nagai R, Abe S, Takeuchi T. Stretch-induced hypertrophic growth of cardiocytes and processing of braintype natriuretic peptide are controlled by proprotein-processing endoprotease furin. J Biol Chem 1997; 272: 20545-54.

[10] Yan W, Wu F, Morser J, Wu Q. Corin, a transmembrane cardiac serine protease, acts as a pro-atrial natriuretic peptide-converting enzyme. Proc Natl Acad Sci U S A 2000; 97: 8525-9.

[11] Apple FS, Panteghini M, Ravkilde J, Mair J, Wu AHB, Tate J, Pagani F, Christenson RH, Jaffe AS, on Behalf of the Committee on Standardization of Markers of Cardiac Damage of the IFCC. Quality Specifications for B-Type Natriuretic Peptide Assays. Clin Chem 2005; 51: 486-93.
[12] Hall C. Essential biochemistry and physiology of (NT-pro)BNP. Eur J Heart Fail 2004; 6: 257-60.

[13] Vanderheyden M, Goethals M, Verstreken S, De Bruyne B, Muller K, Van Schuerbeeck $E_{\text {, }}$ Bartunek J. Wall stress modulates brain natriuretic peptide production in pressure overload cardiomyopathy. Journal of the American College of Cardiology 2004; 44: 2349-54.

[14] Andreassi MG, Del Ry S, Palmieri C, Clerico A Biagini A, Giannessi D. Up-regulation of 'clearance' receptors in patients with chronic heart failure: a possible explanation for the resistance to biological effects of cardiac natriuretic hormones. Eur J Heart Fail 2001; 3: 407-14.

[15] Hystad ME, Oie E, Grogaard HK, Kuusnemi K, Vuolteenaho O, Attramadal $H$, Hall C. Gene expression of natriuretic peptides and their receptors type- $A$ and $-C$ after myocardial infarction in rats. Scand J Clin Lab Invest 2001; 61: $139-50$

[16] Rademaker MT, Charles CJ, Kosoglou T, Protter AA, Espiner EA, Nicholls MG, Richards AM. Clearance receptors and endopeptidase: equal role in natriuretic peptide metabolism in heart failure. Am J Physiol Heart Circ Physiol 1997; 273: H2372-9.

[17] Pemberton CJ, Johnson ML, Yandle TG, Espiner EA. Deconvolution analysis of cardiac natriuretic peptides during acute volume overload. Hypertension 2000; 36: 355-9.

[18] Ng LL, Geeranavar S, Jennings SC, Loke I, O'Brien RJ. Diagnosis of heart failure using urinary natriuretic peptides. Clin Sci (Lond) 2004; 106: 129-33.

[19] Ng LL, Loke IW, Davies JE, Geeranavar S, Khunti K, Stone MA, Chin DT, Squire IB. Community screening for left ventricular systolic dysfunction using plasma and urinary natriuretic peptides. J Am Coll Cardiol 2005; 45: 1043-50.

[20] Januzzi JL, Jr., Camargo CA, Anwaruddin S, Baggish AL, Chen AA, Krauser DG, Tung $R$, Cameron R, Nagurney JT, Chae CU, Lloyd-Jones DM, Brown DF, Foran-Melanson S, Sluss PM, Lee-Lewandrowski $\mathrm{E}$, Lewandrowski KB. The Nterminal Pro-BNP investigation of dyspnea in the emergency department (PRIDE) study. Am J Cardiol 2005; 95: 948-54.

[21] Hulsmann M, Berger R, Mortl D, Gore O, Meyer $B$, Pacher R. Incidence of normal values of natriuretic peptides in patients with chronic heart failure and impact on survival: a direct comparison of $\mathrm{N}$-terminal atrial natriuretic peptide, $\mathrm{N}$-terminal brain natriuretic peptide and brain natriuretic peptide. Eur J Heart Fail 2005; 7: 552-6

[22] Hughes D, Talwar S, Squire IB, Davies JE, Ng LL. An immunoluminometric assay for $\mathrm{N}$ terminal pro-brain natriuretic peptide: development of a test for left ventricular dysfunction. Clin Sci (Lond) 1999; 96: 373-80. 
[23] Cortes R, Portoles M, Salvador A, Bertomeu V, Garcia de Burgos F, Martinez-Dolz L, Lleti ER, Climent V, Jordan A, Paya R, Sogorb F, Rivera $M$. Diagnostic and prognostic value of urine NTproBNP levels in heart failure patients. Eur J Heart Fail 2006; 8: 621-7.

[24] Prontera C, Emdin M, Zucchelli GC, Ripoli A, Passino C, Clerico A. Analytical performance and diagnostic accuracy of a fully-automated electrochemiluminescent assay for the $\mathrm{N}$ terminal fragment of the pro-peptide of brain natriuretic peptide in patients with cardiomyopathy: comparison with immunoradiometric assay methods for brain natriuretic peptide and atrial natriuretic peptide. Clin Chem Lab Med 2004; 42: 37-44.

[25] Collinson PO, Barnes SC, Gaze DC, Galasko G, Lahiri A, Senior R. Analytical performance of the $\mathrm{N}$ terminal pro $\mathrm{B}$ type natriuretic peptide (NTproBNP) assay on the Elecsys 1010 and 2010 analysers. Eur J Heart Fail 2004; 6: 365-8.

[26] Costello-Boerrigter LC, Boerrigter G, Redfield MM, Rodeheffer RJ, Urban LH, Mahoney DW, Jacobsen SJ, Heublein DM, Burnett JC, Jr. Amino-terminal pro-B-type natriuretic peptide and B-type natriuretic peptide in the general community: determinants and detection of left ventricular dysfunction. J Am Coll Cardiol 2006; 47: 345-53.
[27] van Kimmenade RR, Januzzi JL, Jr., Baggish AL, Lainchbury JG, Bayes-Genis A, Richards AM, Pinto YM. Amino-terminal pro-brain natriuretic Peptide, renal function, and outcomes in acute heart failure: redefining the cardiorenal interaction? J Am Coll Cardiol 2006; 48: 16217.

[28] Masson S, Latini R, Anand IS, Vago T, Angelici L, Barlera S, Missov ED, Clerico A, Tognoni G, Cohn JN. Direct Comparison of B-Type Natriuretic Peptide (BNP) and Amino-Terminal proBNP in a Large Population of Patients with Chronic and Symptomatic Heart Failure: The Valsartan Heart Failure (Val-HeFT) Data. Clin Chem 2006; 52: 1528-38.

[29] Karl J, Borgya A, Gallusser A, Huber E, Krueger $\mathrm{K}$, Rollinger W, Schenk J. Development of a novel, N-terminal-proBNP (NT-proBNP) assay with a low detection limit. Scand J Clin Lab Invest Suppl 1999; 230: 177-81.

[30] Emberson JR, Ng LL, Armitage J, Bowman L, Parish S, Collins R. N-terminal Pro-B-type natriuretic peptide, vascular disease risk, and cholesterol reduction among 20,536 patients in the MRC/BHF heart protection study. J Am Coll Cardiol 2007; 49: 311-9. 



\section{General Discussion}

\section{TROPONINS IN CLINICAL PRACTISE}

Cardiac troponins were discovered in the late 1980's and laboratory measurements of these proteins have since shown to be of great value for diagnosing myocardial cell damage and as such for diagnosis of acute coronary syndromes (ACS). Because of their cardiac tissue specificity, troponins have superior clinical value over the more classical enzyme measurements of myoglobin, CK, CK-MB or LDH (and its isoenzymes). ${ }^{1-3}$ In addition to their diagnostic value, ${ }^{4}$ troponins have also been shown to be of great value in risk stratification in patients with $A C S,{ }^{5,6}$ end-stage renal disease (ESRD), ${ }^{7,8}$ and patients with pulmonary embolism. ${ }^{9}$ In these and other studies, ${ }^{10-14}$ elevated troponin values were shown to be independent risk factors for a poor prognosis and higher risk of cardiac death. However, since there have been no internationally defined cut-off values for high and low risk patients, the troponins have not yet been fully integrated in risk stratification protocols. There have been many studies investigating multimarker strategies including the troponins and other cardiac markers such as myeloperoxidase (MPO), B-type natriuretic peptide (BNP), N-terminal pro-B-type natriuretic peptide (NT-proBNP) and Creactive protein (CRP) to determine the individual and combined values of these markers for risk stratification in patients presenting in the Emergency Department with chest pain or dyspnoea. The outcomes of these studies vary, depending on the study design and the numbers of patients included. ${ }^{15-}$ 18 The number of elevated biomarkers of cardiac damage and function was shown to be an independent risk predictor for all-cause death. ${ }^{15,16,19}$ For example, in a cohort of 1635 patients Sabatine et al. showed that the number of elevated biomarkers (CTnI, CRP, and BNP) was a significant predictor of the composite endpoint after adjustment for known clinical predictors: patients with one, two, and three elevated biomarkers had a 2.1- $(p=0.006), 3.1-(p<0.001)$, and 3.7- $(p=0.001)$ fold increase in the composite risk of death, MI, or CHF by 6 months. ${ }^{19}$ In contrast, there has been one study reporting that the combination of CTnI with CK-MB or myoglobin was prognostically non-superior compared to cTnI alone. ${ }^{17}$ The causes of ACS include plaque rupture with acute thrombosis, progressive mechanical obstruction, inflammation, secondary unstable angina, and dynamic obstruction (coronary vasoconstriction). ${ }^{20}$ It is not surprising that a multi-marker strategy reflecting these underlying causes, ${ }^{19}$ including biomarkers for all these underlying causes - either cTnT or cTnI for myocardial damage combined with inflammation (CRP) and heart function (BNP/NT-proBNP) - is superior to a single marker strategy for risk stratification for all-cause-death or death from MI. This is also true for risk stratification for all-cause-death in patients with end stage renal disease. ${ }^{21}$

Troponins can be measured in either serum or plasma samples and are rather stable at room temperature, ${ }^{3}$ Obviously, the time from blood sampling and pre analytical preparation to analysis, and the temperature is of influence on the outcome of the analysis. ${ }^{22}$ Use of heparin plasma samples has 
been shown to result in approximately $6 \%$ lower $\mathrm{CTnT}$ and $\mathrm{CTnI}$ test results compared with serum. ${ }^{3,23,24}$ This effect was elegantly shown to be caused by direct binding of heparin to the troponin molecule and could partly be reversed by the addition of heparinase or protamine. ${ }^{24}$ For the CTnT assay it was recently shown that the negative effect of heparin has been overcome. ${ }^{25}$

Clinically it can be relevant to estimate infarct size. Troponins, being cardiac tissue specific, have been investigated as possible tools for this goal. Historically, infarct size has been estimated using serial and cumulative measurements of enzymes such as $\mathrm{LDH}, \mathrm{CK}$ and $\mathrm{CK}-\mathrm{MB}_{\text {act }}{ }^{26-28}$ The troponins do not show the high correlations with anatomically (post-mortem) measured infarct sizes, or imaging techniques (e.g. thallium-201 scintigraphy) as the enzymatic estimations (cTnT $r=0.53, p=0.042 ;$ CK-MB $_{\text {act }} r=$ $0.64, p=0.01) .{ }^{29}$ However, in several studies the opposite has been claimed, e.g. a single measurement of CTnT at 72 or 96 hours has been shown to correlate well with infarct size as estimated by thallium-201 scintigraphy ( $\mathrm{cTnT}_{72}$ : with reperfusion $\mathrm{r}=0.718$; $\mathrm{p}<0.004$, without reperfusion $\mathrm{r}=0.773$; $\mathrm{p}<0.001){ }^{30}$ single-photon emission computed tomography (SPECT) using technetium-99 ( ${ }^{2} \mathrm{CTnT}_{72}$ : $r=0.62 ; p<0.001),{ }^{31}$ magnetic resonance imaging ( $c T n T_{96}$ : STEMI: $r=0.910$ and NSTEMI: $r=0.575$ ), ${ }^{32}$ or post mortem measurement of infarct size ( $\left.\mathrm{CTnT}_{96}: \mathrm{r}=0.74 ; \mathrm{p}=0.001\right) .^{33}$ Also, the cumulative troponin $\mathrm{T}$ release after 72 and after 168 hours correlated well with infarct size as estimated from cumulative enzyme release $\left(r=0.82\right.$ and 0.84 , respectively).$^{34}$ And a more recent study showed that peak cTnT values correlated strongly to cumulative cTnT values $\left(r_{s}=0.97-0.98\right)$ as well as to DE-MRI $\left(r_{s}=0.8\right.$ $0.82)$, whereas clinical routine sampling showed lower $r_{s}$ values $(0.47-0.60) .{ }^{35}$ In earlier studies we suggested that CTnT is only fractionally recovered after AMI. ${ }^{34}$ However, at that time we were not aware of fragmentation of cardiac troponin $\mathrm{T}$. With the present insights, the partial recovery of cardiac troponin $T$ can also be ascribed to degradation of CTnT as indicated in this thesis (Chapters 2, 3, 4, and 6).

Furthermore, troponins are measured via immunoassays and not enzymatically. Post translational modifications to troponin molecules ${ }^{36}$ and degradation as described in this thesis have major implications for current commercially available immunoassay performance, harmonization and standardization. It is currently unknown if these modifications have any clinical relevance, although disease specific forms have been demonstrated for $\mathrm{CTnI}^{37,} 38$

\section{TROPONIN RELEASE AND CLEARANCE}

As a biochemical marker of myocardial cell death, CTnT is highly similar compared with cTnI. In the cardiomyocyte both are present in complexed form with troponin C and in small quantities (4-8\%) as free molecules in the cytoplasm. ${ }^{39}$ Also, both are present in approximately equimolar amounts and are released after AMI in the same manner: they increase and reach peak levels parallel to each other, but CTnT tends to stay increased longer. This phenomenon is called the biphasic curve and this is seen in the majority of AMI patients with rapid reperfusion, ${ }^{40}$ unlike $\mathrm{CTnI}$ which always shows a monophasic release curve. ${ }^{22}$ Why these similar proteins have different release curves remains unclear. For CTnT it was originally suggested to be caused by the quick release of the small cytosolic (free) fraction and the slow release of the bound fraction. ${ }^{39}$ This is likely to be true because the troponin complex is bound tightly to tropomyosin via CTnT. ${ }^{41-43}$ It was shown that serial amino-terminal truncations of CTnT resulted in troponin complexes that were progressively smaller as judged by Stokes radius, and had a 
progressive loss of ability to interact with tropomyosin and actin. ${ }^{42}$ It is possible that cTnT is released from the contractile apparatus more slowly than CTnI or TnC, which are not directly bound to tropomyosin. Another plausible explanation for both cTnT and cTnI could be related to the detection method (immunoassay) in combination with post translational protein modifications. These have been described for CTnI, ${ }^{38,44}$ but also for $\mathrm{CTnT}^{45}$ As described in Chapter 3, the patients studied also showed the typical biphasic serum release curve for cTnT. Most likely this originates from the disappearance of the intact molecule from the circulation and the presence of degradation products for longer periods. The presence of CTnT degradation products has been described in several studies, ${ }^{36,46-50}$ but their presence has also been disputed. ${ }^{51-53}$ One study using perfused isolated rat hearts in a Langendorff setup showed with Western blot analysis using an antibody against cTnT, that cTnT was not degraded in the reperfusion effluent after 60 minutes of ischemia. ${ }^{54}$ This might indicate that cTnT is indeed released from ischemic cells in the intact form with degradation following in the circulation. The results from our studies (Chapter 3) are partly in line with these findings. We detected the intact protein in serum of three AMI patients within the first 12 hours after AMI. In some other patients fragments were already present in addition to the intact protein. However, more than 12 hours after AMI only fragments and no intact $\mathrm{CTnT}$ is present in the circulation.

It is important to realize that there are several factors influencing the forms of a molecule present in the circulation. ${ }^{38}$ These include parameters that affect the quantity and forms of intracellular proteins (such as CTnT) present in blood such as disease-induced processing, post-translational modifications of the proteins inside the myocardium, as well as any further processing in the blood following the release from the myocardium. The time course of appearance for each protein (or its modified products) in the blood will depend on its molecular mass, its affinity for other proteins, and its localization in the cell. ${ }^{55}$, 56 The disappearance from the circulation is influenced by other factors, including susceptibility to proteolysis and renal and lymphatic filtration. When using immunoassays for the detection of these proteins it is also important to include antibody affinity in this list.

In this thesis (Chapter 6) we describe the appearance of cTnT and cTnI into culture medium of isolated rat neonatal cardiomyocytes after metabolic inhibition. Metabolic inhibition of rat neonatal cardiomyocytes results in reversible cell damage: after about 12 hours cells undergo a transition towards irreversible damage, as characterized by prominent DNA fragmentation, cell membrane leakage, mitochondrial dysfunction, and increased messenger RNA of the protease calpain. ${ }^{57}$ Because a cell culture is a closed system, there is no renal or lymphatic filtration, yet the total amount of both troponins decreased significantly over the 30 hour incubation period. In contrast, the amount of LDH remained constant. Western blot analysis revealed the presence of several degradation products of both cTnT and cTnI. From these combined experiments we concluded that troponins are released from the cardiomyocyte in both the intact, as well as in degraded form and that the available immunoassays do not measure all fragments. These results have major implications for the laboratory analysis of these proteins, ${ }^{58}$ and as such for the clinical interpretation of these parameters in a variety of diseases.

\section{IMPLICATIONS FOR ASSAY HARMONIZATION}

The main problem with cTnI is the plethora of assays available, utilizing different antibody combinations and calibrators. It is not surprising that these assays show a 20 - to 40 -fold difference between assays. 
Results from one assay do therefore not necessarily apply to other CTnI assays or to the cTnT assay. ${ }^{22,}$

${ }^{59}$ Hence, it is important to evaluate the clinical implications of CTnI changes for each specific assay and confirm the prognostic value for the specific CTnI assay utilized at a particular laboratory. Harmonization of these assays is clearly needed. Towards this goal, the American Association of Clinical Chemistry (AACC) CTnI Standardization Committee collaborated with the National Institute of Standards and Technology (NIST) to select 2 candidate standard reference materials (SRM). ${ }^{58}$ The candidate that was shown to have most potential was SRM 2921, which according to the authors could assist in the harmonization once commutability was subsequently validated. ${ }^{60}$ In the Netherlands, a working group of the Dutch Foundation for Quality Assessment in Clinical Laboratories (SKML) recently investigated commutability of serum pools spiked with SRM 2921 and recombinant CTnI in a multi-centre survey by comparison of their behaviour to that of two patient serum pools ( $A$ and $B$ ) across several CTnI assays. ${ }^{61}$ Average recoveries of the SRM 2921-derived serum pool differed per CTnI method and ranged between $9-55 \%$. Overall interlaboratory CVs for CTnI were above $50 \%$ in all tested pools. In case of patient pool $A$ the overall interlaboratory $\mathrm{CV}$ for $\mathrm{CTnI}$ was $58 \%$. With the candidates, i.e. using patient pool B, SRM 2921-based serum pool and the recombinant CTnI based serum pool as calibrators, theoretical interlaboratory CVs for patient pool A would have been $11 \%, 40 \%$ and $52 \%$, respectively. When excluding one method with highest CV values, interlaboratory CVs for patient pool A were $13 \%$, $13 \%$ and $50 \%$. These CV values illustrate that especially the patient pool, and to a lesser extent the SRM 2921 based pool, have potential for harmonization, whereas the pool spiked with recombinant cTnI has no potential for CTnI harmonization. The underlying cause for the low recoveries was not investigated. It is plausible this may be the result of degradation of the material in vitro caused by instability of the molecule itself, degradation by active proteases (calpain-1, caspase-3), ${ }^{62-66}$ or post translational modifications of the molecule. ${ }^{36,38,44}$

Because there is only one manufacturer of CTnT immunoassays (Roche Diagnostics), regional or national harmonization of test results is not required. It is, however, important to realize that the degradation of CTnT as shown and discussed in Chapters 2, 3, 4 and 6 may very well have consequences. First, the use of a combination of two monoclonal antibodies automatically implies that some troponin fragments may not be measured. Clinically this does not have any consequences for the interpretation of the test result. All troponin immunoassays are valuable and validated assays that have proven to be of great value for the diagnosis and prognosis of ACS. Second, modification of the intact protein, to which these antibodies have been raised, may result in increased or decreased antibody binding to the molecule. Wu et al. have performed such experiments in vitro for cTnI and found remarkable differences in reactivity to various forms of $\mathrm{cTnI}$ that have been shown to be present in vivo. ${ }^{59}$

\section{FUTURE DIRECTIONS}

With the increased reliance of clinicians on cardiac troponins it is becoming more and more important for clinical chemists to realize exactly what is being measured with the current commercially available immunoassays. The work presented in this thesis was aimed at clarifying this issue for CTnT and answers therefore only partly the questions related to this issue. Future research will thus be aimed at clarifying the exact nature of the circulating CTnT fragments in a variety of diseases, such as AMI 
patients, ESRD patients on hemodialysis or peritoneal dialysis and participants of prolonged exercise events. The hypothesis in these studies will be that there are disease specific forms of cTnT that are immunoreactive in the current immunoassay and therefore generate a positive test result. Maybe we can in the near future identify these disease specific degradation products and shed light on the often unexplained cTnT elevations seen in the above mentioned (and many other) conditions. It might also be of interest to develop a new cTnT immunoassay, specifically designed to detect the intact protein. Because this is only present in the first 13 hours after AMI, this will allow the distinction between a recent MI and more chronic cTnT elevations seen in for example ESRD patients. Unfortunately, there are legal aspects that prohibit the commercial development of such an assay, because of several patents owned by Roche Diagnostics.

These studies will be performed using a combination of several techniques, including preparative SDSPAGE and tryptic digestion in combination with mass spectrometry to deduct from what part of the intact molecule the fragment originates. Furthermore, studies are now being performed in which antibody coated plates are used to extract cTnT from serum for measurement in immunocapture mass spectrometry and ellipsometry. Efforts are also underway to combine both cTnT and cTnI in all of the above mentioned experiments. 


\section{REFERENCES}

[1] Wu AH. Cardiac markers: from enzymes to proteins, diagnosis to prognosis, laboratory to bedside. Ann Clin Lab Sci 1999; 29: 18-23.

[2] Collinson PO, Gaze DC, Morris F, Morris B, Price A, Goodacre S. Comparison of biomarker strategies for rapid rule out of myocardial infarction in the emergency department using ACC/ESC diagnostic criteria. Ann Clin Biochem 2006; 43: 273-80.

[3] Wu AH, Valdes R, Jr., Apple FS, Gornet T, Stone $M A$, Mayfield-Stokes $S$, Ingersoll-Stroubos AM, Wiler B. Cardiac troponin-T immunoassay for diagnosis of acute myocardial infarction. Clin Chem 1994; 40: 900-7.

[4] Alpert JS, Thygesen K, Antman E, Bassand JP. Myocardial infarction redefined--a consensus document of The Joint European Society of Cardiology/American College of Cardiology Committee for the redefinition of myocardial infarction. J Am Coll Cardiol 2000; 36: 959-69.

[5] Braunwald E, Antman EM, Beasley JW, Califf RM, Cheitlin MD, Hochman JS, Jones RH, Kereiakes D, Kupersmith J, Levin TN, Pepine CJ, Schaeffer JW, Smith $E E$, 3rd, Steward DE, Theroux $P$, Alpert JS, Eagle KA, Faxon DP, Fuster V, Gardner TJ, Gregoratos G, Russell RO, Smith SC, Jr. ACC/AHA guidelines for the management of patients with unstable angina and non-ST-segment elevation myocardial infarction. A report of the American College of Cardiology/American Heart Association Task Force on Practice Guidelines (Committee on the Management of Patients With Unstable Angina). J Am Coll Cardiol 2000; 36: 970-1062.

[6] James SK, Lindback J, Tilly J, Siegbahn A, Venge $\mathrm{P}$, Armstrong $\mathrm{P}$, Califf $\mathrm{R}$, Simoons $\mathrm{ML}$, Wallentin $L$, Lindahl $B$. Troponin-T and $N$ terminal pro-B-type natriuretic peptide predict mortality benefit from coronary revascularization in acute coronary syndromes: a GUSTO-IV substudy. J Am Coll Cardiol 2006; 48: 1146-54.

[7] Khan NA, Hemmelgarn BR, Tonelli M, Thompson $C R$, Levin A. Prognostic value of troponin $T$ and I among asymptomatic patients with end-stage renal disease: a meta-analysis. Circulation 2005; 112: 3088-96.

[8] Wang AM, Lam CK, Yu CM, Wang M, Chan IS Lui SF, Sanderson JE. Troponin T, left ventricular mass, and function are excellent predictors of cardiovascular congestion in peritoneal dialysis. Kidney Int 2006; 70: 44452.

[9] Giannitsis E, Muller-Bardorff M, Kurowski V Weidtmann B, Wiegand U, Kampmann M, Katus $\mathrm{HA}$. Independent prognostic value of cardiac troponin $\mathrm{T}$ in patients with confirmed pulmonary embolism. Circulation 2000; 102: 211-7.

[10] Lindahl B, Toss $H$, Siegbahn A, Venge $P$ Wallentin L. Markers of myocardial damage and inflammation in relation to long-term mortality in unstable coronary artery disease. FRISC Study Group. Fragmin during Instability in Coronary Artery Disease. N Engl J Med 2000; 343: 1139-47.
[11] Wood GN, Keevil B, Gupta J, Foley R, Bubtana A, McDowell G, Ackrill P. Serum troponin $T$ measurement in patients with chronic renal impairment predicts survival and vascular disease: a 2 year prospective study. Nephrol Dial Transplant 2003; 18: 1610-5.

[12] Dierkes J, Domrose U, Westphal S, Ambrosch A, Bosselmann HP, Neumann KH, Luley C. Cardiac troponin $\mathrm{T}$ predicts mortality in patients with end-stage renal disease. Circulation 2000; 102: 1964-9.

[13] Roppolo LP, Fitzgerald $R$, Dillow J, Ziegler $T$, Rice M, Maisel A. A comparison of troponin T and troponin I as predictors of cardiac events in patients undergoing chronic dialysis at a Veteran's Hospital: a pilot study. J Am Coll Cardiol 1999; 34: 448-54

[14] Hartmann F, Giannitsis E, Kurowski V, Frey N, Kampmann M, Katus HA. Risk stratification and therapeutic decision making in patients with acute coronary syndrome--the role of cardiac troponin T. Clin Chem Lab Med 1999; 37: 110711

[15] Bodi V, Sanchis J, Llacer A, Facila L, Nunez J, Pellicer M, Bertomeu V, Ruiz V, Chorro FJ. Multimarker risk strategy for predicting 1month and 1-year major events in non-STelevation acute coronary syndromes. Am Heart J 2005; 149: 268-74.

[16] Christ M, Laule K, Klima T, Hochholzer W, Breidthardt $T$, Perruchoud AP, Mueller $C$. Multimarker strategy for risk prediction in patients presenting with acute dyspnea to the emergency department. Int J Cardiol 2007.

[17] Eggers KM, Oldgren J, Nordenskjold A, Lindah B. Combining different biochemical markers of myocardial ischemia does not improve risk stratification in chest pain patients compared to troponin I alone. Coron Artery Dis 2005; 16: 315-9.

[18] Fonarow GC, Horwich TB. Combining natriuretic peptides and necrosis markers in determining prognosis in heart failure. Rev Cardiovasc Med 2003; 4 Suppl 4: S20-8

[19] Sabatine MS, Morrow DA, de Lemos JA, Gibson CM, Murphy SA, Rifai N, McCabe C, Antman EM, Cannon CP, Braunwald E. Multimarker approach to risk stratification in non-ST elevation acute coronary syndromes: simultaneous assessment of troponin I, C-reactive protein, and B-type natriuretic peptide. Circulation 2002; 105: 1760-3.

[20] Braunwald E. Unstable angina: an etiologic approach to management. Circulation 1998; 98: 2219-22.

[21] Apple FS, Murakami MM, Pearce LA, Herzog CA. Multi-Biomarker Risk Stratification of $\mathrm{N}$ Terminal Pro-B-Type Natriuretic Peptide, HighSensitivity C-Reactive Protein, and Cardiac Troponin T and I in End-Stage Renal Disease for All-Cause Death. Clin Chem 2004. 
[22] Katrukha AG, Bereznikova AV, Filatov VL, Esakova TV, Kolosova OV, Pettersson K, Lovgren T, Bulargina TV, Trifonov IR, Gratsiansky NA, Pulkki K, Voipio-Pulkki LM, Gusev NB. Degradation of cardiac troponin I: implication for reliable immunodetection. Clin Chem 1998; 44: 2433-40.

[23] Gerhardt W, Nordin G, Herbert AK, Linaker Burzell B, Isaksson A, Gustavsson E, Haglund S, Muller-Bardorff M, Katus HA. Troponin T and I Assays Show Decreased Concentrations in Heparin Plasma Compared with Serum: Lower Recoveries in Early than in Late Phases of Myocardial Injury. Clin Chem 2000; 46: 817-21.

[24] Speth M, Seibold K, Katz N. Interaction between heparin and cardiac troponin $\mathrm{T}$ and troponin I from patients after coronary bypass surgery. Clin Biochem 2002; 35: 355-62.

[25] Hermsen D, Apple F, Garcia-Beltran L, Jaffe A, Karon B, Lewandrowski E, Muhlbacher A, Muller R, Ordonez J, Pagani F, Panteghini M, Plecko T, Jarausch J. Results from a multicenter evaluation of the 4th generation Elecsys Troponin T assay. Clin Lab 2007; 53: 1-9.

[26] Hackel DB, Reimer KA, Ideker RE, Mikat EM, Hartwell TD, Parker CB, Braunwald EB, Buja M, Gold HK, Jaffe AS, et al. Comparison of enzymatic and anatomic estimates of myocardial infarct size in man. Circulation 1984; 70: 824-35.

[27] Grande P, Hansen BF, Christiansen C, Naestoft J. Estimation of acute myocardial infarct size in men by serum CK-MB measurements. Circulation 1982; 65: 756-64.

[28] Herlitz J, Hjalmarson A, Lomsky M, Wiklund I. The relationship between infarct size and mortality and morbidity during short-term and long-term follow-up after acute myocardial infarction. Am Heart J 1988; 116: 1378-82.

[29] Mair J, Wagner I, Morass B, Fridrich L, Lechleitner P, Dienstl F, Calzolari C, Larue C, Puschendorf B. Cardiac troponin I release correlates with myocardial infarction size. Eur J Clin Chem Clin Biochem 1995; 33: 869-72.

[30] Licka M, Zimmermann R, Zehelein J, Dengler TJ, Katus HA, Kubler W. Troponin T concentrations 72 hours after myocardial infarction as a serological estimate of infarct size. Heart 2002; 87: 520-4.

[31] Panteghini M, Cuccia C, Bonetti G, Giubbini R, Pagani F, Bonini E. Single-point cardiac troponin $\mathrm{T}$ at coronary care unit discharge after myocardial infarction correlates with infarct size and ejection fraction. Clin Chem 2002; 48: 1432-6.

[32] Steen H, Giannitsis E, Futterer S, Merten C, Juenger $\mathrm{C}$, Katus HA. Cardiac troponin T at 96 hours after acute myocardial infarction correlates with infarct size and cardiac function. J Am Coll Cardiol 2006; 48: 2192-4.

[33] Remppis A, Ehlermann P, Giannitsis E, Greten $T$, Most $P$, Muller-Bardorff $M$, Katus HA. Cardiac troponin T levels at 96 hours reflect myocardial infarct size: A pathoanatomical study. Cardiology 2000; 93: 249-53.

[34] Kragten JA, Hermens WT, van Dieijen-Visser MP. Cardiac troponin T release into plasma after acute myocardial infarction: only fractional recovery compared with enzymes. Ann Clin Biochem 1996; 33 (Pt 4): 314-23.
[35] Hedstrom E, Astrom-Olsson K, Ohlin H, Frogner $F$, Carlsson $M$, Billgren $T$, Jovinge $S$, Cain $P$, Wagner GS, Arheden H. Peak CKMB and CTnT accurately estimates myocardial infarct size after reperfusion. Scand Cardiovasc J 2007; 41: 44-50.

[36] Labugger R, Organ L, Collier C, Atar D, Van Eyk JE. Extensive troponin I and $T$ modification detected in serum from patients with acute myocardial infarction. Circulation 2000; 102: 1221-6.

[37] McDonough JL, Labugger R, Pickett W, Tse MY, Mackenzie S, Pang SC, Atar D, Ropchan G, Van Eyk JE. Cardiac troponin I is modified in the myocardium of bypass patients. Circulation 2001; 103: 58-64.

[38] Labugger R, Arrell DK, Van Eyk JE. Cardiac troponins: exploiting the diagnostic potential of disease-induced protein modifications. In: Wu $\mathrm{AH}$, ed. Cardiac Markers. 2 ed. Totowa, NJ: Humana Press Inc.; 2003:125-38.

[39] Katus HA, Remppis A, Scheffold T, Diederich $\mathrm{KW}$, Kuebler W. Intracellular compartmentation of cardiac troponin $T$ and its release kinetics in patients with reperfused and nonreperfused myocardial infarction. Am J Cardiol 1991; 67: 1360-7.

[40] Mair J, Thome-Kromer B, Wagner I, Lechleitner P, Dienstl F, Puschendorf B, Michel G. Concentration time courses of troponin and myosin subunits after acute myocardial infarction. Coron Artery Dis 1994; 5: 865-72.

[41] Mak AS, Smillie LB. Structural interpretation of the two-site binding of troponin on the muscle thin filament. J Mol Biol 1981; 149: 541-50.

[42] Hinkle A, Goranson A, Butters CA, Tobacman LS. Roles for the troponin tail domain in thin filament assembly and regulation. A deletional study of cardiac troponin T. J Biol Chem 1999; 274: 7157-64.

[43] Hitchcock SE, Huxley HE, Szent-Gyorgyi AG. Calcium sensitive binding of troponin to actintropomyosin: a two-site model for troponin action. J Mol Biol 1973; 80: 825-36.

[44] McDonough JL, Van Eyk JE. Developing the next generation of cardiac markers: disease-induced modifications of troponin I. Prog Cardiovasc Dis 2004; 47: 207-16.

[45] Jideama NM, Noland TA, Jr., Raynor RL, Blobe GC, Fabbro D, Kazanietz MG, Blumberg PM, Hannun YA, Kuo JF. Phosphorylation specificities of protein kinase $C$ isozymes for bovine cardiac troponin I and troponin T and sites within these proteins and regulation of myofilament properties. J Biol Chem 1996; 271: 23277-83.

[46] Labugger R, McDonough JL, Neverova I, Van Eyk JE. Solubilization, two-dimensional separation and detection of the cardiac myofilament protein troponin T. Proteomics 2002; 2: 673-8.

[47] Diris JH, Hackeng CM, Kooman JP, Pinto YM, Hermens WT, Van Dieijen-Visser MP. Impaired Renal Clearance Explains Elevated Troponin T Fragments in Hemodialysis Patients. Circulation 2004; 109: 23-5. 
[48] Colantonio DA, Van Eyk JE, Przyklenk K. Stunned peri-infarct canine myocardium is characterized by degradation of troponin $\mathrm{T}$, not troponin I. Cardiovasc Res 2004; 63: 217-25.

[49] Michielsen EC, Diris JH, Hackeng CM, Wodzig WK, Van Dieijen-Visser MP. Highly sensitive immunoprecipitation method for extracting and concentrating low-abundance proteins from human serum. Clin Chem 2005; 51: 222-4.

[50] Michielsen EC, Diris JH, Kleijnen VWVC, Wodzig $\mathrm{KW}$, Van Dieijen-Visser MP. Interpretation of cardiac troponin $\mathrm{T}$ behaviour in size-exclusion chromatography. Clin Chem Lab Med 2006; 44: 1422-7.

[51] Fahie-Wilson MN, Carmichael DJ, Delaney MP, Stevens PE, Hall EM, Lamb EJ. Cardiac Troponin $\mathrm{T}$ Circulates in the Free, Intact Form in Patients with Kidney Failure. Clin Chem 2006; 52: 41420.

[52] Michielsen EC, Diris JH, Kleijnen VWVC, Wodzig $\mathrm{KW}$, van Dieijen-Visser MP. Size-exclusion chromatography of circulating cardiac troponin T. Clin Chem 2006; 52: 2306-7; author reply 79.

[53] Fahie-Wilson MN, Hall EM, Lamb EJ. The authors of the article cited above respond. Clin Chem 2006; 52: 2307-9.

[54] Van Eyk JE, Powers F, Law W, Larue C, Hodges RS, Solaro RJ. Breakdown and release of myofilament proteins during ischemia and ischemia/reperfusion in rat hearts: identification of degradation products and effects on the pCaforce relation. Circ Res 1998; 82: 261-71.

[55] Adams JE, 3rd. Clinical application of markers of cardiac injury: basic concepts and new considerations. Clin Chim Acta 1999; 284: 12734.

[56] Mair J. Tissue release of cardiac markers: from physiology to clinical applications. Clin Chem Lab Med 1999; 37: 1077-84.

[57] Chen S], Bradley ME, Lee TC. Chemical hypoxia triggers apoptosis of cultured neonatal rat cardiac myocytes: modulation by calciumregulated proteases and protein kinases. Mol Cell Biochem 1998; 178: 141-9.
[58] Christenson RH, Duh SH, Apple FS, Bodor GS, Bunk DM, Dalluge J, Panteghini M, Potter JD, Welch MJ, Wu AH, Kahn SE. Standardization of cardiac troponin I assays: round Robin of ten candidate reference materials. Clin Chem 2001; 47: 431-7.

[59] Wu AH, Feng YJ, Moore R, Apple FS, McPherson $\mathrm{PH}$, Buechler KF, Bodor $\mathrm{G}$. Characterization of cardiac troponin subunit release into serum after acute myocardial infarction and comparison of assays for troponin $T$ and $\mathrm{I}$. American Association for Clinical Chemistry Subcommittee on cTnI Standardization. Clin Chem 1998; 44: 1198-208.

[60] Bunk DM, Welch MJ. Characterization of a new certified reference material for human cardiac troponin I. Clin Chem 2006; 52: 212-9.

[61] Cobbaert C, Michielsen EC, Weykamp CW, Baadenhuijsen $H$, Van Dieijen-Visser MP. Do NIST SRM 2921 and recombinant cTnI based serum pools have potential to harmonize cTnI results? Clin Chem Lab Med 2007; 45: S18.

[62] Atsma DE, Bastiaanse EM, Jerzewski A, Van der Valk LJ, Van der Laarse A. Role of calciumactivated neutral protease (calpain) in cell death in cultured neonatal rat cardiomyocytes during metabolic inhibition. Circ Res 1995; 76: 1071-8.

[63] Tolnai S, Korecky B. Calcium-dependent proteolysis and its inhibition in the ischemic rat myocardium. Can J Cardiol 1986; 2: 42-7.

[64] Barta J, Toth A, Edes I, Vaszily M, Papp JG, Varro A, Papp Z. Calpain-1-sensitive myofibrillar proteins of the human myocardium. Mol Cell Biochem 2005; 278: 1-8.

[65] Communal C, Sumandea M, de Tombe P, Narula J, Solaro RJ, Hajjar RJ. Functional consequences of caspase activation in cardiac myocytes. Proc Natl Acad Sci U S A 2002; 99: 6252-6.

[66] Kositprapa C, Zhang B, Berger S, Canty JM, Jr. Lee TC. Calpain-mediated proteolytic cleavage of troponin I induced by hypoxia or metabolic inhibition in cultured neonatal cardiomyocytes. Mol Cell Biochem 2000; 214: 47-55. 


\section{SUMMARY}

Cardiac troponins are proteins that facilitate muscle contraction. Together in a complex of three proteins (troponin T, I and C), they form the troponin complex. Troponin $\mathrm{T}$ binds the complex to tropomyosin, troponin I is the inhibiting part and troponin $\mathrm{C}$ binds the calcium ions that are needed for contraction. After binding of calcium the complex loses its natural inhibitory effect and allows the muscle to contract. There are two types of troponin I and $\mathrm{T}$ that are present in either skeletal muscle or heart muscle. The cardiac troponins I (cTnI) and T (cTnT) can be detected in the circulation with immunoassays that only react with the cardiac forms. They are the preferred biomarkers of cardiac tissue damage. It is rather difficult to study these proteins because cTnI and cTnT are not present in the circulation of healthy individuals. Only after cardiac tissue damage in for example acute coronary syndromes (ACS) the troponins will be released from the cardiac cells into the circulation, and depending on the severity of disease sometimes only in very small amounts. To overcome this issue, we developed and optimized a method for concentrating and purifying CTnT from serum from patients with troponin release (Chapter 2). With this method we extracted cTnT from patients with end stage renal disease who were on hemodialysis. The different molecular forms of cTnT were separated based on their molecular weight with gel electrophoresis (SDS-PAGE). We showed the presence of cTnT fragments, but not the intact protein in these patients, who at that time did not have clinically diagnosed cardiac tissue damage or ACS. Importantly, these patients did have positive cTnT concentrations.

We then investigated the release of CTnT in patients with an acute myocardial infarction (AMI). We looked at the release of CTnT after onset of symptoms with the method described in Chapter 2 and investigated the molecular forms of CTnT at different times after AMI (Chapter 3). We showed for the first time that the circulating forms of cTnT are dependent on the time after onset of symptoms. The intact protein is only present in the first 12 hours and thereafter only fragments are present. The current immunoassay detects both the intact form and (several) degraded cTnT forms. Importantly, from in vitro experiments it became clear that the absolute concentration is influenced by fragmentation (Chapter 4). One issue that we could not overcome in these experiments was the availability of the original antibodies that are used in the commercial immunoassay. We therefore utilized size-exclusion chromatography, a different technique for separation of proteins based on size, and used the current immunoassay to detect CTnT (Chapter 4). In vitro studies showed rapid degradation of the intact protein and the appearance of smaller forms that reacted positively in the immunoassay. Analysis of serum from patients with AMI confirmed the presence of smaller circulating forms of cTnT in these patients as was demonstrated in Chapter 3.

Elevations of cTnT after strenuous and prolonged endurance events (marathon, triathlon) have been reported. It remains, however, difficult to determine whether these elevations are the result of reversible or irreversible damage to the heart. When we reviewed the available literature (Chapter 5) we found that $59 \%$ of all participants in these events had detectable cTnT levels within 1 hour after the race that decreased within 24 to 48 hours. This percentage is dependent on the immunoassay generation and the cut-off values for cTnT that were used. Most studies showed that these effects were transient, suggesting that the release of cTnT represents reversible cardiac damage. 
It is unknown in what form the cardiac troponins are released into the circulation. We therefore looked in more detail to the release of cTnI and cTnT from the cardiac cell using neonatal rat cardiomyocytes, a model of metabolically induced ischemia (Chapter 6). We showed parallel release of intact cTnI, cTnT and their degradation products starting directly after onset of irreversible cardiomyocyte damage. There was hardly any troponin release during the reversible phase of the metabolic inhibition, although the total cTnT and cTnI concentrations per culture (cells + medium) decreased during the first 12 hours. Troponin release after 30 hours was only a fraction of the release of Lactate Dehydrogenase activity (LDH). There was progressive loss of CTnI and cTnT that was undetected by the antibodies used and already occurred during the first 12 hours, possibly due to degradation of troponin. In a separate study we investigated the value of a biomarker of heart function and volume overload, serum amino terminalproBNP (NT-proBNP) for ruling out heart failure (HF). We describe that renal function influences NTproBNP levels more than age in this selected population and demonstrate that serum NT-proBNP is the best predictor of $\mathrm{HF}$ (Chapter 7). The product of the serum and urinary NT-proBNP concentrations has equal value, but urinary NT-proBNP alone has a lower diagnostic accuracy. The above mentioned issues are discussed in the light of the most recent literature and insights of the present time in the final chapter, which also states directions for future research (Chapter 8). 


\section{NederLANDSE SAMENVATting}

Cardiale troponines zijn eiwitten die betrokken zijn bij spiercontractie. Samen, in een complex van drie eiwitten (troponine T, I en C), vormen ze het troponine complex. Troponine $\mathrm{T}$ bindt het complex aan tropomyosine, troponine I is het remmende (inhiberende) deel van het complex en troponine $\mathrm{C}$ bindt de calcium ionen die nodig zijn voor spiercontractie. Nadat een calcium ion gebonden is door het troponine complex, verliest troponine I zijn van nature remmende werking en de spier trekt samen. Er bestaan twee vormen van troponine I en T die vóórkomen in of skeletweefsel, of hartspierweefsel. De cardiale troponines I (cTnI) en T (cTnT) kunnen in de bloedsomloop gedetecteerd worden met immunoassays die alleen reageren met de cardiale vormen. De cardiale troponines zijn de meest specifieke biomerkers van hartspierschade. Het is vrij lastig om deze eiwitten te bestuderen omdat cTnI en cTnT niet voorkomen in de bloedsomloop van gezonde individuen. Alleen na hartspierschade, bijvoorbeeld zoals optreedt na een acuut myocard infarct (AMI), komen de troponines vrij uit de hartspiercellen waarna ze in de bloedsomloop terecht komen. Afhankelijk van de ernst van het AMI soms slechts in lage concentraties. Om dit probleem van biologische beschikbaarheid te omzeilen hebben we een methode ontwikkeld en geoptimaliseerd waarmee we cTnT uit serum van patiënten met troponine verhogingen kunnen zuiveren en concentreren (Hoofdstuk 2). Met behulp van deze methode extraheerden we cTnT uit serum van patiënten met eind stadium nierfalen die hiervoor werden gehemodialyseerd. De verschillende moleculaire vormen van cTnT werden gescheiden op grootte (molecuul gewicht) met gelelectrophorese (SDS-PAGE). Wij toonden de aanwezigheid van fragmenten van cTnT aan, maar konden het intacte eiwit niet aantonen in deze patiënten (die op dat moment geen klinisch te diagnosticeren hartspierschade of AMI hadden). Het is belangrijk om te realiseren dat deze patiënten desondanks positieve cTnT concentraties hadden. Vervolgens onderzochten we het vrijkomen van cTnT in patiënten met AMI. Door wederom gebruik te maken van de methode beschreven in Hoofdstuk 2 bestudeerden we het vrijkomen na aanvang van de symptomen (Hoofdstuk 3). We lieten voor het eerst zien dat de circulerende vormen van cTnT in de bloedsomloop afhankelijk zijn van het tijdstip na aanvang van de symptomen. Het intacte eiwit is alleen in de eerste 12 uur aantoonbaar en daarna zijn alleen nog maar fragmenten aantoonbaar. De huidige immunoassay detecteert zowel het intacte eiwit en (enkele) fragmenten of gedegradeerde cTnT vormen. Uit in vitro experimenten werd duidelijk dat de absolute cTnT concentratie zoals gemeten met de huidige immunoassay beïnvloed wordt door fragmentatie (Hoofdstuk 4). Helaas hadden we in alle voorgaande experimenten niet de beschikking over de antilichamen die in de commerciële immunoassay gebruikt worden. Hierdoor was het onmogelijk om de gevonden fragmenten te koppelen aan de kwantitatieve uitslagen van de immunoassay. We hebben daarom gebruik gemaakt van size-exclusion chromatografie, een andere techniek om eiwitten op grootte te scheiden, en gebruikten de commerciële immunoassay om cTnT te detecteren (Hoofdstuk 4). In vitro studies lieten een snelle degradatie van het intacte eiwit zien met tegelijkertijd het verschijnen van kleinere cTnT vormen die positief resultaat gaven in de immunoassay. Analyse van serum van patiënten met AMI bevestigde de aanwezigheid van kleine circulerende vormen van cTnT in deze patients zoals met een andere techniek was aangetoond in het onderzoek beschreven in Hoofdstuk 3. Verhogingen van cTnT na extreme en langdurige inspanning (marathon, triathlon) zijn eerder beschreven. Het blijft echter moeilijk om vast te stellen of deze verhogingen het resultaat zijn van reversibele or irreversibele schade aan het hart. We hebben de beschikbare literatuur op een rijtje 
gezet (Hoofdstuk 5) en vonden dat $59 \%$ van alle deelnemers aan deze evenementen detecteerbare CTnT concentraties hadden binnen 1 uur na de race die afnamen binnen 24 tot 48 uur. Dit percentage is afhenkelijk van de generatie van de immunoassay die werd gebruikt en de afkapwaarden die voor cTnT werden gehanteerd. De meeste studies toonden aan data deze effecten reversibel waren en suggereren vervolgens dat het vrijkomen van CTnT in de bloedsomloop reversibele hartspierschade representeert. Het is onbekend in welke vormen de cardiale troponines in de bloedsomloop worden vrijgemaakt. Daarom bestudeerden we in meer detail door gebruik te maken van neonatale ratten hartspiercellen. Dit is een model voor ischemie door het celmetabolisme stil te leggen (Hoofdstuk 6). Het bleek dat intact CTnI, CTnT en hun degradatieproducten direct vrijkomen nadat de cellen de overgang doormaken van reversibele naar irreversibele schade. Tijdens de reversibele fase kwam er nauwelijks troponine uit de cellen, terwijl de totale hoeveelheid troponine in de cel en het medium waarin ze gekweekt werden afnam in de eerste 12 uur. De hoeveelheid troponine die na 30 uur vrijgekomen was uit de cellen was slechts een fractie van de Lactaat Dehydrogenase activiteit (LDH). Er was progressief verlies van beide troponines in de eerste 12 uur die niet werd gemeten met de door ons gebruikte antilichamen. Mogelijk is de verklaring hiervoor degradatie van de intacte moleculen waardoor antilichamen niet meer kunnen binden. In een aparte studie onderzochten we de diagnostische waarde van een biomarker voor hartfunctie en overvulling, serum amino terminaal-proBNP (NT-proBNP) voor het uitsluiten van hartfalen (HF). We vonden dat nierfunctie een grotere invloed heeft op de NT-proBNP concentratie dan leeftijd in de door ons onderzochte populatie en toonden aan dat serum NT-proBNP de beste voorspeller is voor de aanwezigheid van (Hoofdstuk 7). Het product van de serum en urine NT-proBNP concentraties heeft dezelfde disagnostische waarde, maar de urine NT-proBNP concentratie alleen heeft een lagere diagnostische waarde. De bovengenoemde zaken worden bediscussieerd tegen het licht van de meest recente literatuur en inzichten van vandaag in het laatste hoofdstuk (Hoofstuk 8). Tevens worden hierin mogelijkheden van vervolgonderzoek besproken. 


\section{Curriculum Vitae}

Etienne Michielsen werd geboren op 12 maart 1976 in Dongen als eerste zoon van Cees Michielsen en Corry Michielsen-Van Dongen. Hij heeft één jongere broer, Mathieu. In juni 1995 rondde hij het voorbereidend wetenschappelijk onderwijs (atheneum) af aan het Dr. Schaepman College (later Cambreur College) in Dongen. In september van datzelfde jaar startte hij zijn universitaire opleiding Biomedische Gezondheidswetenschappen in Nijmegen aan de KUN. Tijdens zijn opleiding was hij drie jaar lid van de opleidingscommissie en het SOOS. Daarnaast was hij praeses van de Medische Faculteits Vereniging Nijmegen in 1998/1999. Hij behaalde zijn bul in 2001 en studeerde af in zowel toxicologie (dr. Rob Bos) en pathobiologie (prof. dr. Wim van den Berg). Tijdens zijn toxicologische stage op de Afdeling voor Bloedtransfusie en Transplantatie Immunologie (ABTI) onderzocht hij de effecten van immuunsuppressiva op T-cel activatie en tolerantie inductie bij dr. Irma Joosten en dr. Hans Koenen. In Sydney onderzocht hij onder leiding van prof. dr. Peter Ghosh de beschermende werking van het medicijn pentosan polysulfaat op kraakbeenafbraak tijdens zijn stage voor pathobiologie. Na zijn studie werkte hij een jaar in het marktonderzoek voor de farmaceutische industrie.

In 2003 begon hij op de afdeling Klinische Chemie van het academisch ziekenhuis Maastricht aan het onderzoek dat beschreven staat in dit proefschrift. Onder leiding van zijn promotor prof. dr. Marja van Dieijen-Visser en co-promotor dr. Will Wodzig startte hij op deze afdeling het proteomicsonderzoek op met behulp van massaspectrometrie (SELDI-TOF). Voor dit onderzoek kreeg hij in 2005 de prijs voor beste abstract op het Voorjaarscongres van de Nederlandse Verenigning voor Klinische Chemie (NVKC). Na een jaar verplaatste de onderzoeksvraag zich naar biochemische merkers voor hartschade (cardiaal troponine T) en hartfunctie (NT-proBNP). De resultaten van dit onderzoek staan beschreven in dit proefschrift.

Etienne is nu bij dr. Joost Swaanenburg in opleiding tot klinisch chemicus in het VieCuri Medisch Centrum voor Noord-Limburg. Hij deelt zijn leven met Marieke. Zij leven nu samen in Nijmegen met hun dochter Lotte. 



\section{DANKWOORD}

"Een goede onderzoeker kenmerkt zich doordat hij kennis haalt waar die te vinden is en niet steeds zelf opnieuw het wiel uitvindt." Deze opmerking werd gemaakt door een docent tijdens één van de cursussen die ik aan de Universiteit Maastricht heb gevolgd. Ik heb de afgelopen vier jaar vaak gebruik gemaakt van deze wijze les en op deze plaats wil ik graag die mensen bedanken waar ik kennis heb mogen opdoen tijdens mijn onderzoek in Maastricht.

Allereerst bedank ik prof. dr. M.P. Van Dieijen-Visser (Marja). Ik voelde me bij jou meteen op mijn gemak en dat maakt de drempel om vragen te stellen erg laag. Regelmatig heb ik dan ook gebruik gemaakt van de mogelijkheid om binnen te lopen met weer eens een nieuwe vraag of opmerking. De snelheid waarmee jij mijn manuscripten inhoudelijk en tekstueel kon nakijken grenst haast aan het onmogelijke. Marja, je bent in mijn ogen de ideale promotor. Bedankt voor alle leermomenten, onze goede gesprekken, het vertrouwen en de zelfstandigheid die je me gaf. Even zo laagdrempelig was het contact met mijn copromotor dr. K.W.H. Wodzig (Will). Misschien hebben we te weinig samen genoten van een goed glas bier op een mooi Maastrichts terras. In Leipzig merkte ik dat we daar allebei erg van kunnen genieten.

Bedankt dat ik de kans heb gekregen mezelf te ontplooien vanonder jullie vleugels. Zo heb ik mijn koppigheid onder jullie begeleiding aardig onder controle gekregen...

Ten tweede, maar zeker even belangrijk, Vincent. Het is haast niet te beschrijven hoeveel werk je me uit handen hebt genomen door het uitvoeren van enkele honderden western blots. Daarnaast ben je de drijvende kracht achter de logistiek van alle onderzoeken waar het laboratorium in participeert. Ook dacht je regelmatig mee over hoe we de experimenten het meest efficiënt konden uitvoeren. Bedankt voor vier leerzame, productieve en gezellige jaren.

Robert, jij was mijn kamergenoot van begin tot het eind. Jij bent een erg gedreven en intelligent persoon waarmee ik regelmatig goede discussies heb gehad. Mijns inziens is het een groot voordeel wanneer onderzoekers met elkaar discussieren vanuit een verschillende achtergrond. Dat eerste jaar was voor mij een erg leerzaam jaar, bedankt. Judith, jij kwam niet veel later als broekie bij de "oudere" heren op de kamer. Je wist je snel goed staande te houden. Een geïnteresseerde vraag ligt altijd klaar. Met die nieuwsgierige instelling kom je heel ver. Het was altijd gezellig met je.

Beiden, ongelofelijk bedankt voor de mooie tijd samen binnen en buiten het laboratorium.

Jart, jouw onderzoek naar troponine fragmentatie mocht ik voortzeten, terwijl jij je volop op de opleiding stortte. Ik heb zeker in mijn eerste jaar veel aan je kennis van troponine T gehad. Daarnaast hebben we ook buiten het werk om veel gelachen. Jij introduceerde het geocachen en ik ben je nog steeds dankbaar voor de keer dat ik je als hulplijn heb mogen gebruikt toen ik in een godverlaten gebied een cache niet kon vinden... Die houd je van me tegoed!

Snježana, je werd eigelijk vrij snel een goede vriendin in het verre Maastricht. We hebben samen veel tijd doorgebracht op de salsadansvloer en ik kijk met veel plezier terug op onze gezamenlijke 
gesprekken over de belangrijke zaken in ieders leven. Ik gun je alle geluk in je leven. Slechts weinigen kunnen aanspraak maken op het doorzettingsvermogen dat jij bezit. Een goed voorbeeld voor mij en hopelijk vele anderen. Bedankt voor alles!

Jaap, altijd als ik vastzat met mijn onderzoeksvragen kon ik bij jou terecht voor een ideetje of tien. Ik verbaasde me altijd over waar je ze vandaan haalde. Jouw enthousiastme is bewonderenswaardig en had op mij een aanstekelijke werking. Daarnaast ben je ook een gezellige collega die oprecht in mensen geïnteresseerd is. Bedankt.

Douwe, bedankt voor alle inside-information over de wereld die topsport heet met al zijn doping perikelen. Jouw kennis van massaspectrometrie heeft mij vaak aan het denken gezet over de optimalisatie van de SELDI. Veel succes met de opleiding tot klinisch chemicus.

Ik wil hier ook de andere klinisch chemici, dr. Otto Bekers (één van de fanatiekste bezoekers van mijn filmavonden) en dr. ir. Paul Menheere, meenemen in mijn dankbetuigingen. Ik heb veel geleerd over het vak door jullie aan het werk te zien. Ik hoop dat ik nog steeds veel van jullie kan en mag leren tijdens mijn opleiding in Venlo.

Tijdens mijn werk in Maastricht mocht ik (helaas maar) één stagiare begeleiden, Ellen. Ik heb mijn best gedaan je enthousiast te maken voor het onderzoek en je enkele dingen te leren. Hopelijk ben ik daarin geslaagd. Succes met je verdere loopbaan.

De medewerkers van de afdeling Klinische Chemie bedank ik voor de leuke tijd die ik heb gehad in de afgelopen vier jaar. Enkelen wil ik hier bij naam noemen: Petal, bedankt voor je heerlijke cynische opmerkingen. Ik heb ze altijd prachtig gevonden. Maurice, door jou heb ik het "Mestreechs" snel onder de knie gekregen, waardoor ik me al snel staande kon houden tussen al die Limbo's met hun taaltje. Ook kende je ongeveer iedereen in het azM, waardoor ik altijd bij je terecht kon als ik weer eens iets geregeld wilde hebben. Jos, bedankt voor de inleiding in de chromatografie en de HPLC en de gesprekken over hardlopen. Veel succes met alle komende halve en hele marathons die je nog gaat lopen. Rachel, bedankt voor de leerzame en wijze spreuken die me veel inzicht hebben gegeven. Loe Donselaar, bedankt voor je vaderlijke enthousiastme en interesse in mijn onderzoek en leven.

En dan is er nog de administratie waar Richard (door mij steevast "Hey Bolle" genoemd) de scepter zwaait. Hij kan een aardig robbertje drummen (zoals in de gelegenheidsband van het lab) en is altijd goed gehumeurd. Bedankt voor de noodzakelijke humor, ik heb veel met je gelachen. Hij wordt bijgestaan door twee dames die ik regelmatig om hulp heb gevraagd: Mariëlle en Paula. Iedereen die zijn of haar vrije avonden opofferde bedank ik voor het bezoeken van mijn filmavonden (Servi, Peter, Jan: bedankt voor het leveren van de films en natuurlijk vele geweldige uren kijkplezier!).

Packets Sold Daily bedank ik omdat ik tijdens mijn onderzoek elke vrijdagavond mijn frustraties en verhalen kwijt kon door samen met drie goede vrienden (Emile, Oliver en Twan) muziek te bedenken en spelen. Zoals Bono ooit zei: "Thanks for letting me be in your band!" 
Mijn ouders en broertje bedank ik voor hun steun en begrip als ik weer eens "maanden" niet thuis kwam. Ik heb vaak aan jullie gedacht en daarom draag ik dit proefschrift aan jullie op.

Marieke, jij weet als geen ander hoeveel werk een proefschrift met zich meebrengt. Als laatste bedank ik jou voor je begrip en steun, maar boven alles voor je onvoorwaardelijke liefde.

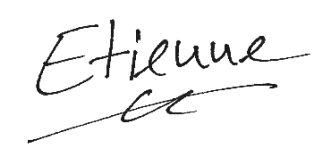





\section{LIST OF PUBLICATIONS}

\section{Papers}

[1] HJ Koenen, ECHJ Michielsen, J Verstappen, E Fasse, I Joosten. Superior T-cell suppression by rapamycin and FK506 over rapamycin and cyclosporine $A$ because of abrogated cytotoxic Tlymphocyte induction, impaired memory responses, and persistent apoptosis.

Transplantation 2003; 75(9): 1581-90.

[2] ECHJ Michielsen, JHC Diris, CM Hackeng, KWH Wodzig, MP Van Dieijen-Visser. Highly sensitive immunoprecipitation assay for extracting and concentrating low abundance proteins from human serum.

Clin Chem 2005; 51(1): 222-4.

[3] ECHJ Michielsen, MMPC Donners, MJAP Daemen, KWH Wodzig, S Heeneman, MP Van DieijenVisser. SELDI-TOF proteomic profiles to predict atherosclerotic plaque rupture.

Ned Tijdschr Klin Chem Labgeneesk 2005; 30: 294-5.

[4] ECHJ Michielsen, JHC Diris, WTh Hermens, WKWH Wodzig, MP van Dieijen-Visser. Cardiac troponin T degradation after acute myocardial infarction.

Ned Tijdschr Klin Chem Labgeneesk 2006; 31: 223-4.

[5] ECHJ Michielsen, JHC Diris, V Kleijnen, KWH Wodzig, MP Van Dieijen-Visser. Interpretation of cardiac troponin $\mathrm{T}$ behaviour in size-exclusion chromatography.

Clin Chem Lab Med 2006; 44(12): 1422-7.

[6] ECHJ Michielsen, JHC Diris, KWH Wodzig, MP Van Dieijen-Visser. Size-exclusion chromatography of circulating cardiac troponin $\mathrm{T}$.

Clin Chem 2006; 52(12): 2306-7.

[7] ECHJ Michielsen, JHC Diris, V Kleijnen, KWH Wodzig, MP Van Dieijen-Visser. Investigation of release and degradation of cardiac troponin $\mathrm{T}$ in patients with acute myocardial infarction.

Clin Biochem 2007; 40(12):851-5.

[8] ECHJ Michielsen, KWH Wodzig, MP Van Dieijen-Visser. Cardiac troponin T release after prolonged strenuous exercise - a review.

Sports Med 2007; Accepted for publication.

[9] MHM Hessel, ECHJ Michielsen, DE Atsma, EJM van der Valk, WH Bax, WT Hermens, MP van Dieijen-Visser, A van der Laarse. Metabolic inhibition of cultured rat cardiomyocytes induces parallel release of cardiac troponin I and $\mathrm{T}$.

Submitted 2007.

[10] ECHJ Michielsen, JA Bakker, RRJ Van Kimmenade, YM Pinto, MP Van Dieijen-Visser. The diagnostic value of serum and urinary NT-proBNP for heart failure.

Ann Clin Biochem 2007; Accepted for publication.

[11] C Cobbaert, ECHJ Michielsen, C Weykamp, H Baadenhuijsen, MP van Dieijen-Visser. Do NIST SRM 2921 and recombinant cTnI-based serum pools have potential to harmonize cTnI results? Ned Tijdschr Klin Chem Labgeneesk 2007; 32: 175-8. 
[12] ECHJ Michielsen, MHM Hessel, A van der Laarse, WKWH Wodzig, MP van Dieijen-Visser. Heterogeniteit van circulerend cardiaal troponine $\mathrm{T}$.

Ned Tijdschr Klin Chem Labgeneesk 2007; 33: 192-4.

[13] JAP Bons, ECHJ Michielsen, D De Boer, FG Bouwman, J Jaeken, MP Van Dieijen-Visser, ME Rubio-Gozalbo, WKWH Wodzig. A specific immunoprecipitation method for isolating isoforms of insulin-like growth factor binding protein-3 from serum.

Clinica Chimica Acta 2008; 387: 59-65.

\section{Posters}

[1] ECHJ Michielsen, JHC Diris, WTh Hermens, KWH Wodzig, MP Van Dieijen-Visser. Cardiac troponin T degradation after acute myocardial infarction.

NVKC voorjaarscongres, April 2006.

[2] ECHJ Michielsen, JHC Diris, VWVC Kleijnen, KWH Wodzig, MP Van Dieijen-Visser. Degradation and release of cardiac troponin $\mathrm{T}$ in patients with acute myocardial infarction.

IFCC Euromedlab, June 2007.

[3] ECHJ Michielsen, J Verjans, MP Van Dieijen-Visser, L Hofstra. Elevation of serum cardiac biomarkers after a short exercise can occur in untrained subjects.

IFCC Euromedlab, June 2007.

\section{Abstracts}

[1] JHC Diris, CM Hackeng, ECHJ Michielsen, WTh Hermens, MP Van Dieijen-Visser. Fragmentatie van troponine $\mathrm{T}$ bij patiënten met een myocardinfarct.

Ned Tijdschr Klin Chem Labgeneesk 2004; 29(2): 76.

[2] ECHJ Michielsen, MMPC Donners, MJAP Daemen, KWH Wodzig, MP van Dieijen-Visser, S Heeneman. Detection of thrombus containing atherosclerotic plaques using Surface-Enhanced Laser Desorption/Ionization Time Of Flight Mass Spectrometry (SELDI-TOF-MS) in a histologically confirmed population.

Ned Tijdschr Klin Chem Labgeneesk 2005; 30(2): 110.

[3] ECHJ Michielsen, JHC Diris, WTh Hermens, KWH Wodzig, MP Van Dieijen-Visser. Cardiac troponin T degradation after acute myocardial infarction.

Ned Tijdschr Klin Chem Labgeneesk 2006; 31(2): 100-101.

[4] C Cobbaert, ECHJ Michielsen, CW Weykamp, H Baadenhuijsen, MP van Diejen-Visser. Do NIST SRM 2921 and recombinant CTnI-based serum pools have potential to harmonize cTnI results? Clin Chem Lab Med 2007;45:S18.

[5] ECHJ Michielsen, KWH Wodzig, MP Van Dieijen-Visser. Heterogeneity of circulating cardiac troponin $\mathrm{T}$.

Clin Chem Lab Med 2007;45:S41.

[6] ECHJ Michielsen, JHC Diris, VWVC Kleijnen, KWH Wodzig, MP Van Dieijen-Visser. Degradation and release of cardiac troponin $\mathrm{T}$ in patients with acute myocardial infarction.

Clin Chem Lab Med 2007;45:S239.

[7] ECHJ Michielsen, JW Verjans, MP Van Dieijen-Visser, L Hofstra. Elevation of serum cardiac biomarkers after a short exercise can occur in untrained subjects.

Clin Chem Lab Med 2007;45:S240. 


\section{Oral presentations}

[1] ECHJ Michielsen, MMPC Donners, MJAP Daemen, KWH Wodzig, MP Van Dieijen-Visser, S Heeneman. Detection of atherosclerotic plaque rupture using surface-enhanced laser desorption/ionization time of flight mass spectrometry (SELDI-TOF-MS) in a histologically confirmed population.

NVKC voorjaarscongres, April 2005.

Awarded for best abstract.

[2] ECHJ Michielsen, KWH Wodzig, MP Van Dieijen-Visser. Heterogeneity of circulating cardiac troponin $\mathrm{T}$.

IFCC Euromedlab Amsterdam, June 2007.

Invited speaker. 
